\title{
A General Procedure for the Esterification of Carboxylic Acids with Diazoalkanes Generated In Situ by the Oxidation of $N$-tert-Butyldimethylsilylhydrazones with (Difluoroiodo)benzene
}

\author{
Michael E. Furrow and Andrew G. Myers*
}

\section{Supporting Information}

Index:

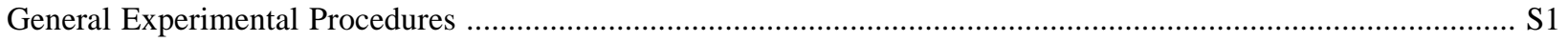

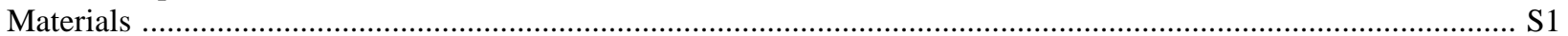

Instrumentation

Procedures for the Esterification of Carboxylic Acids with Diazoalkanes ......................................................... S2

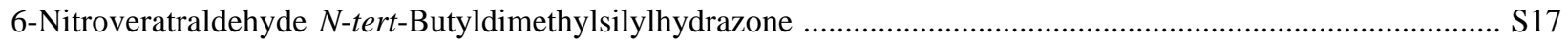

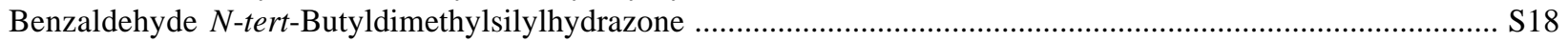

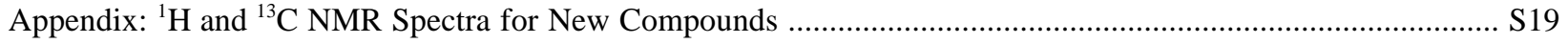

General Experimental Procedures: All reactions were performed in oven- or flame-dried glassware fitted with rubber septa under a positive pressure of argon, unless otherwise noted. Air- and moisture-sensitive liquids were transferred via syringe or stainless steel cannula. Organic solutions were concentrated by rotary evaporation (house vacuum, $\sim 25-40$ Torr) at $\sim 20{ }^{\circ} \mathrm{C}$, unless otherwise noted. Analytical thin-layer chromatography (TLC) was performed using glass plates pre-coated with silica gel $(0.25 \mathrm{~mm}, 60 \AA$ pore size, $230-400$ mesh, Merck KGA) impregnated with a fluorescent indicator $(254 \mathrm{~nm})$. Where indicated, TLC plates were fully submerged in a solution of ethyl acetate/ $n$-hexane containing $5 \%$ acetic acid ( $2 \mathrm{~min})$, then allowed to air dry ( 1 min) prior to use. TLC plates were visualized by exposure to ultraviolet light (UV), then (when necessary) were heated briefly on a hot plate $\left(\sim 200{ }^{\circ} \mathrm{C}, 10-15 \mathrm{~s}\right)$ to remove acetic acid prior to staining. TLC plates were stained by submersion in aqueous ceric ammonium molybdate solution (CAM) or acidic ethanolic $p$-anisaldehyde solution (anis), followed by brief heating on a hot plate $\left(200{ }^{\circ} \mathrm{C}, 10-15 \mathrm{~s}\right)$. Flash chromatography was performed as described by Still et al., ${ }^{1}$

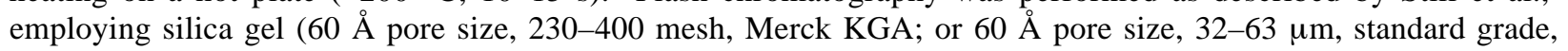
Sorbent Technologies).

Materials: Commercial reagents and solvents were used with the following exceptions. Acetonitrile, dichloromethane, benzene, $n$-hexane, and methanol were purified by the method of Pangborn et al. ${ }^{2}$ Hydrocinnamaldehyde, 3,5,5-trimethylhexanal, $p$-tolualdehyde, 3-phenoxybenzaldehyde, and benzaldehyde were initially dried over $4-\AA$ molecular sieves, then were distilled under reduced pressure immediately prior to use. 1,2:3,4-Di- $O$-isopropylidene-D-hexodiald-1,5-ose ${ }^{3}$ was prepared from commercial 1,2:3,4-di- $O$-isopropylidene-Dgalactopyranose and was purified by flash chromatography on silica gel. 6-Allylveratraldehyde ${ }^{4}$ was prepared from commercial 6-bromoveratraldehyde and was purified by flash chromatography on silica gel. Scandium trifluoromethanesulfonate (Aldrich) was used as received and was weighed under an atmosphere of dry argon. Because of the extremely low loadings of scandium trifluoromethanesulfonate required for the preparation of TBSH derivatives, we typically dispensed the reagent as a solution in dry acetonitrile (freshly prepared, $0.01 \mathrm{M}$ ) and then removed acetonitrile in vacuo as detailed in the procedure for the preparation of 3-(4-methoxyphenyl)-propionic acid 3-phenylpropyl ester. Iodosylbenzene was prepared from commercial iodosobenzene diacetate by the method of Saltzman and Sharefkin. ${ }^{5}$ (Difluoroiodo)benzene was prepared by the treatment of a yellow suspension of iodosylbenzene in dichloromethane with $48 \%$ aqueous hydrofluoric acid solution, dropwise, until the point when all solids had dissolved, providing a colorless, biphasic mixture. The upper, aqueous layer was removed using a polypropylene syringe with a stainless steel needle. This is a modification of the original protocol of Bockemüller ${ }^{6}$ and is essentially identical to a modification independently discovered and published while this work was in progress. $^{7}$

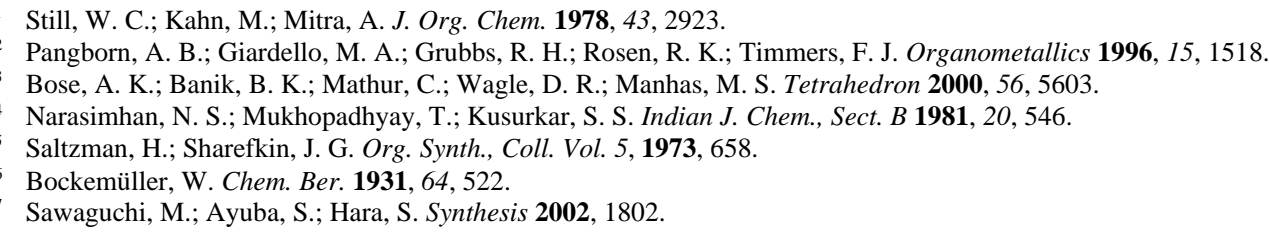


Instrumentation: Proton magnetic resonance $\left({ }^{1} \mathrm{H}\right.$ NMR) spectra and carbon nuclear magnetic resonance $\left({ }^{13} \mathrm{C}\right.$ NMR) spectra were recorded on Varian Mercury $400(400 \mathrm{MHz})$ or Varian INOVA 500 (500 MHz) NMR spectrometers at $25{ }^{\circ} \mathrm{C}$. Proton chemical shifts are expressed in parts per million (ppm, $\delta$ scale) downfield from tetramethylsilane and are referenced to residual protium in the NMR solvent $\left(\mathrm{CHCl}_{3}: \delta 7.26, \mathrm{C}_{6} \mathrm{D}_{5} \mathrm{H}: \delta 7.15, \mathrm{CDHCl}_{2}: \delta 5.32\right.$, $\mathrm{CD}_{2} \mathrm{HOD}: \delta 3.31$ ). Carbon chemical shifts are expressed in parts per million (ppm, $\delta$ scale) downfield from tetramethylsilane and are referenced to the carbon resonance of the NMR solvent $\left(\mathrm{CDCl}_{3}: \delta 77.0, \mathrm{C}_{6} \mathrm{D}_{6}: \delta 128.1\right.$, $\mathrm{CD}_{3} \mathrm{OD}: \delta$ 49.0). Data are represented as follows: chemical shift, multiplicity $(\mathrm{s}=$ singlet, $\mathrm{d}=$ doublet, $\mathrm{t}=$ triplet, $\mathrm{q}$ $=$ quartet, sept $=$ septet, $\mathrm{m}=$ multiplet, $\mathrm{br}=$ broad $)$, integration, and coupling constant $(J)$ in Hertz $(\mathrm{Hz})$. Infrared (IR) spectra were obtained using a Perkin-Elmer 1600 Ft-IR spectrophotometer referenced to a polystyrene standard. Data are represented as follows: frequency of absorption $\left(\mathrm{cm}^{-1}\right)$, and intensity of absorption $(\mathrm{s}=$ strong, $\mathrm{m}=$ medium, $\mathrm{w}=$ weak, $\mathrm{br}=$ broad). High-resolution mass spectra were obtained at the Harvard University Mass Spectrometry Facility.

\section{Specific Experimental Procedures:}

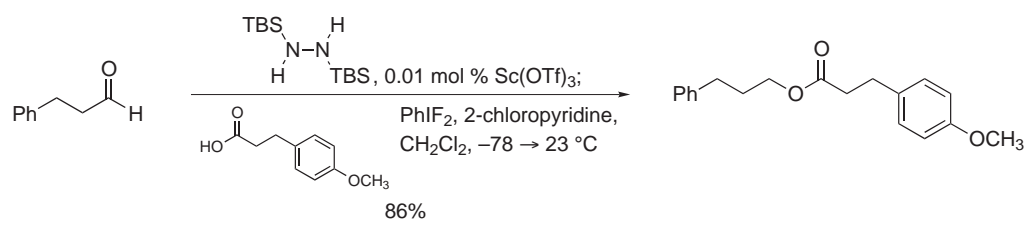

3-(4-Methoxyphenyl)-propionic acid 3-phenylpropyl ester: A freshly prepared solution of scandium trifluoromethanesulfonate in dry acetonitrile $(0.01 \mathrm{M}, 0.011 \mathrm{~mL}, 0.00011 \mathrm{mmol}, 0.00015$ equiv) was transferred by syringe to a $10-\mathrm{mL}$ pear-shape flask equipped with a Teflon-coated stir bar. A 21-gauge needle connected to a source of argon/vacuum (dual manifold, 0.05 Torr) was inserted and the flask was carefully evacuated, with stirring, to evaporate the solvent. When the removal of solvent was complete $(\sim 15 \mathrm{~min})$, the flask was flushed with dry argon and a needle affixed to an argon balloon was inserted through the septum cap. 1,2-Bis(tertbutyldimethylsilyl)hydrazine ( $0.297 \mathrm{~g}, 1.14 \mathrm{mmol}, 1.5$ equiv) was introduced by syringe and the reaction flask was cooled in an ice bath. Hydrocinnamaldehyde $(0.150 \mathrm{~mL}, 1.14 \mathrm{mmol}, 1.5$ equiv) was then added dropwise over 15 min via syringe." The reaction solution, a colorless liquid, was stirred for an additional $15 \mathrm{~min}$ at $0{ }^{\circ} \mathrm{C}$, then the ice bath was removed, and the reaction mixture was allowed to warm to ambient temperature $\left(23^{\circ} \mathrm{C}\right)$. After 15 min, the septum cap was removed and a vacuum adapter connected to a source of argon/vacuum (dual manifold, 0.05 Torr) was affixed, and the flask was carefully evacuated with stirring. After stirring under vacuum for $1 \mathrm{~h}$ at $23{ }^{\circ} \mathrm{C}$, the flask was immersed in an oil bath, and the bath was warmed to $30-35{ }^{\circ} \mathrm{C}$. After stirring under vacuum at $30-35^{\circ} \mathrm{C}$ for $2 \mathrm{~h}$, the heating bath was removed, the flask was flushed with dry argon, a septum cap was affixed, and a needle connected to an argon balloon was inserted through the septum. Dry dichloromethane $(0.5 \mathrm{~mL})$ was added by syringe, providing a colorless solution. Separately, a 50-mL Teflon vial equipped with a Teflon-coated stir bar was charged with iodosylbenzene ( $0.385 \mathrm{~g}, 1.75 \mathrm{mmol}, 2.3$ equiv), a septum cap was affixed, and a needle connected to an argon balloon was inserted through the septum cap. The yellow solid was suspended in dichloromethane $(10 \mathrm{~mL})$ and the suspension was stirred vigorously. Aqueous hydrofluoric acid $(48 \% \mathrm{w} / \mathrm{v}$, approximate volume: $0.150 \mathrm{~mL})$ was added to the stirred suspension dropwise by polypropylene syringe until all particulates had dissolved (rate of addition: 1 drop every 2 seconds). At this point, stirring was stopped, the layers were allowed to separate, and the upper, aqueous layer was removed by polypropylene syringe. The lower phase, a colorless solution, was cooled in a Dry Ice/acetone bath, with stirring, and 2-chloropyridine $(0.360 \mathrm{~mL}, 3.80 \mathrm{mmol}, 5$ equiv $)$ was added dropwise by syringe over $1 \mathrm{~min}$. This was followed by the addition of a solution of 3-(4-methoxyphenyl)-propionic acid (0.137 $\mathrm{g}, 0.760 \mathrm{mmol}, 1$ equiv) in dichloromethane $(1 \mathrm{~mL})$, quantitating the addition with dichloromethane $(2 \times 0.2 \mathrm{~mL})$. To avoid photochemical decomposition of the diazo intermediate, the reaction flask was shielded from light at this stage. The solution of the TBSH derivative prepared above was then added dropwise over $2 \mathrm{~min}$, also by syringe, and the transfer was quantitated with dichloromethane $(2 \times 0.2 \mathrm{~mL})$. The reaction mixture was stirred at $-78{ }^{\circ} \mathrm{C}$ for $4 \mathrm{~h}$, at which point the cooling bath was allowed to warm gradually to $23{ }^{\circ} \mathrm{C}$ over $\sim 3.5 \mathrm{~h}$. The yellow reaction solution was then stirred at $23{ }^{\circ} \mathrm{C}$ for $6 \mathrm{~h}$. $n$-Hexane $(10 \mathrm{~mL})$ and a $1: 1$ mixture of half-saturated aqueous sodium thiosulfate solution and half-saturated aqueous sodium bicarbonate solution $(12 \mathrm{~mL})$ were added and the resulting biphasic mixture was stirred vigorously for $20 \mathrm{~min}$. Stirring was stopped, and the layers were separated. The

\footnotetext{
${ }^{*}$ More rapid additions led to a mild exotherm.
} 
organic layer was dried over sodium sulfate, and the dried solution was filtered through a plug of Celite with suction. Concentration of the filtrate afforded a yellow, oily residue which was purified by flash column chromatography (n-pentane grading to 8:92 ethyl acetate/n-pentane) affording 3-(4-methoxyphenyl)-propionic acid 3-phenylpropyl ester $(0.195 \mathrm{~g}, 0.654 \mathrm{mmol}, 86 \%)$ as a colorless oil.

TLC (acetic acid-buffered silica gel; 30:60 ethyl acetate: $n$-hexane; UV, anis): $R_{f}$ 0.33 (3-(4-methoxyphenyl)propionic acid), 0.50 (3-(4-methoxyphenyl)-propionic acid 3-phenylpropyl ester).

${ }^{1} \mathrm{H}$ NMR (400 MHz, $\left.\mathrm{CDCl}_{3}\right): \delta 7.14-7.30(\mathrm{~m}, 5 \mathrm{H}), 7.13(\mathrm{~d}, 2 \mathrm{H}, J=8.6 \mathrm{~Hz}), 6.83(\mathrm{~d}, 2 \mathrm{H}, J=8.6 \mathrm{~Hz}), 4.08(\mathrm{t}, 2 \mathrm{H}, J$ $=6.6 \mathrm{~Hz}), 3.77(\mathrm{~s}, 3 \mathrm{H}), 2.90(\mathrm{t}, \mathrm{H}, J=7.6 \mathrm{~Hz}), 2.64(\mathrm{t}, 2 \mathrm{H}, J=7.6 \mathrm{~Hz}), 2.60(\mathrm{t}, 2 \mathrm{H}, J=7.6 \mathrm{~Hz}), 1.93(\mathrm{tt}, 2 \mathrm{H}, J=7.6$, $6.6 \mathrm{~Hz}) ;{ }^{13} \mathrm{C} \mathrm{NMR}\left(500 \mathrm{MHz}, \mathrm{CDCl}_{3}\right): \delta 173.3,158.3,141.5,132.8,129.5,128.7,128.7,126.3,114.2,64.0,55.5$,

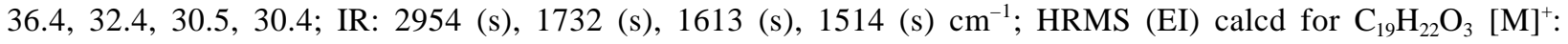
298.1569, found: 298.1569 .

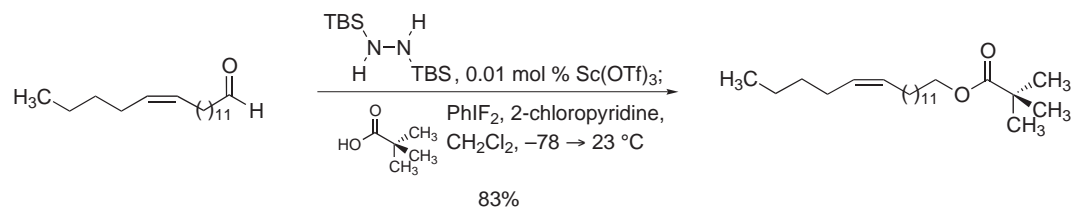

2,2-Dimethylpropionic acid Z-13-octadecenyl ester: A freshly prepared solution of scandium trifluoromethanesulfonate in dry acetonitrile $(0.01 \mathrm{M}, 0.006 \mathrm{~mL}, 0.00006 \mathrm{mmol}, 0.00015$ equiv) was transferred by syringe to a $10-\mathrm{mL}$ pear-shape flask equipped with a Teflon-coated stir bar. A 21-gauge needle connected to a source of argon/vacuum (dual manifold, 0.05 Torr) was inserted through the septum cap of the reaction vessel and the flask was carefully evacuated, with stirring, to evaporate the solvent. When the removal of solvent was complete ( $15 \mathrm{~min}$ ), the flask was flushed with dry argon and a needle affixed to an argon balloon was inserted through the septum cap. 1,2-Bis(tert-butyldimethylsilyl)hydrazine $(0.169 \mathrm{~g}, 0.648 \mathrm{mmol}, 1.52 \mathrm{equiv})$ was introduced by syringe and the reaction flask was cooled in an ice bath. Z-13-octadecenal $(0.200 \mathrm{~mL}, 0.642 \mathrm{mmol}, 1.5 \mathrm{equiv})$ was then added dropwise over 15 min via syringe. ${ }^{*}$ The reaction solution, a colorless liquid, was stirred for an additional 15 min at $0{ }^{\circ} \mathrm{C}$, then the ice bath was removed, and the reaction mixture was allowed to warm to ambient temperature $\left(23{ }^{\circ} \mathrm{C}\right)$. After $15 \mathrm{~min}$, the septum cap was removed and a vacuum adapter connected to a source of argon/vacuum was affixed (dual manifold, 0.05 Torr) and the flask was carefully evacuated with stirring. After stirring under vacuum for $1 \mathrm{~h}$ at $23{ }^{\circ} \mathrm{C}$, the flask was immersed in an oil bath, and the bath was warmed to $30-35{ }^{\circ} \mathrm{C}$. After stirring under vacuum at $30-35^{\circ} \mathrm{C}$ for $3 \mathrm{~h}$, the heating bath was removed, the flask was flushed with dry argon, a septum cap was affixed, and a needle connected to an argon balloon was inserted through the septum. Dry dichloromethane $(0.5 \mathrm{~mL})$ was added by syringe, providing a colorless solution. Separately, a $50-\mathrm{mL}$ Teflon vial equipped with a Teflon-coated stir bar was charged with iodosylbenzene $(0.217 \mathrm{~g}, 0.984 \mathrm{mmol}, 2.3 \mathrm{equiv})$, a septum cap was affixed, and a needle connected to an argon balloon was inserted through the septum cap. The yellow solid was suspended in dichloromethane $(7 \mathrm{~mL})$ and the suspension was stirred vigorously. Aqueous hydrofluoric acid (48\% w/v, approximate volume: $0.120 \mathrm{~mL}$ ) was added to the stirred suspension dropwise by polypropylene syringe until all particulates had dissolved (rate of addition: 1 drop every 2 seconds). At this point, stirring was stopped, the layers were allowed to separate, and the upper, aqueous layer was removed by polypropylene syringe. The lower phase, a colorless solution, was cooled in a Dry Ice/acetone bath, with stirring, and 2-chloropyridine $(0.203 \mathrm{~mL}, 2.14 \mathrm{mmol}$, 5 equiv) was added dropwise by syringe over $1 \mathrm{~min}$. This was followed by the addition of a solution of 2,2dimethylpropionic acid $(0.0440 \mathrm{~g}, 0.428 \mathrm{mmol}, 1$ equiv) in dichloromethane $(0.2 \mathrm{~mL})$, quantitating the addition with dichloromethane $(2 \times 0.2 \mathrm{~mL})$. To avoid photochemical decomposition of the diazo intermediate, the reaction flask was shielded from light at this stage. The solution of the TBSH derivative prepared above was then added dropwise over $2 \mathrm{~min}$, also by syringe, and the transfer was quantitated with dichloromethane $(2 \times 0.2 \mathrm{~mL})$. The reaction mixture was stirred at $-78{ }^{\circ} \mathrm{C}$ for $4 \mathrm{~h}$, at which point the cooling bath was allowed to warm gradually to $23{ }^{\circ} \mathrm{C}$ over $\sim 3.5 \mathrm{~h}$. The yellow reaction solution was then stirred at $23{ }^{\circ} \mathrm{C}$ for $6 \mathrm{~h}$. $n$-Hexane $(7 \mathrm{~mL})$ and a $1: 1$ mixture of halfsaturated aqueous sodium thiosulfate solution and half-saturated aqueous sodium bicarbonate solution $(8 \mathrm{~mL})$ were added, and the resulting biphasic mixture was stirred vigorously for $20 \mathrm{~min}$. Stirring was stopped, and the layers were separated. The organic layer was dried over sodium sulfate, and the dried solution was filtered through a plug of Celite with suction. Concentration of the filtrate afforded a yellow, oily residue which was purified by flash 
column chromatography (5:95 dichloromethane/cyclohexane grading to 15:85 dichloromethane/cyclohexane) affording 2,2-dimethylpropionic acid Z-13-octadecenyl ester $(0.125 \mathrm{~g}, 0.355 \mathrm{mmol}, 83 \%)$ as a colorless oil.

TLC (acetic acid-buffered silica gel; 10:90 ethyl acetate: $n$-hexane; UV, CAM): $R_{f} 0.50$ (2,2-dimethylpropionic acid), 0.75 (2,2-dimethylpropionic acid Z-13-octadecenyl ester).

${ }^{1} \mathrm{H}$ NMR $\left(500 \mathrm{MHz}, \mathrm{CDCl}_{3}\right): \delta 5.35(\mathrm{dt}, 1 \mathrm{H}, J=10.7,4.6 \mathrm{~Hz}), 5.35(\mathrm{dt}, 1 \mathrm{H}, J=10.1,4.6 \mathrm{~Hz}), 4.05(\mathrm{t}, 2 \mathrm{H}, J=6.4$ $\mathrm{Hz}), 2.00-2.05(\mathrm{~m}, 4 \mathrm{H}), 1.62(\mathrm{tt}, 2 \mathrm{H}, J=6.7,6.4 \mathrm{~Hz}), 1.26-1.37(\mathrm{~m}, 22 \mathrm{H}), 1.20(\mathrm{~s}, 9 \mathrm{H}), 0.90,(\mathrm{t}, 2 \mathrm{H}, J=7.0 \mathrm{~Hz})$; ${ }^{13} \mathrm{C}$ NMR $\left(500 \mathrm{MHz}, \mathrm{CDCl}_{3}\right): \delta 178.9,130.1,130.1,64.7,39.0,32.2,30.0,29.9,29.9,29.9,29.8,29.8,29.8,29.5$, 29.5, 28.9, 27.4, 27.2, 26.2, 22.6, 14.2; IR: 2926 (s), $1732(\mathrm{~s}), 1463(\mathrm{~m}) \mathrm{cm}^{-1}$; HRMS (ES) calcd for $\mathrm{C}_{23} \mathrm{H}_{45} \mathrm{O}_{2}$ $[\mathrm{M}+\mathrm{H}]^{+}: 353.3419$, found: 353.3407 .

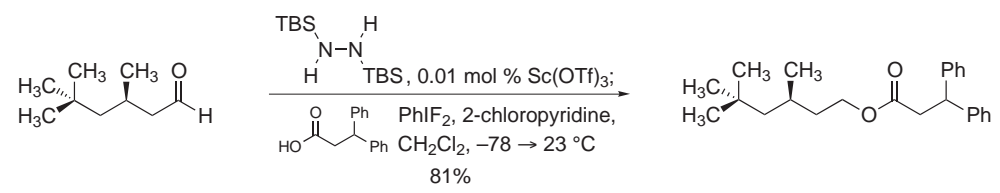

3,3-Diphenylpropionic acid 3,5,5-trimethylhexanyl ester: A freshly prepared solution of scandium trifluoromethanesulfonate in dry acetonitrile $(0.01 \mathrm{M}, 0.009 \mathrm{~mL}, 0.00009 \mathrm{mmol}, 0.00015$ equiv) was transferred by syringe to a $10-\mathrm{mL}$ pear-shape flask equipped with a Teflon-coated stir bar. A 21 -gauge needle connected to a source of argon/vacuum (dual manifold, 0.05 Torr) was inserted through the septum cap of the reaction vessel and the flask was carefully evacuated, with stirring, to evaporate the solvent. When the removal of solvent was complete ( $15 \mathrm{~min})$, the flask was flushed with dry argon and a needle affixed to an argon balloon was inserted through the septum cap. 1,2-Bis(tert-butyldimethylsilyl)hydrazine $(0.225 \mathrm{~g}, 0.862 \mathrm{mmol}, 1.5$ equiv) was introduced by syringe and the reaction flask was cooled in an ice bath. 3,5,5-Trimethylhexanal $(0.150 \mathrm{~mL}, 0.862 \mathrm{mmol}, 1.5$ equiv) was then added dropwise over 15 min via syringe. ${ }^{*}$ The reaction solution, a colorless liquid, was stirred for an additional $15 \mathrm{~min}$ at $0{ }^{\circ} \mathrm{C}$, then the ice bath was removed, and the reaction mixture was allowed to warm to ambient temperature $\left(23^{\circ} \mathrm{C}\right)$. After $15 \mathrm{~min}$, the septum cap was removed and a vacuum adapter connected to a source of argon/vacuum was affixed (dual manifold, 0.05 Torr) and the flask was carefully evacuated with stirring. After stirring under vacuum for $1 \mathrm{~h}$ at $23{ }^{\circ} \mathrm{C}$, the flask was immersed in an oil bath, and the bath was warmed to $30-35^{\circ} \mathrm{C}$. After stirring under vacuum at $30-35{ }^{\circ} \mathrm{C}$ for $2 \mathrm{~h}$, the heating bath was removed, the flask was flushed with dry argon, a septum cap was affixed, and a needle connected to an argon balloon was inserted through the septum. Dry dichloromethane $(0.5 \mathrm{~mL})$ was added by syringe providing a colorless solution. Separately, a $50-\mathrm{mL}$ Teflon vial equipped with a Teflon-coated stir bar was charged with iodosylbenzene $(0.291 \mathrm{~g}, 1.32 \mathrm{mmol}, 2.3$ equiv), a septum cap was affixed, and a needle connected to an argon balloon was inserted through the septum cap. The yellow solid was suspended in dichloromethane $(8 \mathrm{~mL})$ and the suspension was stirred vigorously. Aqueous hydrofluoric acid $(48 \% \mathrm{w} / \mathrm{v}$, approximate volume: $0.160 \mathrm{~mL}$ ) was added to the stirred suspension dropwise by polypropylene syringe until all particulates had dissolved (rate of addition: 1 drop every 2 seconds). At this point, stirring was stopped, the layers were allowed to separate, and the upper, aqueous layer was removed by polypropylene syringe. The lower phase, a colorless solution, was cooled in a Dry Ice/acetone bath with stirring, and 2-chloropyridine $(0.272 \mathrm{~mL}, 2.14$ mmol, 5 equiv) was added dropwise by syringe over $1 \mathrm{~min}$. At this point, the septum was briefly removed, solid 3,3-diphenylpropionic acid $(0.130 \mathrm{~g}, 0.575 \mathrm{mmol}, 1$ equiv) was added, and the septum and argon balloon were reaffixed. To avoid photochemical decomposition of the diazo intermediate, the reaction flask was shielded from light at this stage. The solution of the TBSH derivative prepared above was then added dropwise over 2 min, also by syringe, and the transfer was quantitated with dichloromethane $(2 \times 0.2 \mathrm{~mL})$. The reaction mixture was stirred at $-78{ }^{\circ} \mathrm{C}$ for $4 \mathrm{~h}$, at which point the cooling bath was allowed to warm gradually to $23{ }^{\circ} \mathrm{C}$ over $\sim 3.5 \mathrm{~h}$. The yellow reaction solution was then stirred at $23{ }^{\circ} \mathrm{C}$ for $6 \mathrm{~h}$. $n$-Hexane $(8 \mathrm{~mL})$ and a $1: 1$ mixture of half-saturated aqueous sodium thiosulfate solution and half-saturated aqueous sodium bicarbonate solution $(10 \mathrm{~mL})$ were added and the resulting biphasic mixture was stirred vigorously for $20 \mathrm{~min}$. Stirring was stopped, and the layers were separated. The organic layer was dried over sodium sulfate, and the dried solution was filtered through a plug of Celite with suction. Concentration of the filtrate afforded a yellow, oily residue which was purified by flash column chromatography (8:92 dichloromethane/n-pentane grading to 2:8:90 ethyl acetate/dichloromethane/ $n$-pentane) affording 3,3-diphenylpropionic acid 3,5,5-trimethylhexanyl ester $(0.164 \mathrm{~g}, 0.465 \mathrm{mmol}, 81 \%)$ as a colorless oil. 
TLC (acetic acid-buffered silica gel; $30: 70$ ethyl acetate: $n$-hexane; UV, anis): $R_{f} 0.39$ (3,3-diphenylpropionic acid), 0.61 (3,3-diphenylpropionic acid 3,5,5-trimethylhexanyl ester).

${ }^{1} \mathrm{H}$ NMR $\left(400 \mathrm{MHz}, \mathrm{CDCl}_{3}\right): \delta 7.17-7.32(\mathrm{~m}, 10 \mathrm{H}), 4.58(\mathrm{dd}, 1 \mathrm{H}, J=8.1,8.1 \mathrm{~Hz}), 4.01(\mathrm{dd}, 1 \mathrm{H}, J=6.6,6.6 \mathrm{~Hz})$, $4.01(\mathrm{dd}, 1 \mathrm{H}, J=6.6,6.6 \mathrm{~Hz}), 3.08(\mathrm{~d}, 1 \mathrm{H}, J=8.1 \mathrm{~Hz}), 3.08(\mathrm{~d}, 1 \mathrm{H}, J=8.1 \mathrm{~Hz}), 1.46-1.56(\mathrm{~m}, 1 \mathrm{H}), 1.29-1.39(\mathrm{~m}$, $1 \mathrm{H}), 1.19(\mathrm{dd}, 1 \mathrm{H}, J=14.2,3.4 \mathrm{~Hz}), 1.05(\mathrm{dd}, 1 \mathrm{H}, J=14.2,6.1 \mathrm{~Hz}), 0.91-0.95(\mathrm{~m}, 1 \mathrm{H}), 0.89(\mathrm{~s}, 9 \mathrm{H}), 0.88(\mathrm{~d}, 3 \mathrm{H}, J$ $=6.4 \mathrm{~Hz}) ;{ }^{13} \mathrm{C} \mathrm{NMR}\left(400 \mathrm{MHz}, \mathrm{CDCl}_{3}\right): \delta 172.1,143.8,128.8,127.9,126.8,63.3,51.2,47.3,41.1,37.9,31.3,30.2$, 26.3, 22.8; IR: $2956(\mathrm{~s}), 1732(\mathrm{~s}), 1495(\mathrm{~m}) \mathrm{cm}^{-1}$; HRMS (ES) calcd for $\mathrm{C}_{24} \mathrm{H}_{33} \mathrm{O}_{2}[\mathrm{M}+\mathrm{H}]^{+}:$353.2481, found: 353.2473 .
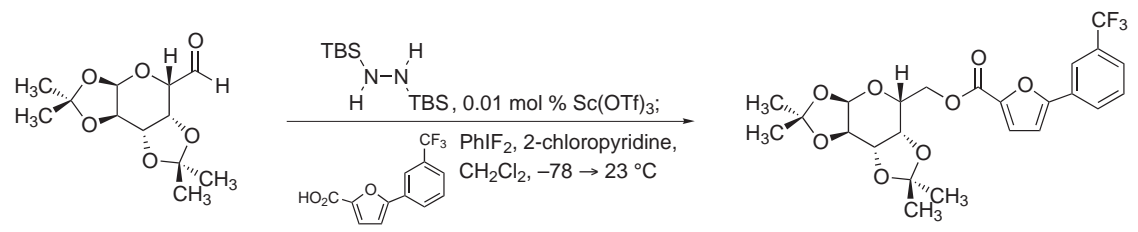

$92 \%$

5-(3-Trifluoromethylphenyl)furan-2-carboxylic acid $2 R, 3 S: 4 R, 5 R$-Di- $O$-isopropylidenetetrahydropyran-5Sylmethyl ester: A freshly prepared solution of scandium trifluoromethanesulfonate in dry acetonitrile $(0.01 \mathrm{M}$, $0.006 \mathrm{~mL}, 0.00006 \mathrm{mmol}, 0.0003$ equiv) was transferred by syringe to a $10-\mathrm{mL}$ pear-shape flask equipped with a Teflon-coated stir bar. A 21-gauge needle connected to a source of argon/vacuum (dual manifold, 0.05 Torr) was inserted through the septum cap of the reaction vessel and the flask was carefully evacuated, with stirring, to evaporate the solvent. When the removal of solvent was complete $(\sim 15 \mathrm{~min})$, the flask was flushed with dry argon and a needle affixed to an argon balloon was inserted through the septum cap. 1,2-Bis(tertbutyldimethylsilyl)hydrazine $(0.151 \mathrm{~g}, 0.581 \mathrm{mmol}, 3$ equiv) was introduced by syringe and the reaction flask was cooled in an ice bath. A freshly prepared solution of 1,2:3,4-Di- $O$-isopropylidene-D-hexodiald-1,5-ose $(0.150 \mathrm{~g}$, $0.581 \mathrm{mmol}, 3$ equiv) in dry dichloromethane $(0.15 \mathrm{~mL})$ was then added dropwise over $15 \mathrm{~min}$ via syringe. ${ }^{*}$ The addition was quantitated with dichloromethane $(2 \times 0.1 \mathrm{~mL})$. The colorless reaction solution was stirred for an additional $15 \mathrm{~min}$ at $0{ }^{\circ} \mathrm{C}$, then the ice bath was removed, and the reaction mixture was allowed to warm to ambient temperature $\left(23^{\circ} \mathrm{C}\right)$. After $15 \mathrm{~min}$, the septum cap was removed and a vacuum adapter connected to a source of argon/vacuum was affixed (dual manifold, 0.05 Torr) and the flask was carefully evacuated with stirring. After stirring under vacuum for $1 \mathrm{~h}$ at $23{ }^{\circ} \mathrm{C}$, the flask was immersed in an oil bath, and the bath was warmed to $30-35^{\circ} \mathrm{C}$. After stirring under vacuum at $30-35{ }^{\circ} \mathrm{C}$ for $2 \mathrm{~h}$, the heating bath was removed, the flask was flushed with dry argon, a septum cap was affixed, and a needle connected to an argon balloon was inserted through the septum. Dry dichloromethane $(0.5 \mathrm{~mL})$ was added by syringe providing a colorless solution. Separately, a $50-\mathrm{mL}$ Teflon vial equipped with a Teflon-coated stir bar was charged with iodosylbenzene ( $0.196 \mathrm{~g}, 0.890 \mathrm{mmol}, 4.6$ equiv), a septum cap was affixed, and a needle connected to an argon balloon was inserted through the septum cap. The yellow solid was suspended in dichloromethane $(6 \mathrm{~mL})$ and the suspension was stirred vigorously. Aqueous hydrofluoric acid ( $48 \% \mathrm{w} / \mathrm{v}$, approximate volume: $0.110 \mathrm{~mL}$ ) was added to the stirred suspension dropwise by polypropylene syringe until all particulates had dissolved (rate of addition: 1 drop every 2 seconds). At this point, stirring was stopped, the layers were allowed to separate, and the upper, aqueous layer was removed by polypropylene syringe. The lower phase, a colorless solution, was cooled in a Dry Ice/acetone bath, with stirring, and 2-chloropyridine $(0.272 \mathrm{~mL}$, $2.14 \mathrm{mmol}, 10$ equiv) was added dropwise by syringe over $1 \mathrm{~min}$. At this point, the septum was briefly removed, solid 5-[3-(trifluoromethyl)phenyl]-2-furoic acid (0.0496 g, $0.194 \mathrm{mmol}, 1$ equiv) was added, and the septum and argon balloon were reaffixed. To avoid photochemical decomposition of the diazo intermediate, the reaction flask was shielded from light at this stage. The solution of the TBSH derivative prepared above was then added dropwise over $2 \mathrm{~min}$, also by syringe, and the transfer was quantitated with dichloromethane $(2 \times 0.2 \mathrm{~mL})$. The reaction mixture was stirred at $-78{ }^{\circ} \mathrm{C}$ for $4 \mathrm{~h}$, at which point the cooling bath was allowed to warm gradually to $23{ }^{\circ} \mathrm{C}$ over $\sim 3.5 \mathrm{~h}$. The yellow reaction solution was then stirred at $23{ }^{\circ} \mathrm{C}$ for $6 \mathrm{~h}$. $n$-Hexane $(6 \mathrm{~mL})$ and a $1: 1$ mixture of halfsaturated aqueous sodium thiosulfate solution and half-saturated aqueous sodium bicarbonate solution $(8 \mathrm{~mL})$ were added and the resulting biphasic mixture was stirred vigorously for $20 \mathrm{~min}$. Stirring was stopped, and the layers were separated. The organic layer was dried over sodium sulfate, and the dried solution was filtered through a plug of Celite with suction. Concentration of the filtrate afforded a yellow, oily residue which was purified by flash column chromatography (5:95 ethyl acetate/ $n$-hexane grading to 15:85 ethyl acetate/ $n$-hexane) affording 5-(3- 
trifluoromethylphenyl)furan-2-carboxylic acid $2 R, 3 S: 4 R, 5 R$-Di- $O$-isopropylidenetetrahydropyran-5S-ylmethyl ester $(0.0886 \mathrm{~g}, 0.178 \mathrm{mmol}, 92 \%)$ as a viscous, colorless oil.

TLC (acetic acid-buffered silica gel; 30:70 ethyl acetate: $n$-hexane; UV, anis): $R_{f} 0.10$ (5-[3-(trifluoromethyl)phenyl]2 -furoic acid), 0.52 (5-(3-trifluoromethylphenyl)furan-2-carboxylic acid $2 R, 3 S: 4 R, 5 R$-Di- $O$ isopropylidenetetrahydropyran-5S-ylmethyl ester).

${ }^{1} \mathrm{H}$ NMR $\left(500 \mathrm{MHz}, \mathrm{CDCl}_{3}\right): \delta 8.01(\mathrm{~s}, 1 \mathrm{H}), 7.94(\mathrm{~d}, 1 \mathrm{H}, J=7.8 \mathrm{~Hz}), 7.59(\mathrm{~d}, 1 \mathrm{H}, J=7.8 \mathrm{~Hz}), 7.54(\mathrm{dd}, 1 \mathrm{H}, J=7.8$, $7.8 \mathrm{~Hz}), 7.29(\mathrm{~d}, 1 \mathrm{H}, J=3.4 \mathrm{~Hz}), 6.82(\mathrm{~d}, 1 \mathrm{H}, J=3.4 \mathrm{~Hz}), 5.58(\mathrm{~d}, 1 \mathrm{H}, J=4.9 \mathrm{~Hz}), 4.67(\mathrm{dd}, 1 \mathrm{H}, J=7.8,2.4 \mathrm{~Hz})$, $4.53(\mathrm{dd}, 1 \mathrm{H}, J=11.7,4.9 \mathrm{~Hz}), 4.48(\mathrm{dd}, 1 \mathrm{H}, J=11.7,7.3 \mathrm{~Hz}), 4.36(\mathrm{dd}, 1 \mathrm{H}, J=4.9,2.4 \mathrm{~Hz}), 4.34(\mathrm{dd}, 1 \mathrm{H}, J=7.8$, $2.0 \mathrm{~Hz}), 4.22(\mathrm{ddd}, 1 \mathrm{H}, J=7.3,4.9,2.0 \mathrm{~Hz}), 1.56(\mathrm{~s}, 3 \mathrm{H}), 1.50(\mathrm{~s}, 3 \mathrm{H}), 1.37(\mathrm{~s}, 3 \mathrm{H}), 1.35(\mathrm{~s}, 3 \mathrm{H}) ;{ }^{13} \mathrm{C}$ NMR $(500$ $\left.\mathrm{MHz}, \mathrm{CDCl}_{3}\right): \delta 158.6,156.1,144.3,131.6(\mathrm{q}, J=32.5 \mathrm{~Hz}), 130.5,129.6,128.1,125.6(\mathrm{q}, J=3.7 \mathrm{~Hz}), 124.1(\mathrm{q}, J=$ $272.8 \mathrm{~Hz}), 121.8(\mathrm{q}, J=4.1 \mathrm{~Hz}), 120.4,110.0,109.1,108.3,96.5,71.3,71.0,70.8,66.4,64.3,26.3,26.2,25.2$, 24.7; ${ }^{19} \mathrm{~F}$ NMR (500 MHz, $\mathrm{CDCl}_{3}$ ): $\delta$-63.24; IR: $2989(\mathrm{~m}), 1722(\mathrm{~s}), 1530(\mathrm{~m}) \mathrm{cm}^{-1}$; HRMS (ES) calcd for $\mathrm{C}_{24} \mathrm{H}_{26} \mathrm{~F}_{3} \mathrm{O}_{8}$ $[\mathrm{M}+\mathrm{H}]^{+}: 499.1580$, found: 499.1581 .
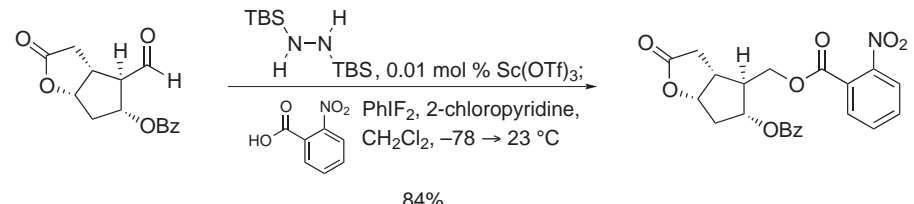

$(3 a R, 4 S, 5 R, 6 a S)-5-(B e n z o y l o x y) h e x a h y d r o-4-[(2-n i t r o b e n z o y l o x y) m e t h y l]-2 H-c y c l o p e n t a[b]$ furan-2-one: A freshly prepared solution of scandium trifluoromethanesulfonate in dry acetonitrile $(0.01 \mathrm{M}, 0.005 \mathrm{~mL}, 0.00005$ mmol, 0.0003 equiv) was transferred by syringe to a $10-\mathrm{mL}$ pear-shape flask equipped with a Teflon-coated stir bar. A 21-gauge needle connected to a source of argon/vacuum (dual manifold, 0.05 Torr) was inserted through the septum cap of the reaction vessel and the flask was carefully evacuated, with stirring, to evaporate the solvent. When the removal of solvent was complete ( 15 min), the flask was flushed with dry argon and a needle affixed to an argon balloon was inserted through the septum cap. 1,2-Bis(tert-butyldimethylsilyl)hydrazine $(0.123 \mathrm{~g}, 0.471$ mmol, 3.16 equiv) was introduced by syringe and the reaction flask was cooled in an ice bath. A freshly prepared solution of [3aR( $3 \mathrm{a} \alpha, 4 \alpha, 5 \beta, 6 \mathrm{a} \alpha)]$-(-)-5-(benzoyloxy)hexahydro-2-oxo-2 $\mathrm{H}$-cyclopenta[ $b]$-furan-4-carboxaldehyde $(0.123 \mathrm{~g}, 0.449 \mathrm{mmol}, 3$ equiv) in dry dichloromethane $(0.5 \mathrm{~mL})$ was then added dropwise over 15 min via syringe. The addition was quantitated with dichloromethane $(2 \times 0.1 \mathrm{~mL})$. The colorless reaction solution was stirred for an additional $15 \mathrm{~min}$ at $0{ }^{\circ} \mathrm{C}$, the ice bath was removed, and the reaction mixture was allowed to warm to ambient temperature $\left(23{ }^{\circ} \mathrm{C}\right)$. After $3.5 \mathrm{~h}$, the septum cap was removed and a vacuum adapter connected to a source of argon/vacuum was affixed (dual manifold, 0.05 Torr) and the flask was carefully evacuated with stirring. After stirring under vacuum for $1 \mathrm{~h}$ at $23{ }^{\circ} \mathrm{C}$, the flask was immersed in an oil bath, and the bath was warmed to $30-35^{\circ} \mathrm{C}$. The colorless, oily residue was stirred under vacuum at $30-35^{\circ} \mathrm{C}$ for $2 \mathrm{~h}$, then the bath was removed and the flask was allowed to cool to $23{ }^{\circ} \mathrm{C}$. At this point, the flask was flushed with dry argon, the vacuum adapter was removed, dry benzene $(3 \mathrm{~mL})$ was added, and the vacuum adapter (positive argon pressure) was replaced. The resulting colorless solution was frozen by immersing the flask in a Dry Ice-acetone bath. The flask was then evacuated with warming to $23{ }^{\circ} \mathrm{C}$ in order to remove volatiles $(\sim 1 \mathrm{~h})$. The flask was then flushed with dry argon, a septum cap was affixed, and a needle connected to an argon balloon was inserted through the septum. Dry dichloromethane $(0.5$ $\mathrm{mL}$ ) was added by syringe to the white solid residue, providing a colorless solution. Separately, a 50-mL Teflon vial equipped with a Teflon-coated stir bar was charged with iodosylbenzene $(0.151 \mathrm{~g}, 0.688 \mathrm{mmol}, 4.6$ equiv), a septum cap was affixed, and a needle connected to an argon balloon was inserted through the septum cap. The yellow solid was suspended in dichloromethane $(5 \mathrm{~mL})$ and the suspension was stirred vigorously. Aqueous hydrofluoric acid $(48 \% \mathrm{w} / \mathrm{v}$, approximate volume: $0.090 \mathrm{~mL})$ was added to the stirred suspension dropwise by polypropylene syringe until all particulates had dissolved (rate of addition: 1 drop every 2 seconds). At this point, stirring was stopped, the layers were allowed to separate, and the upper, aqueous layer was removed by polypropylene syringe. The lower phase, a colorless solution, was cooled in a Dry Ice/acetone bath with stirring, and 2-chloropyridine $(0.272 \mathrm{~mL}, 2.14 \mathrm{mmol}, 10$ equiv) was added dropwise by syringe over $1 \mathrm{~min}$. At this point, the septum was briefly removed, solid 2-nitrobenzoic acid $(0.0250,0.299,1$ equiv) was added, and the septum and argon balloon were reaffixed. To avoid photochemical decomposition of the diazo intermediate, the reaction flask was shielded from light at this stage. The solution of the TBSH derivative prepared above was then added dropwise 
over $2 \mathrm{~min}$, also by syringe, and the transfer was quantitated with dichloromethane $(2 \times 0.2 \mathrm{~mL})$. The reaction mixture was stirred at $-78{ }^{\circ} \mathrm{C}$ for $4 \mathrm{~h}$, at which point the cooling bath was allowed to warm gradually to $23{ }^{\circ} \mathrm{C}$ over $\sim 3.5 \mathrm{~h}$. The yellow reaction solution was then stirred at $23{ }^{\circ} \mathrm{C}$ for $6 \mathrm{~h}$. $n$-Hexane $(5 \mathrm{~mL})$ and a $1: 1$ mixture of halfsaturated aqueous sodium thiosulfate solution and half-saturated aqueous sodium bicarbonate solution $(8 \mathrm{~mL})$ were added and the resulting biphasic mixture was stirred vigorously for $20 \mathrm{~min}$. Stirring was stopped, and the layers were separated. The organic layer was dried over sodium sulfate, and the dried solution was filtered through a plug of Celite with suction. Concentration of the filtrate afforded a yellow, oily residue which was purified by flash column chromatography (3:47:50 ethyl acetate/dichloromethane/ $n$-hexane) affording $(3 \mathrm{a} R, 4 S, 5 R, 6 \mathrm{a} S)$-5(benzoyloxy)hexahydro-4-[(2-nitrobenzoyloxy)methyl]-2H-cyclopenta[b]furan-2-one $(0.0537 \mathrm{~g}, 0.126 \mathrm{mmol}, 84 \%)$ as a viscous, colorless oil.

TLC (acetic acid-buffered silica gel; 15:85 ethyl acetate:dichloromethane; UV, CAM): $R_{f} 0.37$ (2-nitrobenzoic acid), 0.63 ((3a $R, 4 S, 5 R, 6 \mathrm{a} S)$-5-(benzoyloxy)-4-[(2-nitrobenzoyloxy)methyl]hexahydro-2 $H$-cyclopenta[ $b]$ furan-2-one).

${ }^{1} \mathrm{H}$ NMR (500 MHz, CDCl $)$ : $\delta 7.96(\mathrm{~d}, 2 \mathrm{H}, J=8.6 \mathrm{~Hz}), 7.89(\mathrm{~d}, 1 \mathrm{H}, J=8.0 \mathrm{~Hz}), 7.76(\mathrm{~d}, 1 \mathrm{H}, J=7.3 \mathrm{~Hz}), 7.67$ (dd, $1 \mathrm{H}, J=7.6,7.3 \mathrm{~Hz}), 7.64(\mathrm{dd}, 1 \mathrm{H}, J=7.9,7.6 \mathrm{~Hz}), 7.54(\mathrm{t}, 1 \mathrm{H}, J=7.3 \mathrm{~Hz}), 7.41(\mathrm{dd}, 2 \mathrm{H}, J=8.6,7.3 \mathrm{~Hz}), 5.35$ $(\mathrm{ddd}, 1 \mathrm{H}, J=6.3,3.5,2.8 \mathrm{~Hz}), 5.09(\mathrm{dd}, 1 \mathrm{H}, J=6.4,6.1 \mathrm{~Hz}), 4.42(\mathrm{dd}, 1 \mathrm{H}, J=11.3,5.8 \mathrm{~Hz}), 4.36(\mathrm{dd}, 1 \mathrm{H}, J=11.3$, $6.4 \mathrm{~Hz}$ ), $2.96(\mathrm{dd}, 1 \mathrm{H}, J=18.0,10.4 \mathrm{~Hz}), 2.88$ (dddd, $1 \mathrm{H}, J=10.4,6.4,5.0,1.5 \mathrm{~Hz}), 2.56(\mathrm{dd}, 1 \mathrm{H}, J=18.0,1.5 \mathrm{~Hz})$, 2.55 (dddd, $1 \mathrm{H}, J=6.4,5.8,5.0,3.5 \mathrm{~Hz}), 2.46(\mathrm{ddd}, 1 \mathrm{H}, J=15.9,6.3,6.1 \mathrm{~Hz}), 2.35(\mathrm{dd}, 1 \mathrm{H}, J=15.9,2.8 \mathrm{~Hz}) ;{ }^{13} \mathrm{C}$ NMR (500 MHz, $\mathrm{CDCl}_{3}$ ): $\delta 176.5,166.1,165.4,133.6,133.4,132.4,130.3,129.9,129.6,128.8,128.7,127.1$, 124.2, 84.5, 77.4, 66.1, 51.9, 40.9, 38.5, 36.1; IR: 2957 (w), 1771 (s), 1716 (s), 1533 (s) $\mathrm{cm}^{-1}$; HRMS (ES) calcd for $\mathrm{C}_{22} \mathrm{H}_{20} \mathrm{NO}_{8}[\mathrm{M}+\mathrm{H}]^{+}: 426.1189$, found: 426.1187 .
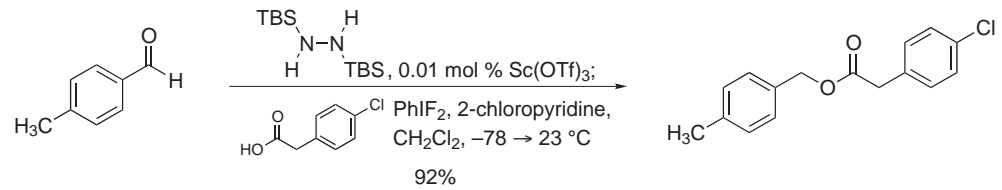

4-Methylbenzyl 2-(4-chlorophenyl)acetate: A freshly prepared solution of scandium trifluoromethanesulfonate in dry acetonitrile $(0.01 \mathrm{M}, 0.017 \mathrm{~mL}, 0.00017 \mathrm{mmol}, 0.00015$ equiv) was transferred by syringe to a 10 -mL pearshape flask equipped with a Teflon-coated stir bar. A 21-gauge needle connected to a source of argon/vacuum (dual manifold, 0.05 Torr) was inserted through the septum cap of the reaction vessel and the flask was carefully evacuated, with stirring, to evaporate the solvent. When the removal of solvent was complete ( $15 \mathrm{~min})$, the flask was flushed with dry argon and a needle affixed to an argon balloon was inserted through the septum cap. 1,2Bis(tert-butyldimethylsilyl)hydrazine $(0.443 \mathrm{~g}, 1.70 \mathrm{mmol}, 1.5$ equiv) was introduced by syringe and the reaction flask was cooled in an ice bath. $p$-Tolualdehyde $(0.200 \mathrm{~mL}, 1.70 \mathrm{mmol}, 1.5$ equiv) was then added dropwise over 15 min via syringe. ${ }^{*}$ The reaction solution, a colorless liquid, was stirred for an additional 15 min at $0{ }^{\circ} \mathrm{C}$, during which time a white solid precipitated. The septum cap was removed, a vacuum adapter connected to a source of argon/vacuum was affixed (dual manifold, 0.05 Torr), and the flask was carefully evacuated with stirring. After stirring under vacuum for $1 \mathrm{~h}$ at $23{ }^{\circ} \mathrm{C}$, the flask was immersed in an oil bath, and the bath was warmed to $30-35^{\circ} \mathrm{C}$. After stirring under vacuum at $30-35{ }^{\circ} \mathrm{C}$ for $2 \mathrm{~h}$, the heating bath was removed, the flask was flushed with dry argon, a septum cap was affixed, and a needle connected to an argon balloon was inserted through the septum. Dry dichloromethane $(0.5 \mathrm{~mL})$ was added by syringe providing a colorless solution. Separately, a $50-\mathrm{mL}$ Teflon vial equipped with a Teflon-coated stir bar was charged with iodosylbenzene ( $0.572 \mathrm{~g}, 1.13 \mathrm{mmol}, 2.3$ equiv), a septum cap was affixed, and a needle connected to an argon balloon was inserted through the septum cap. The yellow solid was suspended in dichloromethane $(12 \mathrm{~mL})$ and the suspension was stirred vigorously. Aqueous hydrofluoric acid ( $48 \% \mathrm{w} / \mathrm{v}$, approximate volume: $0.300 \mathrm{~mL}$ ) was added to the stirred suspension dropwise by polypropylene syringe until all particulates had dissolved (rate of addition: 1 drop every 2 seconds). At this point, stirring was stopped, the layers were allowed to separate, and the upper, aqueous layer was removed by polypropylene syringe. The lower phase, a colorless solution, was cooled in a Dry Ice/acetone bath, with stirring, and 2-chloropyridine $(0.535 \mathrm{~mL}$, $5.65 \mathrm{mmol}, 5$ equiv) was added dropwise by syringe over $1 \mathrm{~min}$. This was followed by the addition of a solution of 2-(4-chlorophenyl)acetic acid $(0.193 \mathrm{~g}, 1.13 \mathrm{mmol}, 1$ equiv) in dichloromethane $(0.5 \mathrm{~mL})$ by syringe over $1 \mathrm{~min}$, quantitating the addition with dichloromethane $(2 \times 0.2 \mathrm{~mL})$. To avoid photochemical decomposition of the diazo intermediate, the reaction flask was shielded from light at this stage. The solution of the TBSH derivative prepared above was then added dropwise over 2 min, also by syringe, and the transfer was quantitated with dichloromethane 
$(2 \times 0.2 \mathrm{~mL})$. The reaction mixture was stirred at $-78{ }^{\circ} \mathrm{C}$ for $4 \mathrm{~h}$, at which point the cooling bath was allowed to warm gradually to $23{ }^{\circ} \mathrm{C}$ over $\sim 3.5 \mathrm{~h}$. The yellow reaction solution was then stirred at $23{ }^{\circ} \mathrm{C}$ for $6 \mathrm{~h}$. $n$-Hexane $(12$ $\mathrm{mL}$ ) and a 1:1 mixture of half-saturated aqueous sodium thiosulfate solution and half-saturated aqueous sodium bicarbonate solution $(14 \mathrm{~mL})$ were added and the resulting biphasic mixture was stirred vigorously for 20 min. Stirring was stopped, and the layers were separated. The organic layer was dried over sodium sulfate, and the dried solution was filtered through a plug of Celite with suction. Concentration of the filtrate afforded a yellow, oily residue which was purified by flash column chromatography ( $n$-hexane grading to 5:95 ethyl acetate/n-hexane) affording 4-methylbenzyl 2-(4-chlorophenyl)-acetate $\left(0.286 \mathrm{~g}, 1.04 \mathrm{mmol}, 92 \%, \mathrm{mp} 54-55^{\circ} \mathrm{C}\right)$ as a white solid.

TLC (acetic acid-buffered silica gel; 30:70 ethyl acetate: $n$-hexane; UV, CAM): $R_{f} 0.41$ (2-(4-chlorophenyl)-acetic acid), 0.62 (4-methylbenzyl 2-(4-chlorophenyl)-acetate).

${ }^{1} \mathrm{H}$ NMR (400 MHz, $\left.\mathrm{CDCl}_{3}\right): \delta 7.31(\mathrm{~d}, 2 \mathrm{H}, J=8.6 \mathrm{~Hz}), 7.24(\mathrm{~d}, 2 \mathrm{H}, J=8.1 \mathrm{~Hz}), 7.23(\mathrm{~d}, 2 \mathrm{H}, J=8.6 \mathrm{~Hz}), 7.19(\mathrm{~d}$, $2 \mathrm{H}, J=8.1 \mathrm{~Hz}), 5.12(\mathrm{~s}, 2 \mathrm{H}), 3.64(\mathrm{~s}, 2 \mathrm{H}), 2.38(\mathrm{~s}, 3 \mathrm{H}) ;{ }^{13} \mathrm{C} \mathrm{NMR}\left(400 \mathrm{MHz}, \mathrm{CDCl}_{3}\right): \delta 171.3,138.5,133.3,132.9$, 132.6, 131.0, 129.5, 129.0, 128.7, 67.0, 40.9, 21.5; IR: 2947 (w), 1732 (s), 1494 (w) cm ${ }^{-1}$; HRMS (EI) calcd for $\mathrm{C}_{16} \mathrm{H}_{15} \mathrm{ClO}_{2}[\mathrm{M}]^{+}:$274.0761, found: 274.0758 .
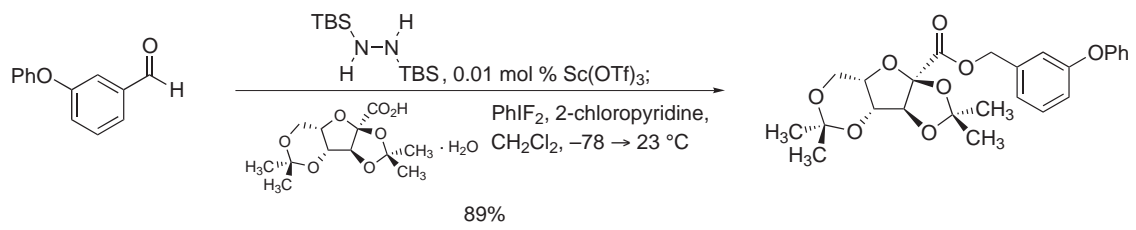

2,3:4,6-Di- $\boldsymbol{O}$-isopropylidene-2-keto-L-gulonic acid 3-phenoxybenzyl ester: A freshly prepared solution of scandium trifluoromethanesulfonate in dry acetonitrile $(0.01 \mathrm{M}, 0.005 \mathrm{~mL}, 0.00005 \mathrm{mmol}, 0.0003$ equiv) was transferred by syringe to a 10-mL pear-shape flask equipped with a Teflon-coated stir bar. A 21-gauge needle connected to a source of argon/vacuum (dual manifold, 0.05 Torr) was inserted through the septum cap of the reaction vessel and the flask was carefully evacuated, with stirring, to evaporate the solvent. When the removal of solvent was complete $(\sim 15 \mathrm{~min})$, the flask was flushed with dry argon and a needle affixed to an argon balloon was inserted through the septum cap. 1,2-Bis(tert-butyldimethylsilyl)hydrazine $(0.134 \mathrm{~g}, 0.513 \mathrm{mmol}, 3$ equiv) was introduced by syringe and the reaction flask was cooled in an ice bath. 3-Phenoxybenzaldehyde $(0.087 \mathrm{~mL}, 0.513$ mmol, 3 equiv) was then added dropwise over $15 \mathrm{~min}$ via syringe. ${ }^{*}$ The reaction solution, a colorless liquid, was stirred for an additional $15 \mathrm{~min}$ at $0{ }^{\circ} \mathrm{C}$, then the ice bath was removed, and the reaction mixture was allowed to warm to ambient temperature $\left(23^{\circ} \mathrm{C}\right)$. After $15 \mathrm{~min}$, the septum cap was removed and a vacuum adapter connected to a source of argon/vacuum was affixed (dual manifold, 0.05 Torr) and the flask was carefully evacuated with stirring. After stirring under vacuum for $1 \mathrm{~h}$ at $23{ }^{\circ} \mathrm{C}$, the flask was immersed in an oil bath, and the bath was warmed to $30-35{ }^{\circ} \mathrm{C}$. After stirring under vacuum at $30-35^{\circ} \mathrm{C}$ for $2 \mathrm{~h}$, the heating bath was removed, the flask was flushed with dry argon, a septum cap was affixed, and a needle connected to an argon balloon was inserted through the septum. Dry dichloromethane $(0.5 \mathrm{~mL})$ was added by syringe providing a colorless solution. Separately, a 50 $\mathrm{mL}$ Teflon vial equipped with a Teflon-coated stir bar was charged with iodosylbenzene $(0.173 \mathrm{~g}, 0.787 \mathrm{mmol}, 4.6$ equiv), a septum cap was affixed, and a needle connected to an argon balloon was inserted through the septum cap. The yellow solid was suspended in dichloromethane $(5 \mathrm{~mL})$ and the suspension was stirred vigorously. Aqueous hydrofluoric acid (48\% w/v, approximate volume: $0.100 \mathrm{~mL})$ was added to the stirred suspension dropwise by polypropylene syringe until all particulates had dissolved (rate of addition: 1 drop every 2 seconds). At this point, stirring was stopped, the layers were allowed to separate, and the upper, aqueous layer was removed by polypropylene syringe. The lower phase, a colorless solution, was cooled in a Dry Ice/acetone bath with stirring, and 2-chloropyridine $(0.162 \mathrm{~mL}, 1.71 \mathrm{mmol}, 10$ equiv) was added dropwise by syringe over $1 \mathrm{~min}$. At this point, the septum was briefly removed, solid 2,3:4,6-di- $O$-isopropylidene-2-keto-L-gulonic acid monohydrate $(0.0500$ g, $0.171 \mathrm{mmol}, 1$ equiv) was added, and the septum and argon balloon were reaffixed. To avoid photochemical decomposition of the diazo intermediate, the reaction flask was shielded from light at this stage. The solution of the TBSH derivative prepared above was then added dropwise over 2 min, also by syringe, and the transfer was quantitated with dichloromethane $(2 \times 0.2 \mathrm{~mL})$. The reaction mixture was stirred at $-78{ }^{\circ} \mathrm{C}$ for $4 \mathrm{~h}$, at which point the cooling bath was allowed to warm gradually to $23{ }^{\circ} \mathrm{C}$ over $\sim 3.5 \mathrm{~h}$. The yellow reaction solution was then stirred at $23{ }^{\circ} \mathrm{C}$ for $6 \mathrm{~h}$. $n$-Hexane $(5 \mathrm{~mL})$ and a $1: 1$ mixture of half-saturated aqueous sodium thiosulfate solution and halfsaturated aqueous sodium bicarbonate solution $(8 \mathrm{~mL})$ were added and the resulting biphasic mixture was stirred 
vigorously for $20 \mathrm{~min}$. Stirring was stopped, and the layers were separated. The organic layer was dried over sodium sulfate, and the dried solution was filtered through a plug of Celite with suction. Concentration of the filtrate afforded a yellow, oily residue which was purified by flash column chromatography (0.5:99.5 ethyl acetate/dichloromethane grading to 2:98 ethyl acetate/dichloromethane) affording 2,3:4,6-di- $O$-isopropylidene-2keto-L-gulonic acid 3-phenoxybenzyl ester $(0.0696 \mathrm{~g}, 0.153 \mathrm{mmol}, 89 \%)$ as a slightly yellow, viscous oil.

TLC (acetic acid-buffered silica gel; 50:50 ethyl acetate: $n$-hexane; UV, anis): $R_{f} 0.10$ (2,3:4,6-di- $O$-isopropylidene2-keto-L-gulonic acid), 0.49 (2,3:4,6-di-O-isopropylidene-2-keto-L-gulonic acid 3-phenoxybenzyl ester).

${ }^{1} \mathrm{H}$ NMR $\left(500 \mathrm{MHz}, \mathrm{CDCl}_{3}\right): \delta 7.32(\mathrm{dd}, 1 \mathrm{H}, J=8.3,7.3 \mathrm{~Hz}), 7.30(\mathrm{dd}, 2 \mathrm{H}, J=8.8,7.8 \mathrm{~Hz}), 7.14(\mathrm{~d}, 1 \mathrm{H}, J=7.3$ $\mathrm{Hz}), 7.11(\mathrm{t}, 1 \mathrm{H}, J=7.8 \mathrm{~Hz}), 7.06(\mathrm{~s}, 1 \mathrm{H}), 7.00(\mathrm{~d}, 2 \mathrm{H}, J=8.8 \mathrm{~Hz}), 6.94(\mathrm{~d}, 1 \mathrm{H}, J=8.3 \mathrm{~Hz}), 5.27(\mathrm{~s}, 2 \mathrm{H}), 4.83(\mathrm{~s}$, $1 \mathrm{H}), 4.30(\mathrm{~d}, 1 \mathrm{H}, J=2.4 \mathrm{~Hz}), 4.17(\mathrm{~s}, 1 \mathrm{H}), 4.11(\mathrm{~d}, 1 \mathrm{H}, J=13.7 \mathrm{~Hz}), 4.06(\mathrm{dd}, 1 \mathrm{H}, J=13.7,2.4 \mathrm{~Hz}), 1.53(\mathrm{~s}, 3 \mathrm{H})$, 1.41 (s, 3H), 1.37 (s, 3H), $1.27(\mathrm{~s}, 3 \mathrm{H}) ;{ }^{13} \mathrm{C}$ NMR $\left(500 \mathrm{MHz}, \mathrm{CDCl}_{3}\right): \delta$ 166.7, 157.7, 157.2, 137.7, 130.1, 130.0, 123.6, 122.7, 119.2, 118.7, 118.3, 114.2, 110.6, 97.8, 87.7, 74.2, 73.0, 67.0, 60.0, 28.8, 27.2, 26.0, 19.0; IR: 2991 (m), 1747 (s), $1585(\mathrm{~s}), 1488(\mathrm{~s}) \mathrm{cm}^{-1}$; HRMS (ES) calcd for $\mathrm{C}_{25} \mathrm{H}_{29} \mathrm{O}_{8}[\mathrm{M}+\mathrm{H}]^{+}:$457.1862, found: 457.1868.
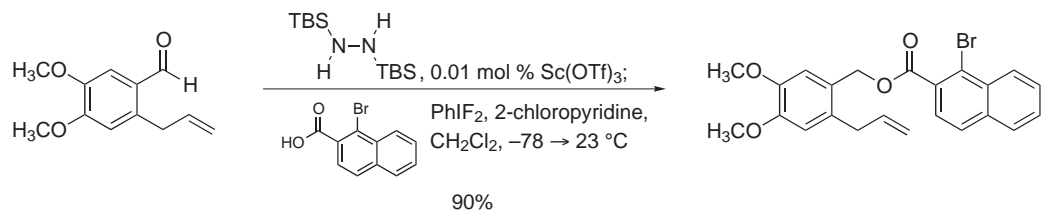

6-Allyl-3,4-dimethoxybenzyl 1-bromo-2-naphthoate: A freshly prepared solution of scandium trifluoromethanesulfonate in dry acetonitrile $(0.01 \mathrm{M}, 0.007 \mathrm{~mL}, 0.00007 \mathrm{mmol}, 0.00015$ equiv) was transferred by syringe to a $10-\mathrm{mL}$ pear-shape flask equipped with a Teflon-coated stir bar. A 21-gauge needle connected to a source of argon/vacuum (dual manifold, 0.05 Torr) was inserted through the septum cap of the reaction vessel and the flask was carefully evacuated, with stirring, to evaporate the solvent. When the removal of solvent was complete ( 15 min), the flask was flushed with dry argon and a needle affixed to an argon balloon was inserted through the septum cap. 1,2-Bis(tert-butyldimethylsilyl)hydrazine $(0.190 \mathrm{~g}, 0.727 \mathrm{mmol}, 1.5$ equiv) was introduced by syringe and the reaction flask was cooled in an ice bath. 6-Allylveratraldehyde $(0.150 \mathrm{~g}, 0.727 \mathrm{mmol}, 1.5$ equiv) was then added dropwise over $15 \mathrm{~min}$ via syringe." The reaction solution, a colorless liquid, was stirred for an additional 15 $\min$ at $0{ }^{\circ} \mathrm{C}$, then the ice bath was removed, and the reaction mixture was allowed to warm to ambient temperature $\left(23{ }^{\circ} \mathrm{C}\right)$. After $15 \mathrm{~min}$, the septum cap was removed and a vacuum adapter connected to a source of argon/vacuum was affixed (dual manifold, 0.05 Torr) and the flask was carefully evacuated with stirring. After stirring under vacuum for $1 \mathrm{~h}$ at $23{ }^{\circ} \mathrm{C}$, the flask was immersed in an oil bath, and the bath was warmed to $30-35{ }^{\circ} \mathrm{C}$. After stirring under vacuum at $30-35{ }^{\circ} \mathrm{C}$ for $2 \mathrm{~h}$, the heating bath was removed, the flask was flushed with dry argon, a septum cap was affixed, and a needle connected to an argon balloon was inserted through the septum. Dry dichloromethane $(0.5 \mathrm{~mL})$ was added by syringe providing a colorless solution. Separately, a $50-\mathrm{mL}$ Teflon vial equipped with a Teflon-coated stir bar was charged with iodosylbenzene $(0.245 \mathrm{~g}, 1.12 \mathrm{mmol}, 2.3$ equiv), a septum cap was affixed, and a needle connected to an argon balloon was inserted through the septum cap. The yellow solid was suspended in dichloromethane $(10 \mathrm{~mL})$ and the suspension was stirred vigorously. Aqueous hydrofluoric acid $(48 \% \mathrm{w} / \mathrm{v}$, approximate volume: $0.140 \mathrm{~mL}$ ) was added to the stirred suspension dropwise by polypropylene syringe until all particulates had dissolved (rate of addition: 1 drop every 2 seconds). At this point, stirring was stopped, the layers were allowed to separate, and the upper, aqueous layer was removed by polypropylene syringe. The lower phase, a colorless solution, was cooled in a Dry Ice/acetone bath with stirring, and 2-chloropyridine $(0.230 \mathrm{~mL}, 2.42 \mathrm{mmol}, 5$ equiv) was added dropwise by syringe over $1 \mathrm{~min}$. At this point, the septum was briefly removed, solid 1-bromo-2naphthoic acid $(0.122 \mathrm{~g}, 0.485 \mathrm{mmol}, 1$ equiv) was added, and the septum and argon balloon were reaffixed. To avoid photochemical decomposition of the diazo intermediate, the reaction flask was shielded from light at this stage. The solution of the TBSH derivative prepared above was then added dropwise over $2 \mathrm{~min}$, also by syringe, and the transfer was quantitated with dichloromethane $(2 \times 0.2 \mathrm{~mL})$. The reaction mixture was stirred at $-78{ }^{\circ} \mathrm{C}$ for an additional $4 \mathrm{~h}$, at which point the cooling bath was allowed to warm gradually to $23{ }^{\circ} \mathrm{C}$ over $\sim 3.5 \mathrm{~h}$. The yellow reaction solution was then stirred at $23{ }^{\circ} \mathrm{C}$ for $6 \mathrm{~h}$. $n$-Hexane $(7 \mathrm{~mL})$ and a $1: 1$ mixture of half-saturated aqueous sodium thiosulfate solution and half-saturated aqueous sodium bicarbonate solution $(9 \mathrm{~mL})$ were added and the resulting biphasic mixture was stirred vigorously for $20 \mathrm{~min}$. Stirring was stopped and the layers were separated. The organic layer was dried over sodium sulfate, and the dried solution was filtered through a plug of Celite with 
suction. Concentration of the filtrate afforded a yellow, oily residue which was purified by 2 rounds of flash column chromatography (first column:dichloromethane; second column: 5:95 ethyl acetate/n-hexane grading to 25:75 ethyl acetate/n-hexane) affording 6-Allyl-3,4-dimethoxybenzyl 1-bromo-2-naphthoate (0.192 g, $0.436 \mathrm{mmol}, 90 \%)$ as a slightly yellow, viscous oil.

TLC (acetic acid-buffered silica gel; 30:70 ethyl acetate: $n$-hexane; UV, CAM): $R_{f} 0.30$ (1-bromo-2-naphthoic acid), 0.38 (6-Allyl-3,4-dimethoxybenzyl 1-bromo-2-naphthoate).

${ }^{1} \mathrm{H}$ NMR (400 MHz, $\left.\mathrm{CDCl}_{3}\right): \delta 8.42(\mathrm{~d}, 1 \mathrm{H}, J=8.6 \mathrm{~Hz}), 7.80(\mathrm{~d}, 1 \mathrm{H}, J=8.1 \mathrm{~Hz}), 7.79(\mathrm{~d}, 1 \mathrm{H}, J=8.3 \mathrm{~Hz}), 7.64(\mathrm{~d}$, $1 \mathrm{H}, J=8.3 \mathrm{~Hz}), 7.62(\mathrm{dd}, 1 \mathrm{H}, J=8.6,6.8 \mathrm{~Hz}), 7.56(\mathrm{dd}, 1 \mathrm{H}, J=8.1,6.8 \mathrm{~Hz}), 7.04(\mathrm{~s}, 1 \mathrm{H}), 6.75(\mathrm{~s}, 1 \mathrm{H}), 5.99(\mathrm{ddt}$, $1 \mathrm{H}, J=17.1,10.0,6.1 \mathrm{~Hz}), 5.42(\mathrm{~s}, 2 \mathrm{H}), 5.08(\mathrm{ddt}, 1 \mathrm{H}, J=10.0,1.7,1.5 \mathrm{~Hz}), 5.04(\mathrm{ddt}, 1 \mathrm{H}, J=17.1,2.0,1.7 \mathrm{~Hz})$, $3.89(\mathrm{~s}, 3 \mathrm{H}), 3.88(\mathrm{~s}, 3 \mathrm{H}), 3.51(\mathrm{ddd}, 2 \mathrm{H}, J=6.1,2.0,1.5 \mathrm{~Hz}) ;{ }^{13} \mathrm{C}$ NMR $\left(400 \mathrm{MHz}, \mathrm{CDCl}_{3}\right): \delta 167.5,149.5,147.6$, 137.3, 135.4, 132.5, 131.9, 131.6, 128.7, 128.4, 128.4, 128.4, 128.1, 126.0, 125.6, 122.8, 116.3, 113.9, 113.2, 65.7, 56.3, 56.2, 36.9; IR: 2935 (m), 1728 (s), 1608 (m), 1519 (s) $\mathrm{cm}^{-1}$; HRMS (ES) calcd for $\mathrm{C}_{23} \mathrm{H}_{21} \mathrm{BrNaO}_{4}[\mathrm{M}+\mathrm{Na}]^{+}$: 463.0521, found: 463.0522 .
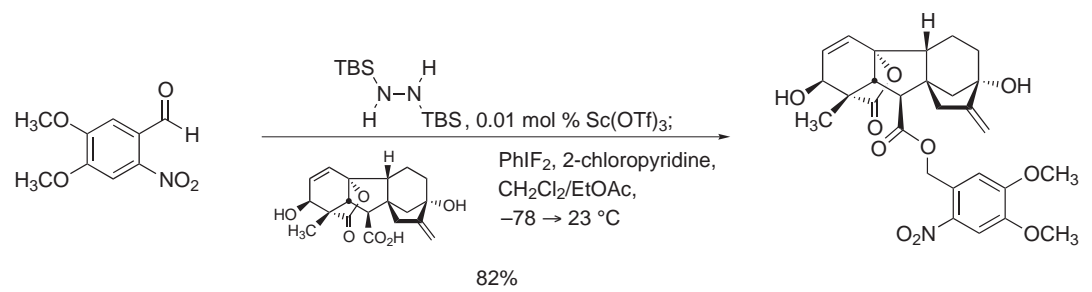

Gibberellic acid 4,5-dimethoxy-2-nitrobenzyl ester: A freshly prepared solution of scandium trifluoromethanesulfonate in dry acetonitrile $(0.01 \mathrm{M}, 0.002 \mathrm{~mL}, 0.00002 \mathrm{mmol}, 0.0003$ equiv) was transferred by syringe to a $10-\mathrm{mL}$ pear-shape flask equipped with a Teflon-coated stir bar. A 21-gauge needle connected to a source of argon/vacuum (dual manifold, 0.05 Torr) was inserted through the septum cap of the reaction vessel and the flask was carefully evacuated, with stirring, to evaporate the solvent. When the removal of solvent was complete ( $15 \mathrm{~min}$ ), the flask was flushed with dry argon and a needle affixed to an argon balloon was inserted through the septum cap. 1,2-Bis(tert-butyldimethylsilyl)hydrazine $(0.0594 \mathrm{~g}, 0.228 \mathrm{mmol}, 3.15$ equiv) was introduced by syringe and the reaction flask was cooled in an ice bath. A freshly prepared solution of 6-nitroveratraldehyde $(0.0458 \mathrm{~g}, 0.217 \mathrm{mmol}, 3$ equiv) in dry dichloromethane $(0.25 \mathrm{~mL})$ was then added dropwise over $15 \mathrm{~min}$ via syringe. $\quad$ The reaction solution, a yellow liquid, was stirred for an additional $15 \mathrm{~min}$ at $0{ }^{\circ} \mathrm{C}$, then the ice bath was removed, and the reaction mixture was allowed to warm to ambient temperature $\left(23{ }^{\circ} \mathrm{C}\right)$. After $2.5 \mathrm{~h}$, the septum cap was removed and a vacuum adapter connected to a source of argon/vacuum was affixed (dual manifold, 0.05 Torr) and the flask was carefully evacuated with stirring. After stirring under vacuum for $1 \mathrm{~h}$ at $23{ }^{\circ} \mathrm{C}$, the flask was flushed with dry argon, the vacuum adapter was removed, dry benzene $(1 \mathrm{~mL})$ was added, and the vacuum adapter (positive argon pressure) was replaced. The resulting yellow solution was frozen by immersing the flask in a Dry Ice-acetone bath. The flask was then evacuated with warming to $23{ }^{\circ} \mathrm{C}$ in order to remove volatiles $(\sim 1 \mathrm{~h})$. The flask was then flushed with dry argon, a septum cap was affixed, and a needle connected to an argon balloon was inserted through the septum. Dry dichloromethane $(1 \mathrm{~mL})$ was added by syringe, producing a yellow solution. Separately, a 50-mL Teflon vial equipped with a Teflon-coated stir bar was charged with iodosylbenzene $(0.0728 \mathrm{~g}$, $0.331 \mathrm{mmol}, 4.6$ equiv), a septum cap was affixed, and a needle connected to an argon balloon was inserted through the septum cap. The yellow solid was suspended in dichloromethane $(4 \mathrm{~mL})$ and the suspension was stirred vigorously. Aqueous hydrofluoric acid ( $48 \% \mathrm{w} / \mathrm{v}$, approximate volume: $0.050 \mathrm{~mL}$ ) was added to the stirred suspension dropwise by polypropylene syringe until all particulates had dissolved (rate of addition: 1 drop every 2 seconds). At this point, stirring was stopped, the layers were allowed to separate, and the upper, aqueous layer was removed by polypropylene syringe. The lower phase, a colorless solution, was cooled in a Dry Ice/acetone bath with stirring, and 2-chloropyridine $(0.068 \mathrm{~mL}, 0.720 \mathrm{mmol}, 10$ equiv) was added dropwise by syringe over $1 \mathrm{~min}$. At this point, the septum was briefly removed, solid (+)-gibberellic acid $(0.0249 \mathrm{~g}, 0.072 \mathrm{mmol}, 1$ equiv) was added, and the septum and argon balloon were reaffixed. Ethyl acetate $\left(4 \mathrm{~mL}\right.$, precooled to $\left.-78{ }^{\circ} \mathrm{C}\right)$ was then added by cannula. To avoid photochemical decomposition of the diazo intermediate, the reaction flask was shielded from light at this stage. The solution of the TBSH derivative prepared above was then added dropwise over 2 min, also by syringe, and the transfer was quantitated with dichloromethane $(2 \times 0.2 \mathrm{~mL})$. The reaction mixture was stirred at 
$-78{ }^{\circ} \mathrm{C}$ for $4 \mathrm{~h}$, at which point the cooling bath was allowed to warm gradually to $23{ }^{\circ} \mathrm{C}$ over $\sim 3.5 \mathrm{~h}$. The yellow reaction solution was then stirred at $23{ }^{\circ} \mathrm{C}$ for $4 \mathrm{~h}$. A 1:1 mixture of half-saturated aqueous sodium thiosulfate solution and half-saturated aqueous sodium bicarbonate solution $(6 \mathrm{~mL})$ was added and the resulting biphasic mixture was stirred vigorously for $20 \mathrm{~min}$. Stirring was stopped and the layers were separated. The organic layer was dried over sodium sulfate, and the dried solution was filtered through a plug of Celite with suction. Concentration of the filtrate afforded a yellow, oily residue which was purified by flash column chromatography through a short column of silica gel $(2.5 \mathrm{~cm}$ dia. $\times 2.5 \mathrm{~cm} \mathrm{~h}$; dichloromethane grading to 5:95 methanol/dichloromethane) affording gibberellic acid 4,5-dimethoxy-2-nitrobenzyl ester (0.0321 g, $0.0593 \mathrm{mmol}$, $82 \%)$ as a yellow, viscous oil.

TLC (acetic acid-buffered silica gel; 5:95 methanol/dichloromethane; UV, PMA): $R_{f} 0.09$ [(+)-Gibberellic acid], 0.47 (gibberellic acid 4,5-dimethoxy-2-nitrobenzyl ester).

${ }^{1} \mathrm{H}$ NMR (500 MHz, $\left.\mathrm{CD}_{3} \mathrm{OD}\right): \delta 7.69(\mathrm{~s}, 1 \mathrm{H}), 7.16(\mathrm{~s}, 1 \mathrm{H}), 6.35(\mathrm{~d}, 1 \mathrm{H}, J=9.5 \mathrm{~Hz}), 5.86(\mathrm{dd}, 1 \mathrm{H}, J=9.5,3.7 \mathrm{~Hz})$, $5.51(\mathrm{~d}, 1 \mathrm{H}, J=13.7 \mathrm{~Hz}), 5.45(\mathrm{~d}, 1 \mathrm{H}, J=13.7 \mathrm{~Hz}), 5.19(\mathrm{~s}, 1 \mathrm{H}), 4.91(\mathrm{~s}, 1 \mathrm{H}), 3.99(\mathrm{~d}, 1 \mathrm{H}, J=3.7 \mathrm{~Hz}), 3.94(\mathrm{~s}, 3 \mathrm{H})$, $3.90(\mathrm{~s}, 3 \mathrm{H}), 3.27(\mathrm{~d}, 1 \mathrm{H}, J=10.7 \mathrm{~Hz}), 2.82(\mathrm{~d}, 1 \mathrm{H}, J=10.7 \mathrm{~Hz}), 2.18-2.22(\mathrm{~m}, 2 \mathrm{H}), 1.92-2.02(\mathrm{~m}, 3 \mathrm{H}), 1.66-1.88$ $(\mathrm{m}, 4 \mathrm{H}), 1.18(\mathrm{~s}, 3 \mathrm{H}) ;{ }^{13} \mathrm{C}$ NMR $\left(500 \mathrm{MHz}, \mathrm{CD}_{3} \mathrm{OD}\right): \delta 179.6,171.9,156.8,153.8,148.9,140.6,132.9,132.0$, 125.8, 111.9, 108.2, 106.6, 91.2, 77.4, 69.3, 63.8, 56.0, 55.7, 53.8, 52.9, 51.1, 51.0, 50.6, 44.5, 43.0, 38.7, 16.8, 14.0; IR: 3230 (br, w), 2938 (w), 1770 (s), 1738 (s), 1524 (s) cm ${ }^{-1}$; HRMS (ES) calcd for $\mathrm{C}_{28} \mathrm{H}_{35} \mathrm{~N}_{2} \mathrm{O}_{10}\left[\mathrm{M}+\mathrm{NH}_{4}\right]^{+}$: 559.2292, found: 559.2303 .

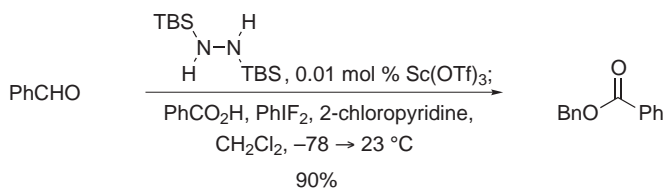

Benzoic acid benzyl ester: A freshly prepared solution of scandium trifluoromethanesulfonate in dry acetonitrile (0.01 M, $0.012 \mathrm{~mL}, 0.00012 \mathrm{mmol}, 0.00015$ equiv) was transferred by syringe to a $10-\mathrm{mL}$ pear-shape flask equipped with a Teflon-coated stir bar. A 21-gauge needle connected to a source of argon/vacuum (dual manifold, 0.05 Torr) was inserted through the septum cap of the reaction vessel and the flask was carefully evacuated, with stirring, to evaporate the solvent. When the removal of solvent was complete $(\sim 15 \mathrm{~min})$, the flask was flushed with dry argon and a needle affixed to an argon balloon was inserted through the septum cap. 1,2-Bis(tertbutyldimethylsilyl)hydrazine ( $0.323 \mathrm{~g}, 1.24 \mathrm{mmol}, 1.52$ equiv) was introduced by syringe and the reaction flask was cooled in an ice bath. Benzaldehyde $(0.125 \mathrm{~mL}, 1.23 \mathrm{mmol}, 1.5$ equiv) was then added dropwise over 15 min via syringe." The reaction solution, a colorless liquid, was stirred for an additional $15 \mathrm{~min}$ at $0{ }^{\circ} \mathrm{C}$, then the ice bath was removed, and the reaction mixture was allowed to warm to ambient temperature $\left(23^{\circ} \mathrm{C}\right)$. After $15 \mathrm{~min}$, the septum cap was removed and a vacuum adapter connected to a source of argon/vacuum was affixed (dual manifold, 0.05 Torr) and the flask was carefully evacuated with stirring. After stirring under vacuum for $1 \mathrm{~h}$ at $23{ }^{\circ} \mathrm{C}$, the flask was immersed in an oil bath, and the bath was warmed to $30-35{ }^{\circ} \mathrm{C}$. After stirring under vacuum at $30-35{ }^{\circ} \mathrm{C}$ for $1 \mathrm{~h}$, the heating bath was removed, the flask was flushed with dry argon, a septum cap was affixed, and a needle connected to an argon balloon was inserted through the septum. Dry dichloromethane $(0.5 \mathrm{~mL})$ was added by syringe, producing a colorless solution. Separately, a 50-mL Teflon vial equipped with a Teflon-coated stir bar was charged with iodosylbenzene $(0.414 \mathrm{~g}, 1.88 \mathrm{mmol}, 2.3$ equiv), a septum cap was affixed, and a needle connected to an argon balloon was inserted through the septum cap. The yellow solid was suspended in dichloromethane $(10 \mathrm{~mL})$ and the suspension was stirred vigorously. Aqueous hydrofluoric acid $(48 \% \mathrm{w} / \mathrm{v}$, approximate volume: $0.240 \mathrm{~mL})$ was added to the stirred suspension dropwise by polypropylene syringe until all particulates had dissolved (rate of addition: 1 drop every 2 seconds). At this point, stirring was stopped, the layers were allowed to separate, and the upper, aqueous layer was removed by polypropylene syringe. The lower phase, a colorless solution, was cooled in a Dry Ice/acetone bath, with stirring, and 2-chloropyridine $(0.388 \mathrm{~mL}, 4.10 \mathrm{mmol}, 5$ equiv) was added dropwise by syringe over $1 \mathrm{~min}$. At this point, the septum was removed, benzoic acid ( $0.122 \mathrm{~g}, 0.485 \mathrm{mmol}, 1$ equiv) was added as a neat solid, and the septum and argon balloon were replaced. To avoid photochemical decomposition of the diazo intermediate, the reaction flask was shielded from light at this stage. The solution of the TBSH derivative prepared above was then added dropwise over $2 \mathrm{~min}$, also by syringe, and the transfer was quantitated with dichloromethane $(2 \times 0.2 \mathrm{~mL})$. The reaction mixture was stirred at $-78{ }^{\circ} \mathrm{C}$ for $4 \mathrm{~h}$, at which point the cooling bath was allowed to warm gradually to $23{ }^{\circ} \mathrm{C}$ over $\sim 3.5 \mathrm{~h}$. The yellow reaction solution was then stirred at $23{ }^{\circ} \mathrm{C} 6 \mathrm{~h} . n$ - 
Pentane $(10 \mathrm{~mL})$ and a 1:1 mixture of half-saturated aqueous sodium thiosulfate solution and half-saturated aqueous sodium bicarbonate solution $(8 \mathrm{~mL})$ were added and the resulting biphasic mixture was stirred vigorously for 20 min. Stirring was stopped, and the layers were separated. The organic layer was dried over sodium sulfate, and the dried solution was filtered through a plug of Celite with suction. Solvents were carefully removed by rotary evaporation $\left(0{ }^{\circ} \mathrm{C}, \sim 150\right.$ Torr $)$ to afford a yellow, oily residue which was purified by flash column chromatography (80:20 $n$-pentane/dichloromethane; fractions were carefully concentrated by rotary evaporation at $0{ }^{\circ} \mathrm{C}, \sim 150$ torr) affording benzoic acid benzyl ester $(0.157 \mathrm{~g}, 0.740 \mathrm{mmol}, 90 \%)$ as a colorless oil which was identical in all respects to commercial material.

TLC (dichloromethane; UV): $R_{f} 0.12$ (benzoic acid), 0.51 (benzoic acid benzyl ester).

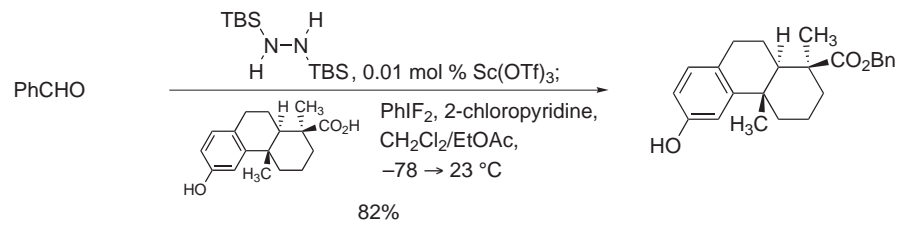

Podocarpic acid benzyl ester: A freshly prepared solution of scandium trifluoromethanesulfonate in dry acetonitrile $(0.01 \mathrm{M}, 0.008 \mathrm{~mL}, 0.00008 \mathrm{mmol}, 0.0009$ equiv) was transferred by syringe to a $10-\mathrm{mL}$ pear-shape flask equipped with a Teflon-coated stir bar. A 21-gauge needle connected to a source of argon/vacuum (dual manifold, 0.05 Torr) was inserted through the septum cap of the reaction vessel and the flask was carefully evacuated, with stirring, to evaporate the solvent. When the removal of solvent was complete ( $15 \mathrm{~min})$, the flask was flushed with dry argon and a needle affixed to an argon balloon was inserted through the septum cap. 1,2Bis(tert-butyldimethylsilyl)hydrazine $(0.216 \mathrm{~g}, 0.827 \mathrm{mmol}, 9.09$ equiv) was introduced by syringe and the reaction flask was cooled in an ice bath. Benzaldehyde $(0.083 \mathrm{~mL}, 0.819 \mathrm{mmol}, 9$ equiv) was then added dropwise over 15 min via syringe." The reaction solution, a colorless liquid, was stirred for an additional $15 \mathrm{~min}$ at $0{ }^{\circ} \mathrm{C}$, then the ice bath was removed, and the reaction mixture was allowed to warm to ambient temperature $\left(23^{\circ} \mathrm{C}\right)$. After $15 \mathrm{~min}$, the septum cap was removed and a vacuum adapter connected to a source of argon/vacuum was affixed (dual manifold, 0.05 Torr) and the flask was carefully evacuated with stirring. After stirring under vacuum for $1 \mathrm{~h}$ at $23{ }^{\circ} \mathrm{C}$, the flask was immersed in an oil bath, and the bath was warmed to $30-35{ }^{\circ} \mathrm{C}$. After stirring under vacuum at $30-35{ }^{\circ} \mathrm{C}$ for $1 \mathrm{~h}$, the heating bath was removed, the flask was flushed with dry argon, a septum cap was affixed, and a needle connected to an argon balloon was inserted through the septum. Dry dichloromethane $(1 \mathrm{~mL})$ was added by syringe, producing a colorless solution. Separately, a 50-mL Teflon vial equipped with a Teflon-coated stir bar was charged with iodosylbenzene $(0.156 \mathrm{~g}, 0.710 \mathrm{mmol}, 7.8$ equiv), a septum cap was affixed, and a needle connected to an argon balloon was inserted through the septum cap. The yellow solid was suspended in dichloromethane $(6 \mathrm{~mL})$ and the suspension was stirred vigorously. Aqueous hydrofluoric acid $(48 \% \mathrm{w} / \mathrm{v}$, approximate volume: $0.100 \mathrm{~mL})$ was added to the stirred suspension dropwise by polypropylene syringe until all particulates had dissolved (rate of addition: 1 drop every 2 seconds). At this point, stirring was stopped, the layers were allowed to separate, and the upper, aqueous layer was removed by polypropylene syringe. The lower phase, a colorless solution, was cooled in a Dry Ice/acetone bath with stirring, and 2-chloropyridine $(0.258 \mathrm{~mL}, 2.73 \mathrm{mmol}, 30$ equiv) was added dropwise by syringe over $1 \mathrm{~min}$. To avoid photochemical decomposition of the diazo intermediate, the reaction flask was shielded from light at this stage. The solution of the TBSH derivative prepared above was then added dropwise over $1 \mathrm{~min}$, also by syringe, and the transfer was quantitated with dichloromethane $(2 \times 0.2 \mathrm{~mL})$. This was followed by the addition of a solution of podocarpic acid $(0.0250 \mathrm{~g}, 0.0912 \mathrm{mmol}, 1$ equiv) in ethyl acetate $(0.5 \mathrm{~mL})$ by syringe, quantitating the addition with ethyl acetate $(2 \times 0.1 \mathrm{~mL})$. The reaction mixture was stirred at $-78{ }^{\circ} \mathrm{C}$ for $4 \mathrm{~h}$, at which point the cooling bath was allowed to warm gradually to $23{ }^{\circ} \mathrm{C}$ over $\sim 3.5 \mathrm{~h}$. The yellow reaction solution was then stirred at $23{ }^{\circ} \mathrm{C}$ for $4 \mathrm{~h}$. Ethyl acetate $(0.5 \mathrm{~mL})$ and half-saturated aqueous sodium thiosulfate solution $(4 \mathrm{~mL})$ were added followed by aqueous sodium phosphate buffer solution $(\mathrm{pH} 7,0.2 \mathrm{M}, 4 \mathrm{~mL})$ and the resulting biphasic mixture was stirred vigorously for $20 \mathrm{~min}$. Stirring was stopped and the layers were separated. The organic layer was dried over sodium sulfate, and the dried solution was filtered through a plug of Celite with suction. Concentration of the filtrate afforded a yellow, oily residue which was purified by flash column chromatography (0.5:99.5 methanol/dichloromethane) affording podocarpic acid benzyl ester $(0.0273 \mathrm{~g}, 0.0749 \mathrm{mmol}, 82 \%)$ as a viscous, yellow oil. 
TLC (acetic acid-buffered silica gel; dichloromethane; UV, PMA): $R_{f} 0.00$ (Podocarpic acid), 0.51 (Podocarpic acid benzyl ester).

${ }^{1} \mathrm{H}$ NMR (400 MHz, CDCl $)$ ): $\delta 7.28-7.38(\mathrm{~m}, 5 \mathrm{H}), 6.89(\mathrm{~d}, 1 \mathrm{H}, J=8.3 \mathrm{~Hz}), 6.72(\mathrm{~d}, 1 \mathrm{H}, J=2.5 \mathrm{~Hz}), 6.58(\mathrm{dd}, 1 \mathrm{H}, J$ $=8.3,2.5 \mathrm{~Hz}), 5.14(\mathrm{~d}, 1 \mathrm{H}, J=12.5 \mathrm{~Hz}), 5.07(\mathrm{~d}, 1 \mathrm{H}, J=12.5 \mathrm{~Hz}), 4.70(\mathrm{br} \mathrm{s}, 1 \mathrm{H}), 2.80(\mathrm{dd}, 1 \mathrm{H}, J=17.6,4.4 \mathrm{~Hz})$, $2.68(\mathrm{ddd}, 1 \mathrm{H}, J=17.6,12.7,5.9 \mathrm{~Hz}), 2.31(\mathrm{dd}, 1 \mathrm{H}, J=13.4,3.2 \mathrm{~Hz}), 2.14-2.20(\mathrm{~m}, 2 \mathrm{H}), 2.01$ (ddddd, $1 \mathrm{H}, J=$ 13.9, 13.7, 13.7, 3.2, 3.2 Hz), 1.91 (dddd, $1 \mathrm{H}, J=13.2,12.7,12.2,4.4 \mathrm{~Hz}$ ), 1.62 (ddd, $1 \mathrm{H}, J=13.9,4.3,4.0 \mathrm{~Hz}$ ), $1.53(\mathrm{dd}, 1 \mathrm{H}, J=12.2,1.2 \mathrm{~Hz}), 1.38(\mathrm{ddd}, 1 \mathrm{H}, J=13.7,13.4,4.0 \mathrm{~Hz}), 1.30(\mathrm{~s}, 3 \mathrm{H}), 1.09$ (ddd, $1 \mathrm{H}, J=13.7,13.4$, $4.3 \mathrm{~Hz}), 0.98(\mathrm{~s}, 3 \mathrm{H}) ;{ }^{13} \mathrm{C}$ NMR $\left(400 \mathrm{MHz}, \mathrm{CDCl}_{3}\right): \delta 177.5,153.8,149.7,136.1,130.3,128.7,128.6,128.3,127.8$, 113.2, 112.3, 66.5, 53.1, 44.4, 39.6, 38.9, 37.9, 31.5, 28.9, 23.3, 21.4, 20.2; IR: 3418 (br m), 2957 (s), 1722 (s), 1609 (m), $1500(\mathrm{~m}) \mathrm{cm}^{-1}$; HRMS (CI) calcd for $\mathrm{C}_{24} \mathrm{H}_{32} \mathrm{NO}_{3}\left[\mathrm{M}+\mathrm{NH}_{4}\right]^{+}: 382.2383$, found: 382.2374 .

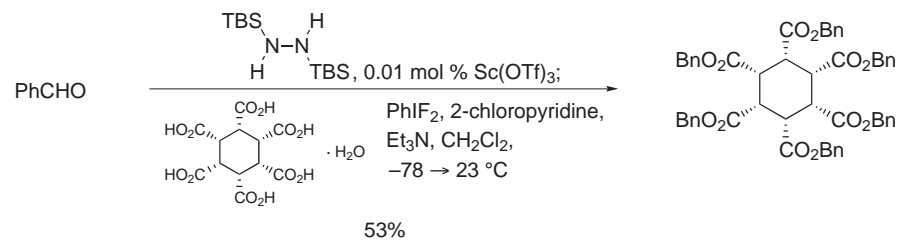

All-cis cyclohexane-1,2,3,4,5,6-hexacarboxylic acid hexabenzyl ester: A freshly prepared solution of scandium trifluoromethanesulfonate in dry acetonitrile $(0.01 \mathrm{M}, 0.012 \mathrm{~mL}, 0.00012 \mathrm{mmol}, 0.0018$ equiv) was transferred by syringe to a $10-\mathrm{mL}$ pear-shape flask equipped with a Teflon-coated stir bar. A 21-gauge needle connected to a source of argon/vacuum (dual manifold, 0.05 Torr) was inserted through the septum cap of the reaction vessel and the flask was carefully evacuated, with stirring, to evaporate the solvent. When the removal of solvent was complete ( $15 \mathrm{~min}$ ), the flask was flushed with dry argon and a needle affixed to an argon balloon was inserted through the septum cap. 1,2-Bis(tert-butyldimethylsilyl)hydrazine $(0.324 \mathrm{~g}, 1.24 \mathrm{mmol}, 18.2$ equiv) was introduced by syringe and the reaction flask was cooled in an ice bath. Benzaldehyde $(0.125 \mathrm{~mL}, 1.23 \mathrm{mmol}, 18$ equiv) was then added dropwise over 15 min via syringe. ${ }^{*}$ The reaction solution, a colorless liquid, was stirred for an additional 15 min at 0 ${ }^{\circ} \mathrm{C}$, then the ice bath was removed, and the reaction mixture was allowed to warm to ambient temperature $\left(23^{\circ} \mathrm{C}\right)$. After 15 min, the septum cap was removed and a vacuum adapter connected to a source of argon/vacuum was affixed (dual manifold, 0.05 Torr) and the flask was carefully evacuated with stirring. After stirring under vacuum for $1 \mathrm{~h}$ at $23{ }^{\circ} \mathrm{C}$, the flask was immersed in an oil bath, and the bath was warmed to $30-35{ }^{\circ} \mathrm{C}$. After stirring under vacuum at $30-35^{\circ} \mathrm{C}$ for $2 \mathrm{~h}$, the heating bath was removed, the flask was flushed with dry argon, a septum cap was affixed, and a needle connected to an argon balloon was inserted through the septum. Dry dichloromethane $(0.5$ $\mathrm{mL}$ ) was added by syringe providing a colorless solution. Separately, a 50-mL Teflon vial equipped with a Tefloncoated stir bar was charged with iodosylbenzene $(0.414 \mathrm{~g}, 1.88 \mathrm{mmol}, 27.6$ equiv), a septum cap was affixed, and a needle connected to an argon balloon was inserted through the septum cap. The yellow solid was suspended in dichloromethane $(9 \mathrm{~mL})$ and the suspension was stirred vigorously. Aqueous hydrofluoric acid $(48 \% \mathrm{w} / \mathrm{v}$, approximate volume: $0.230 \mathrm{~mL}$ ) was added to the stirred suspension dropwise by polypropylene syringe until all particulates had dissolved (rate of addition: 1 drop every 2 seconds). At this point, stirring was stopped, the layers were allowed to separate, and the upper, aqueous layer was removed by polypropylene syringe. The lower phase, a colorless solution, was cooled in a Dry Ice/acetone bath with stirring, and 2-chloropyridine $(0.389 \mathrm{~mL}, 4.11 \mathrm{mmol}$, 60 equiv) was added dropwise by syringe over $1 \mathrm{~min}$. This was followed by the addition of a solution of all-cis cyclohexanehexacarboxylic acid monohydrate $(0.0250 \mathrm{~g}, 0.0683 \mathrm{mmol}, 1$ equiv) in $2.2: 1$ dichloromethane/triethylamine $(0.37 \mathrm{~mL})$ by syringe over $1 \mathrm{~min}$, quantitating the addition with dichloromethane $(2$ $\times 0.1 \mathrm{~mL}$ ). To avoid photochemical decomposition of the diazo intermediate, the reaction flask was shielded from light at this stage. The solution of the TBSH derivative prepared above was then added dropwise over 2 min, also by syringe, and the transfer was quantitated with dichloromethane $(2 \times 0.2 \mathrm{~mL})$. The reaction mixture was stirred at $-78{ }^{\circ} \mathrm{C}$ for an additional $4 \mathrm{~h}$, at which point the cooling bath was allowed to warm gradually to $23{ }^{\circ} \mathrm{C}$ over $\sim 3.5 \mathrm{~h}$. The yellow reaction solution was stirred at $23{ }^{\circ} \mathrm{C}$ for $6 \mathrm{~h}$. $n$-Hexane $(10 \mathrm{~mL})$ and a $1: 1$ mixture of half-saturated aqueous sodium thiosulfate solution and half-saturated aqueous sodium bicarbonate solution $(10 \mathrm{~mL})$ were added and the resulting biphasic mixture was stirred vigorously for $20 \mathrm{~min}$. Stirring was stopped and the layers were separated. The organic layer was dried over sodium sulfate, and the dried solution was filtered through a plug of Celite with suction. Concentration of the filtrate afforded a yellow, oily residue which was purified by flash column chromatography (dichloromethane) affording all-cis cyclohexane-1,2,3,4,5,6-hexacarboxylic acid hexabenzyl ester $(0.0323 \mathrm{~g}, 0.0363 \mathrm{mmol}, 53 \%)$ as a white solid $\left(\mathrm{mp} 155-157^{\circ} \mathrm{C}\right)$. 
TLC (acetic acid-buffered silica gel; 40:60 ethyl acetate: $n$-hexane; UV, CAM): $R_{f} 0.00$ (all cis cyclohexanehexacarboxylic acid), 0.44 (all cis cyclohexane-1,2,3,4,5,6-hexacarboxylic acid hexabenzyl ester).

${ }^{1} \mathrm{H}$ NMR $\left(500 \mathrm{MHz}, \mathrm{CDCl}_{3}\right): \delta 7.38(\mathrm{~d}, 6 \mathrm{H}, J=7.3 \mathrm{~Hz}), 6.97-7.12(\mathrm{~m}, 24 \mathrm{H}), 5.33(\mathrm{~s}, 6 \mathrm{H}), 4.71(\mathrm{~s}, 6 \mathrm{H}), 3.79(\mathrm{t}, 3 \mathrm{H}$, $J=4.6 \mathrm{~Hz}), 1.87(\mathrm{t}, 3 \mathrm{H}, J=4.6 \mathrm{~Hz}) ;{ }^{13} \mathrm{C} \mathrm{NMR}\left(500 \mathrm{MHz}, \mathrm{CDCl}_{3}\right): \delta 169.7,169.2,136.8,136.3,129.9,128.9,128.5$, 128.4, 128.2, 128.2, 67.7, 66.7, 47.1, 39.3; IR: 3033 (w), 1738 (s), 1498 (w) cm ${ }^{-1}$; HRMS (ES) calcd for $\mathrm{C}_{54} \mathrm{H}_{49} \mathrm{O}_{12}$ $[\mathrm{M}+\mathrm{H}]^{+}:$889.3224, found: 889.3237.
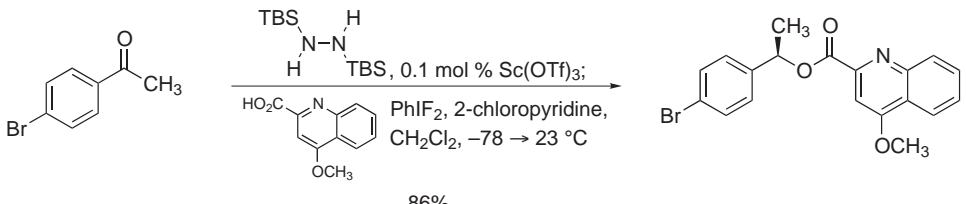

1-(4-Bromophenyl)-ethyl 4-methoxy-2-quinolinecarboxylate: A freshly prepared solution of scandium trifluoromethanesulfonate in dry acetonitrile $(0.01 \mathrm{M}, 0.075 \mathrm{~mL}, 0.00075 \mathrm{mmol}, 0.003$ equiv) was transferred by syringe to a 10-mL pear-shape flask equipped with a Teflon-coated stir bar. A 21-gauge needle connected to a source of argon/vacuum (dual manifold, 0.05 Torr) was inserted through the septum cap of the reaction vessel and the flask was carefully evacuated, with stirring, to evaporate the solvent. When the removal of solvent was complete ( $15 \mathrm{~min})$, the flask was flushed with dry argon, the septum cap was removed, and $4^{\prime}$-bromoacetophenone $(0.150 \mathrm{~g}$, $0.754 \mathrm{mmol}, 3$ equiv) was added. The flask was fitted with a rubber septum, a needle affixed to an argon balloon was inserted through the septum cap, and the reaction flask was cooled in an ice bath. 1,2-Bis(tertbutyldimethylsilyl)hydrazine $\left(0.207 \mathrm{~g}, 0.794 \mathrm{mmol}, 3.15\right.$ equiv, pre-cooled to $\left.0{ }^{\circ} \mathrm{C}\right)$ was then introduced by syringe. The resulting white slurry was stirred for $30 \mathrm{~min}$ at $0{ }^{\circ} \mathrm{C}$, the septum cap was removed, and a vacuum adapter connected to a source of argon/vacuum was affixed (dual manifold, 0.05 Torr) and the flask was carefully evacuated. The ice bath was removed and the reaction flask was allowed to warm to ambient temperature $\left(23{ }^{\circ} \mathrm{C}\right.$, stirring was maintained throughout). After stirring under vacuum for $1 \mathrm{~h}$ at $23{ }^{\circ} \mathrm{C}$, the reaction flask was immersed in an oil bath, and the bath was warmed to $30-35^{\circ} \mathrm{C}$. After stirring under vacuum at $30-35^{\circ} \mathrm{C}$ for $2 \mathrm{~h}$, the heating bath was removed, the flask was flushed with dry argon, a septum cap was affixed, and a needle connected to an argon balloon was inserted through the septum. Dry dichloromethane $(0.5 \mathrm{~mL})$ was added by syringe, producing a colorless solution. Separately, a 50-mL Teflon vial equipped with a Teflon-coated stir bar was charged with iodosylbenzene $(0.254 \mathrm{~g}, 1.16 \mathrm{mmol}, 4.6$ equiv), a septum cap was affixed, and a needle connected to an argon balloon was inserted through the septum cap. The yellow solid was suspended in dichloromethane $(8 \mathrm{~mL})$ and the suspension was stirred vigorously. Aqueous hydrofluoric acid $(48 \% \mathrm{w} / \mathrm{v}$, approximate volume: $0.150 \mathrm{~mL}) \mathrm{was}$ added to the stirred suspension dropwise by polypropylene syringe until all particulates had dissolved (rate of addition: 1 drop every 2 seconds). At this point, stirring was stopped, the layers were allowed to separate, and the upper, aqueous layer was removed by polypropylene syringe. The lower phase, a colorless solution, was cooled in a Dry Ice/acetone bath, with stirring, and 2-chloropyridine $(0.238 \mathrm{~mL}, 2.51 \mathrm{mmol}, 10$ equiv) was added dropwise by syringe over $1 \mathrm{~min}$. At this point, the septum was briefly removed, solid 4-methoxy-2-quinolinecarboxylic acid $(0.0511 \mathrm{~g}, 0.251 \mathrm{mmol}, 1$ equiv) was added, and the septum and argon balloon were replaced. To avoid photochemical decomposition of the diazo intermediate, the reaction flask was shielded from light at this stage The solution of the TBSH derivative prepared above was then added dropwise over $2 \mathrm{~min}$, also by syringe, and the transfer was quantitated with dichloromethane $(2 \times 0.2 \mathrm{~mL})$. The reaction mixture was stirred at $-78{ }^{\circ} \mathrm{C}$ for $4 \mathrm{~h}$, at which point the cooling bath was allowed to warm gradually to $23{ }^{\circ} \mathrm{C}$ over $\sim 3.5 \mathrm{~h}$. The yellow reaction solution was then stirred at $23{ }^{\circ} \mathrm{C}$ for $6 \mathrm{~h}$. $n$-Hexane $(8 \mathrm{~mL})$ and a $1: 1$ mixture of half-saturated aqueous sodium thiosulfate solution/half-saturated aqueous sodium bicarbonate solution $(10 \mathrm{~mL})$ were added and the resulting biphasic mixture was vigorously stirred for $20 \mathrm{~min}$. Stirring was stopped and the layers were separated. The organic layer was dried over sodium sulfate, and the dried solution was filtered through a plug of Celite with suction. Concentration of the filtrate afforded a yellow, oily residue which was purified by flash column chromatography (dichloromethane) affording 1-(4-Bromophenyl)-ethyl 4-methoxy-2-quinolinecarboxylate $(0.0835 \mathrm{~g}, 0.216 \mathrm{mmol}, 86 \%)$ as a colorless, viscous oil.

TLC (acetic acid-buffered silica gel; 30:70 ethyl acetate: $n$-hexane; UV, anis): $R_{f} 0.00$ (4-methoxy-2quinolinecarboxylic acid), 0.31 (1-(4-Bromophenyl)-ethyl 4-methoxy-2-quinolinecarboxylate). 
${ }^{1} \mathrm{H}$ NMR $\left(500 \mathrm{MHz}, \mathrm{C}_{6} \mathrm{D}_{6}\right): \delta 8.33(\mathrm{~d}, 1 \mathrm{H}, J=8.5 \mathrm{~Hz}), 8.12(\mathrm{~d}, 1 \mathrm{H}, J=8.2 \mathrm{~Hz}), 7.44(\mathrm{~s}, 1 \mathrm{H}), 7.28(\mathrm{dd}, 1 \mathrm{H}, J=8.2$, $7.0 \mathrm{~Hz}), 7.22(\mathrm{~d}, 2 \mathrm{H}, J=8.5 \mathrm{~Hz}), 7.15(\mathrm{dd}, 1 \mathrm{H}, J=8.5,7.0 \mathrm{~Hz}), 7.12(\mathrm{~d}, 2 \mathrm{H}, J=8.5 \mathrm{~Hz}), 6.11(\mathrm{q}, 1 \mathrm{H}, J=6.7 \mathrm{~Hz})$, $3.17(\mathrm{~s}, 3 \mathrm{H}), 1.45(\mathrm{~d}, 3 \mathrm{H}, J=6.7 \mathrm{~Hz}) ;{ }^{13} \mathrm{C} \mathrm{NMR}\left(500 \mathrm{MHz}, \mathrm{C}_{6} \mathrm{D}_{6}\right): \delta 165.7,163.0,150.0,149.1,141.2,131.8,130.6$, 130.4, 128.3, 127.4, 122.4, 121.9, 121.9, 100.5, 73.2, 55.1, 22.2; IR: 2980 (w), 1715 (s), 1588 (s), 1566 (m), 1510 (m) $\mathrm{cm}^{-1}$; HRMS (ES) calcd for $\mathrm{C}_{19} \mathrm{H}_{17} \mathrm{BrNO}_{3}[\mathrm{M}+\mathrm{H}]^{+}$: 386.0392, found: 386.0387.
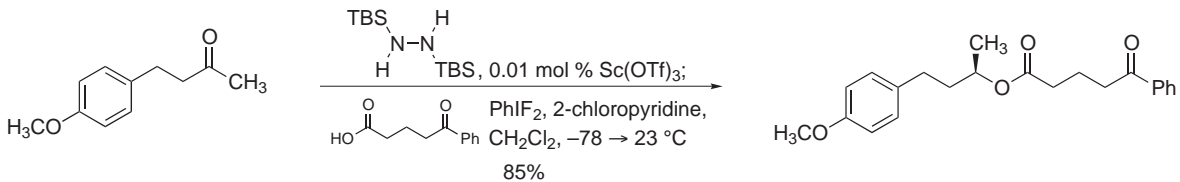

3-(4-Methoxyphenyl)-1-methylpropyl 3-benzoylbutyrate: A freshly prepared solution of scandium trifluoromethanesulfonate in dry acetonitrile $(0.01 \mathrm{M}, 0.008 \mathrm{~mL}, 0.00008 \mathrm{mmol}, 0.0003$ equiv) was transferred by syringe to a $50-\mathrm{mL}$ round-bottom flask equipped with a Teflon-coated stir bar. A 21-gauge needle connected to a source of argon/vacuum (dual manifold, 0.05 Torr) was inserted through the septum cap of the reaction vessel and the flask was carefully evacuated, with stirring, to evaporate the solvent. When the removal of solvent was complete ( $15 \mathrm{~min}$ ), the flask was flushed with dry argon and a needle affixed to an argon balloon was inserted through the septum cap. 1,2-Bis(tert-butyldimethylsilyl)hydrazine $(0.229 \mathrm{~g}, 0.880 \mathrm{mmol}, 3$ equiv) was introduced by syringe and the reaction flask was cooled in an ice bath. 4-(4-Methoxyphenyl)-2-butanone $(0.150 \mathrm{~mL}, 0.880 \mathrm{mmol}, 3$ equiv) was then added dropwise over 15 min via syringe." The reaction solution, a colorless liquid, was stirred for an additional $15 \mathrm{~min}$ at $0{ }^{\circ} \mathrm{C}$, then the ice bath was removed, and the reaction mixture was allowed to warm to ambient temperature $\left(23{ }^{\circ} \mathrm{C}\right)$. After stirring at $23{ }^{\circ} \mathrm{C}$ for $15 \mathrm{~min}$, the septum cap was removed, a vacuum adapter connected to a source of argon/vacuum was affixed (dual manifold, 0.05 Torr) and the flask was carefully evacuated with stirring. After stirring under vacuum for $1 \mathrm{~h}$ at $23{ }^{\circ} \mathrm{C}$, the flask was immersed in an oil bath, and the bath was warmed to $30-35^{\circ} \mathrm{C}$. After stirring under vacuum at $30-35^{\circ} \mathrm{C}$ for $2 \mathrm{~h}$, the heating bath was removed, the flask was flushed with dry argon, a septum cap was affixed, and a needle connected to an argon balloon was inserted through the septum. Dry dichloromethane $(0.5 \mathrm{~mL})$ was added by syringe, producing a colorless solution. Separately, a $50-$ $\mathrm{mL}$ Teflon vial equipped with a Teflon-coated stir bar was charged with iodosylbenzene $(0.297 \mathrm{~g}, 1.35 \mathrm{mmol}, 4.6$ equiv), a septum cap was affixed, and a needle connected to an argon balloon was inserted through the septum cap. The yellow solid was suspended in dichloromethane $(9 \mathrm{~mL})$ and the suspension was stirred vigorously. Aqueous hydrofluoric acid $(48 \% \mathrm{w} / \mathrm{v}$, approximate volume: $0.170 \mathrm{~mL})$ was added to the stirred suspension dropwise by polypropylene syringe until all particulates had dissolved (rate of addition: 1 drop every 2 seconds). At this point, stirring was stopped, the layers were allowed to separate, and the upper, aqueous layer was removed by polypropylene syringe. The lower phase, a colorless solution, was cooled in a Dry Ice/acetone bath with stirring, and 2-chloropyridine $(0.278 \mathrm{~mL}, 2.94 \mathrm{mmol}, 10$ equiv) was added dropwise by syringe over $1 \mathrm{~min}$. At this point, the septum was briefly removed, solid 3-benzoylbutyric acid $(0.0564 \mathrm{~g}, 0.293 \mathrm{mmol}, 1$ equiv) was added, and the septum and argon balloon were replaced. To avoid photochemical decomposition of the diazo intermediate, the reaction flask was shielded from light at this stage The solution of the TBSH derivative prepared above was then added dropwise over $2 \mathrm{~min}$, also by syringe, and the transfer was quantitated with dichloromethane $(2 \times 0.2 \mathrm{~mL})$. The reaction mixture was stirred at $-78{ }^{\circ} \mathrm{C}$ for $4 \mathrm{~h}$, at which point the cooling bath was allowed to warm gradually to $23{ }^{\circ} \mathrm{C}$ over $\sim 3.5 \mathrm{~h}$. The yellow reaction solution was then stirred at $23{ }^{\circ} \mathrm{C}$ for $6 \mathrm{~h}$. $n$-Hexane $(9 \mathrm{~mL})$ and a $1: 1$ mixture of half-saturated aqueous sodium thiosulfate solution and half-saturated aqueous sodium bicarbonate solution $(11 \mathrm{~mL})$ were added and the resulting biphasic mixture was stirred vigorously for $20 \mathrm{~min}$. Stirring was stopped and the layers were separated. The organic layer was dried over sodium sulfate, and the dried solution was filtered through a plug of Celite with suction. Concentration of the filtrate afforded a yellow, oily residue which was purified by flash column chromatography ( 2 columns, first column: dichloromethane; second column: 5:95 ethyl acetate/ $n$-hexane) affording 3-(4-methoxyphenyl)-1-methylpropyl 3-benzoylbutyrate $(0.0882 \mathrm{~g}, 0.249 \mathrm{mmol}, 85 \%)$ as a colorless oil.

TLC (acetic acid-buffered silica gel; 30:70 ethyl acetate: $n$-hexane; UV, anis): $R_{f} 0.23$ (3-benzoylbutyric acid), 0.44 (3-(4-Methoxyphenyl)-1-methylpropyl 3-benzoylbutyrate).

${ }^{1} \mathrm{H}$ NMR (400 MHz, $\left.\mathrm{CDCl}_{3}\right): \delta 7.97(\mathrm{~d}, 2 \mathrm{H}, J=8.6 \mathrm{~Hz}), 7.56(\mathrm{t}, 1 \mathrm{H}, J=6.6 \mathrm{~Hz}), 7.46(\mathrm{dd}, 2 \mathrm{H}, J=8.6,6.6 \mathrm{~Hz}), 7.07$ $(\mathrm{d}, 2 \mathrm{H}, J=8.6 \mathrm{~Hz}), 6.82(\mathrm{~d}, 2 \mathrm{H}, J=8.6 \mathrm{~Hz}), 4.95(\mathrm{ddq}, 1 \mathrm{H}, J=7.7,6.1,5.0 \mathrm{~Hz}), 3.77(\mathrm{~s}, 3 \mathrm{H}), 3.06(\mathrm{t}, 2 \mathrm{H}, J=7.2$ 
$\mathrm{Hz}$ ), $2.62(\mathrm{ddd}, 1 \mathrm{H}, J=13.9,9.9,6.0 \mathrm{~Hz}), 2.55(\mathrm{ddd}, 1 \mathrm{H}, J=13.9,9.7,6.5 \mathrm{~Hz}), 2.42(\mathrm{t}, 2 \mathrm{H}, J=7.2 \mathrm{~Hz}), 2.09$ (tt, $2 \mathrm{H}, J=7.2,7.2 \mathrm{~Hz}$ ), 1.90 (dddd, $1 \mathrm{H}, J=13.9,9.7,7.7,6.0 \mathrm{~Hz}$ ), 1.76 (dddd, $1 \mathrm{H}, J=13.9,9.9,6.5,5.0 \mathrm{~Hz}$ ), 1.25 (d, $3 \mathrm{H}, J=6.1 \mathrm{~Hz}) ;{ }^{13} \mathrm{C}$ NMR $\left(400 \mathrm{MHz}, \mathrm{CDCl}_{3}\right): \delta 199.7,1731,158.1,137.1,133.8,133.3,129.4,128.8,128.3,114.1$, 70.8, 55.5, 38.1, 37.7, 33.9, 31.1, 20.3, 19.7; IR: 2936 (m), 1728 (s), 1688 (s), 1613 (m), 1514 (s) cm ${ }^{-1}$; HRMS (ES) calcd for $\mathrm{C}_{22} \mathrm{H}_{27} \mathrm{O}_{4}[\mathrm{M}+\mathrm{H}]^{+}:$355.1909, found: 355.1906 .

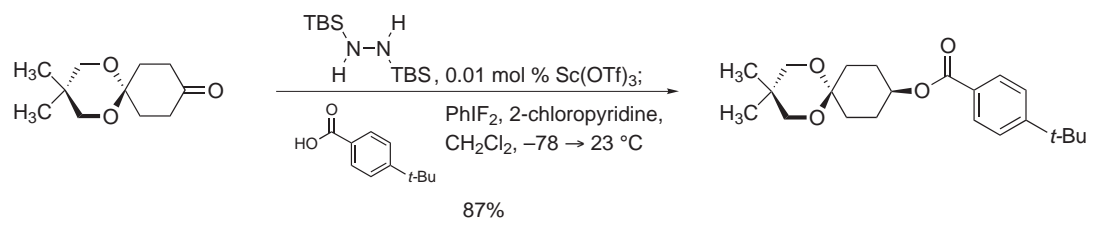

4-tert-Butylbenzoic acid 3,3-dimethyl-1,5-dioxa-spiro[5.5]undec-9-yl ester: A freshly prepared solution of scandium trifluoromethanesulfonate in dry acetonitrile $(0.01 \mathrm{M}, 0.010 \mathrm{~mL}, 0.0001 \mathrm{mmol}, 0.0003$ equiv) was transferred by syringe to a 10-mL pear-shape flask equipped with a Teflon-coated stir bar. A 21-gauge needle connected to a source of argon/vacuum (dual manifold, 0.05 Torr) was inserted through the septum cap of the reaction vessel and the flask was carefully evacuated, with stirring, to evaporate the solvent. When the removal of solvent was complete ( 15 min), the flask was flushed with dry argon and a needle affixed to an argon balloon was inserted through the septum cap. 1,2-Bis(tert-butyldimethylsilyl)hydrazine $(0.277 \mathrm{~g}, 1.06 \mathrm{mmol}, 3.15$ equiv) was introduced by syringe and the reaction flask was cooled in an ice bath. A freshly prepared solution of 1,4cyclohexanedione mono-2,2-dimethyltrimethylene ketal $(0.200 \mathrm{~g}, 1.01 \mathrm{mmol}, 3$ equiv) in dry dichloromethane $(0.2$ $\mathrm{mL})$ was then added dropwise over 15 min via syringe." The addition was quantitated with dichloromethane $(2 \times$ $0.1 \mathrm{~mL}$ ). The reaction solution, a colorless liquid, was stirred for an additional $15 \mathrm{~min}$ at $0{ }^{\circ} \mathrm{C}$, the ice bath was removed, and the reaction mixture was allowed to warm to ambient temperature $\left(23^{\circ} \mathrm{C}\right)$. After stirring at $23{ }^{\circ} \mathrm{C}$ for $15 \mathrm{~min}$, the solution was diluted with dry $n$-hexane $(2 \mathrm{~mL})$, the septum cap was removed, and the white suspension was filtered through a plug of glass wool into a $10-\mathrm{mL}$ pear-shape receiving flask, and the filtration was quantitated with $n$-hexane $(2 \times 1 \mathrm{~mL})$. The flask was placed on a rotary evaporator and the solvents were removed in vacuo. The flask was flushed with dry dinitrogen and was charged with a Teflon-coated stir bar. A vacuum adapter connected to a source of argon/vacuum was affixed (dual manifold, 0.05 Torr) and the flask was carefully evacuated with stirring. After stirring under vacuum for $1 \mathrm{~h}$ at $23{ }^{\circ} \mathrm{C}$, the flask was immersed in an oil bath, and the bath was warmed to $30-35^{\circ} \mathrm{C}$. After stirring under vacuum at $30-35^{\circ} \mathrm{C}$ for $2 \mathrm{~h}$, the heating bath was removed, the flask was flushed with dry argon, a septum cap was affixed, and a needle connected to an argon balloon was inserted through the septum. Dry dichloromethane $(0.6 \mathrm{~mL})$ was added by syringe providing a colorless solution. Separately, a $50-$ $\mathrm{mL}$ Teflon vial equipped with a Teflon-coated stir bar was charged with iodosylbenzene $(0.340 \mathrm{~g}, 1.55 \mathrm{mmol}, 4.6$ equiv), a septum cap was affixed, and a needle connected to an argon balloon was inserted through the septum cap. The yellow solid was suspended in dichloromethane $(10 \mathrm{~mL})$ and the suspension was stirred vigorously. Aqueous hydrofluoric acid $(48 \% \mathrm{w} / \mathrm{v}$, approximate volume: $0.190 \mathrm{~mL})$ was added to the stirred suspension dropwise by polypropylene syringe until all particulates had dissolved (rate of addition: 1 drop every 2 seconds). At this point, stirring was stopped, the layers were allowed to separate, and the upper, aqueous layer was removed by polypropylene syringe. The lower phase, a colorless solution, was cooled in a Dry Ice/acetone bath, with stirring, and 2-chloropyridine $(0.318 \mathrm{~mL}, 3.36 \mathrm{mmol}, 10$ equiv) was added dropwise by syringe over $1 \mathrm{~min}$. At this point, the septum was briefly removed, solid 4-tert-butylbenzoic acid $(0.0600 \mathrm{~g}, 0.337 \mathrm{mmol}, 1$ equiv) was added, and the septum and argon balloon were replaced. To avoid photochemical decomposition of the diazo intermediate, the reaction flask was shielded from light at this stage. The solution of the TBSH derivative prepared above was then added dropwise over $2 \mathrm{~min}$, also by syringe, and the transfer was quantitated with dichloromethane $(2 \times 0.2 \mathrm{~mL})$. The reaction mixture was stirred at $-78{ }^{\circ} \mathrm{C}$ for $4 \mathrm{~h}$, at which point the cooling bath was allowed to warm gradually to $23{ }^{\circ} \mathrm{C}$ over $\sim 3.5 \mathrm{~h}$. The yellow reaction solution was then stirred at $23{ }^{\circ} \mathrm{C}$ for $6 \mathrm{~h}$. $n$-Hexane $(10 \mathrm{~mL})$ and a $1: 1$ mixture of half-saturated aqueous sodium thiosulfate solution and half-saturated aqueous sodium bicarbonate solution $(12 \mathrm{~mL})$ were added and the resulting biphasic mixture was stirred vigorously for $20 \mathrm{~min}$. Stirring was stopped, and the layers were separated. The organic layer was dried over sodium sulfate, and the dried solution was filtered through a plug of Celite with suction. Concentration of the filtrate afforded a yellow, oily residue which was purified by flash column chromatography (dichloromethane) affording 4-tert-butylbenzoic acid 3,3-dimethyl-1,5dioxa-spiro[5.5]undec-9-yl ester (0.106 g, $0.295 \mathrm{mmol}, 87 \%)$ as a white solid (mp 112-114 $\left.{ }^{\circ} \mathrm{C}\right)$. 
TLC (acetic acid-buffered silica gel; 40:60 ethyl acetate: $n$-hexane; UV, anis): $R_{f} 0.58$ (4-tert-butylbenzoic acid), 0.64 (4-tert-butylbenzoic acid 3,3-dimethyl-1,5-dioxa-spiro[5.5]undec-9-yl ester).

${ }^{1} \mathrm{H} \mathrm{NMR}\left(400 \mathrm{MHz}, \mathrm{CDCl}_{3}\right): \delta 7.97(\mathrm{~d}, 2 \mathrm{H}, J=8.7 \mathrm{~Hz}), 7.44(\mathrm{~d}, 2 \mathrm{H}, J=8.7 \mathrm{~Hz}), 5.10-5.16(\mathrm{~m}, 1 \mathrm{H}), 3.54(\mathrm{~s}, 2 \mathrm{H})$, $3.51(\mathrm{~s}, 2 \mathrm{H}), 1.98-2.06(\mathrm{~m}, 2 \mathrm{H}), 1.81-1.92(\mathrm{~m}, 6 \mathrm{H}), 1.33(\mathrm{~s}, 9 \mathrm{H}), 0.98(\mathrm{~s}, 6 \mathrm{H}) ;{ }^{13} \mathrm{C}$ NMR $\left(500 \mathrm{MHz}, \mathrm{CDCl}_{3}\right): \delta$ 166.2, 156.7, 129.7, 128.2, 125.5, 97.2, 70.9, 70.5, 70.2, 35.3, 31.4, 30.5, 28.9, 27.3, 22.9; IR: 2956 (s), 1716 (s), $1610(\mathrm{~m}) \mathrm{cm}^{-1}$; HRMS (ES) calcd for $\mathrm{C}_{22} \mathrm{H}_{33} \mathrm{O}_{4}[\mathrm{M}+\mathrm{H}]^{+}: 361.2379$, found: 361.2375 .

\section{Synthesis of Previously Unpublished TBSH Derivatives:}
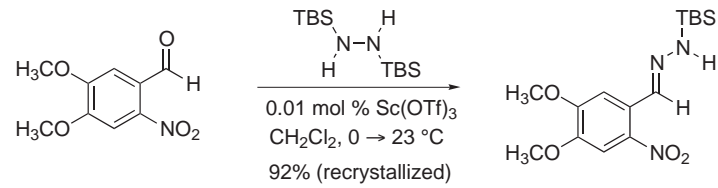

6-Nitroveratraldehyde $\boldsymbol{N}$-tert-Butyldimethylsilylhydrazone: A freshly prepared solution of scandium trifluoromethanesulfonate in dry acetonitrile $(0.01 \mathrm{M}, 0.047 \mathrm{~mL}, 0.00047 \mathrm{mmol}, 0.0001$ equiv) was transferred by syringe to a $25-\mathrm{mL}$ pear-shape flask equipped with a Teflon-coated stir bar. A 21-gauge needle connected to a source of argon/vacuum (dual manifold, 0.05 Torr) was inserted through the septum cap of the reaction vessel and the flask was carefully evacuated, with stirring, to evaporate the solvent. When the removal of solvent was complete ( $15 \mathrm{~min}$ ), the flask was flushed with dry argon and a needle affixed to an argon balloon was inserted through the septum cap. 1,2-Bis(tert-butyldimethylsilyl)hydrazine $(1.30 \mathrm{~g}, 4.97 \mathrm{mmol}, 1.05$ equiv) was introduced by syringe and the reaction flask was cooled in an ice bath. A freshly prepared solution of 6-nitroveratraldehyde $(1.00 \mathrm{~g}, 4.74$ mmol, 1 equiv) in dry dichloromethane $(3 \mathrm{~mL})$ was then added dropwise over 15 min via syringe." The addition was quantitated with dichloromethane $(2 \times 0.2 \mathrm{~mL})$. The yellow reaction solution was stirred for an additional $15 \mathrm{~min}$ at $0{ }^{\circ} \mathrm{C}$, then the ice bath was removed, and the reaction mixture was allowed to warm to ambient temperature $\left(23^{\circ} \mathrm{C}\right)$. After $4 \mathrm{~h}$, the yellow solution was transferred to a $100-\mathrm{mL}$ round-bottom flask by cannula, quantitating the transfer with additional dichloromethane $(2 \times 1 \mathrm{~mL})$. The flask was then placed on a rotary evaporator and the solvents were removed in vacuo to provide an orange solid residue. The flask was flushed with dry dinitrogen, then was fitted with a vacuum adapter connected to a source of argon/vacuum (dual manifold, 0.05 Torr) and the flask was evacuated. After $6 \mathrm{~h}$ at $23{ }^{\circ} \mathrm{C}$, the flask was flushed with dry argon, and ethyl ether $(70 \mathrm{~mL})$ was added. The resulting yellow solution was filtered through a fritted funnel into a $250 \mathrm{~mL}$ round-bottom flask, and the filtration was quantitated with additional ethyl ether $(3 \times 2 \mathrm{~mL})$. The receiving flask containing the yellow filtrate was flushed with dry argon, the flask was capped with a rubber septum, and a needle affixed to an argon balloon was inserted through the septum cap. The flask was cooled in a Dry Ice/acetone bath for $6 \mathrm{~h}$ leading to the formation of orange crystals, which were collected by vacuum filtration. The crystals were rinsed with $n$-hexane $(15 \mathrm{~mL})$, then were transferred to a $25 \mathrm{~mL}$ round-bottom flask and dried in vacuo ( 0.05 Torr). The mother liquors were cooled in a Dry Ice/acetone bath (under argon) for $4 \mathrm{~h}$, producing additional orange crystals, which were also collected by vacuum filtration. The second crop of crystals was rinsed with $n$-hexane $(15 \mathrm{~mL})$, then was combined with the first crop of crystals, and the combined solids were dried in vacuo ( 0.05 Torr) for $1 \mathrm{~h}$. The product was judged to be $>95 \%$ pure by ${ }^{1} \mathrm{H}$ and ${ }^{13} \mathrm{C}$ NMR analysis, and consisted of a $22: 78$ mixture of syn and anti stereoisomeric 6nitroveratraldehyde $\mathrm{N}$-tert-butyldimethylsilylhydrazones, respectively (1.48 g, $4.36 \mathrm{mmol}, 92 \%)$.

${ }^{1} \mathrm{H}$ NMR (400 MHz, $\mathrm{CDCl}_{3}$, * denotes syn stereoisomer): $\delta 8.31(\mathrm{~s}, 1 \mathrm{H}), 7.75\left(\mathrm{~s}, 1 \mathrm{H}^{*}\right), 7.59(\mathrm{~s}, 1 \mathrm{H}), 7.53(\mathrm{~s}, 1 \mathrm{H})$, $7.38\left(\mathrm{~s}, 1 \mathrm{H}^{*}\right), 6.89\left(\mathrm{~s}, 1 \mathrm{H}^{*}\right), 6.08(\mathrm{br} \mathrm{s}, 1 \mathrm{H}), 5.60\left(\mathrm{br} \mathrm{s}, 1 \mathrm{H}^{*}\right), 3.98\left(\mathrm{~s}, 3 \mathrm{H}^{*}\right), 3.95(\mathrm{~s}, 3 \mathrm{H}), 3.94\left(\mathrm{~s}, 3 \mathrm{H}^{*}\right), 3.93(\mathrm{~s}, 3 \mathrm{H})$, $0.97(\mathrm{~s}, 9 \mathrm{H}), 0.89\left(\mathrm{~s}, 9 \mathrm{H}^{*}\right), 0.20(\mathrm{~s}, 6 \mathrm{H}), 0.13\left(\mathrm{~s}, 6 \mathrm{H}^{*}\right) ;{ }^{13} \mathrm{C} \mathrm{NMR}\left(400 \mathrm{MHz}, \mathrm{CDCl}_{3}\right.$, syn and anti stereoisomers): $\delta$ 153.7, 153.2, 149.1, 148.2, 139.1, 134.6, 134.5, 132.8, 127.3, 121.8, 111.1, 108.3, 107.9, 107.4, 56.8, 56.6, 56.5, 56.3, 26.4, 26.4, 18.4, 18.3, -5.3, -5.6; IR (syn and anti stereoisomers): 3275 (m), 2928 (m), 1580 (w), 1513 (s) $\mathrm{cm}^{-1}$; HRMS (CI) calcd for $\mathrm{C}_{25} \mathrm{H}_{26} \mathrm{~N}_{3} \mathrm{O}_{4} \mathrm{Si}[\mathrm{M}+\mathrm{H}]^{+}: 340.1692$, found: 340.1697 . 


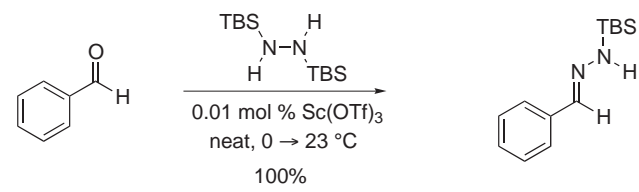

Benzaldehyde $N$-tert-Butyldimethylsilylhydrazone: A 25 - $\mathrm{mL}$ round-bottom flask equipped with a Teflon-coated stir bar, was charged with scandium trifluoromethanesulfonate $(0.0015 \mathrm{~g}, 0.0030 \mathrm{mmol}, 0.0001$ equiv) and a needle affixed to an argon balloon was inserted through the septum cap. 1,2-Bis(tert-butyldimethylsilyl)hydrazine (7.78 g, $29.8 \mathrm{mmol}, 1.01$ equiv) was introduced by syringe and the reaction flask was cooled in an ice bath. Benzaldehyde (3.00 mL, $29.5 \mathrm{mmol}, 1$ equiv) was then added dropwise over $15 \mathrm{~min}$ via syringe. ${ }^{*}$ The reaction solution, a colorless liquid, was stirred for an additional $15 \mathrm{~min}$ at $0{ }^{\circ} \mathrm{C}$, then the ice bath was removed, and the reaction mixture was allowed to warm to ambient temperature $\left(23^{\circ} \mathrm{C}\right)$. After $15 \mathrm{~min}$, the septum cap was removed and a vacuum adapter connected to a source of argon/vacuum was affixed (dual manifold, 0.05 Torr) and the flask was carefully evacuated with stirring. After stirring under vacuum for $1 \mathrm{~h}$ at $23{ }^{\circ} \mathrm{C}$, the flask was immersed in an oil bath, and the bath was warmed to $30-35{ }^{\circ} \mathrm{C}$. The colorless, oily residue was stirred under vacuum at $30-35{ }^{\circ} \mathrm{C}$ for $12 \mathrm{~h}$. At this point ${ }^{1} \mathrm{H}$ NMR and ${ }^{13} \mathrm{C}$ NMR analysis showed that all traces of tert-butyldimethylsilanol had been removed. The colorless, liquid product, benzaldehyde $N$-tert-butyldimethylsilylhydrazone, was judged to be $>95 \%$ pure by ${ }^{1} \mathrm{H}$ and ${ }^{13} \mathrm{C}$ NMR analysis, and was also a single stereoisomer (presumed anti, $6.92 \mathrm{~g}, 29.5 \mathrm{mmol}, 100 \%$ ).

${ }^{1} \mathrm{H}$ NMR $\left(500 \mathrm{MHz}, \mathrm{CD}_{2} \mathrm{Cl}_{2}\right): \delta 7.55(\mathrm{~s}, 1 \mathrm{H}), 7.52(\mathrm{~d}, 2 \mathrm{H}, J=7.9 \mathrm{~Hz}), 7.32(\mathrm{dd}, 2 \mathrm{H}, J=7.9,6.1 \mathrm{~Hz}), 7.23(\mathrm{t}, 1 \mathrm{H}, J=$ $6.1 \mathrm{~Hz}), 5.73(\mathrm{br} \mathrm{s}, 1 \mathrm{H}), 0.98(\mathrm{~s}, 9 \mathrm{H}), 0.21(\mathrm{~s}, 6 \mathrm{H}) ;{ }^{13} \mathrm{C} \mathrm{NMR}\left(400 \mathrm{MHz}, \mathrm{CDCl}_{3}\right): \delta 138.7,136.7,128.6,127.6$, 125.8, 26.5, 18.3, -5.3; IR: 3279 (w), 3061 (w), 2928 (s), 1594 (s), 1567 (s) cm ${ }^{-1}$; HRMS (CI) calcd for $\mathrm{C}_{13} \mathrm{H}_{23} \mathrm{~N}_{2} \mathrm{Si}$ $[\mathrm{M}+\mathrm{H}]^{+}: 235.1630$, found: 235.1636 . 


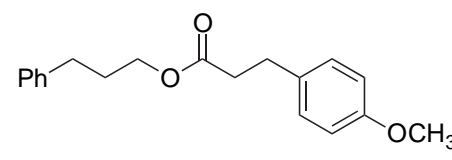

Appendix:
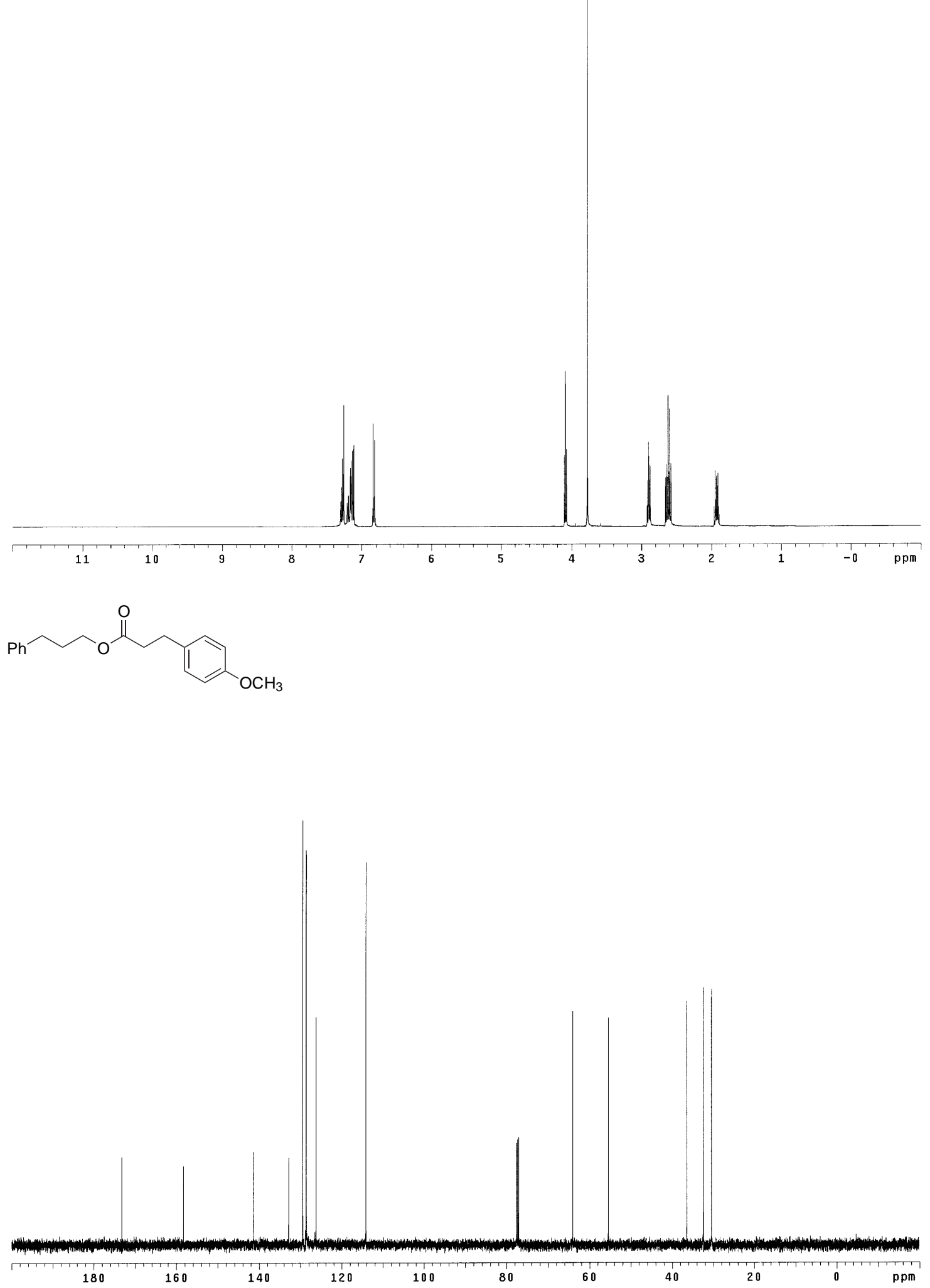
$\overbrace{\substack{\mathrm{CH}_{3} \\ \mathrm{CH}_{3}}}^{\mathrm{CCH} \mathrm{CH}_{3}}$

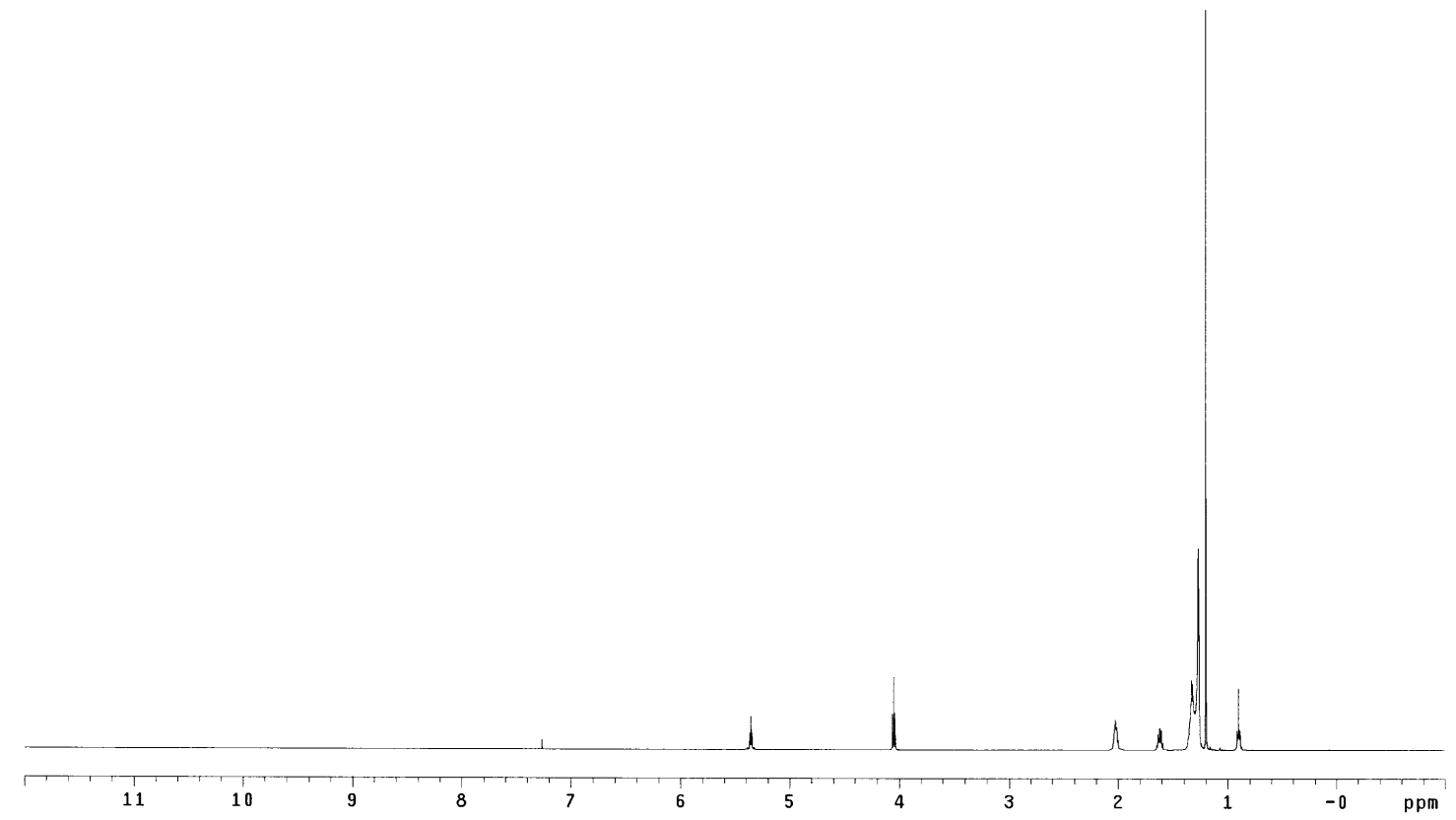

$\overbrace{\mathrm{CH}_{3}}^{\mathrm{C} \mathrm{CH}_{3}}$

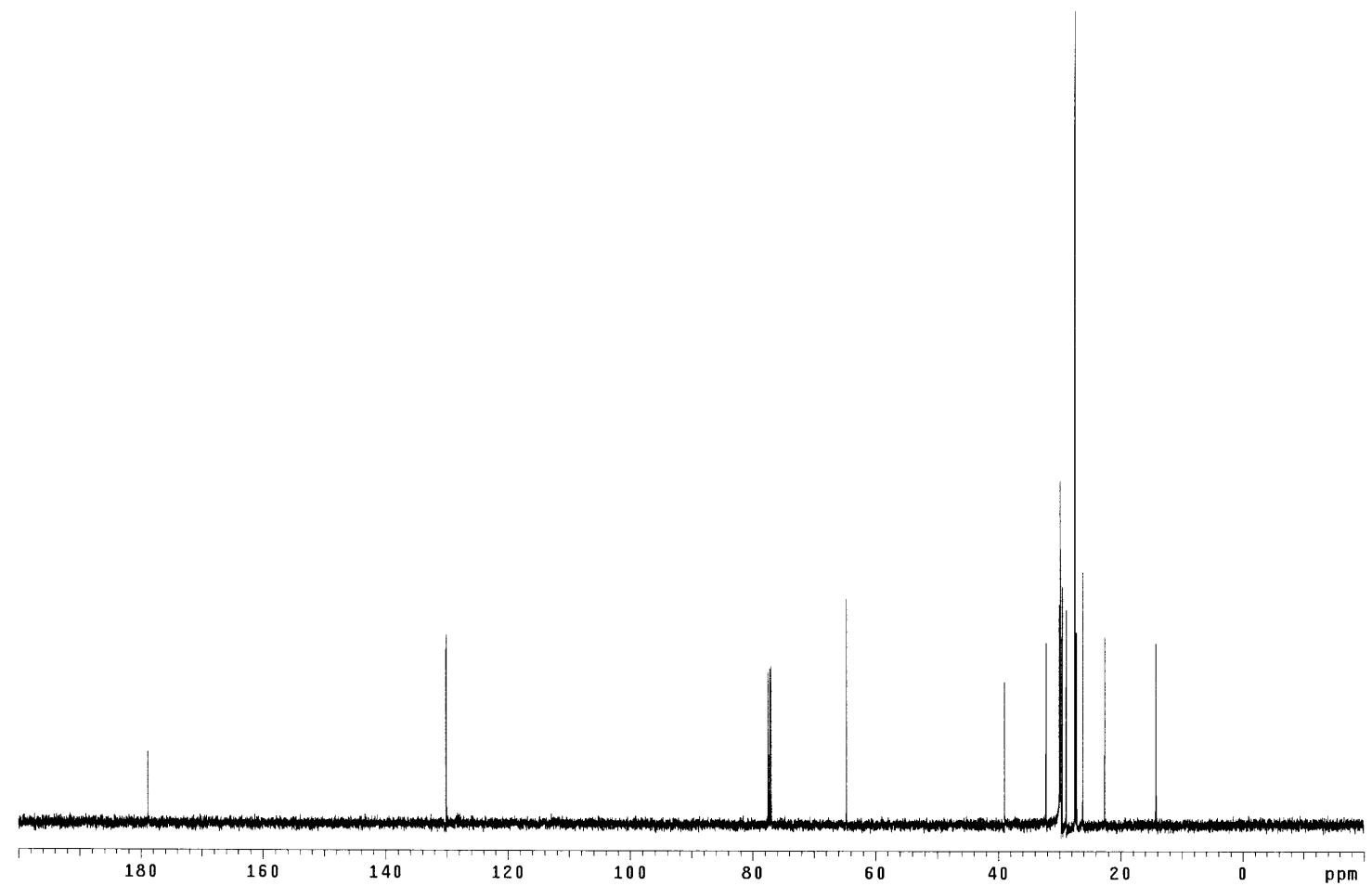




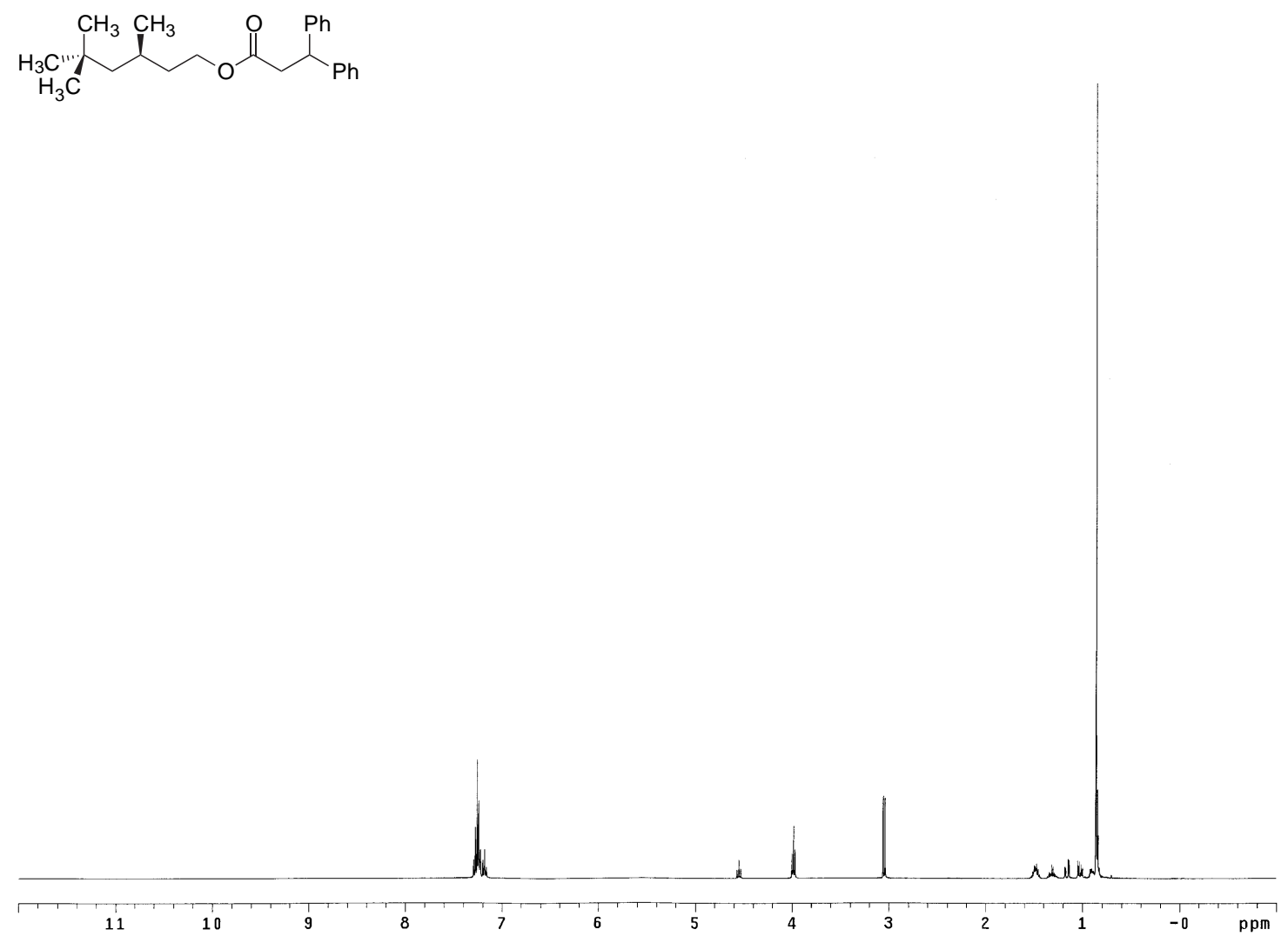

(N)

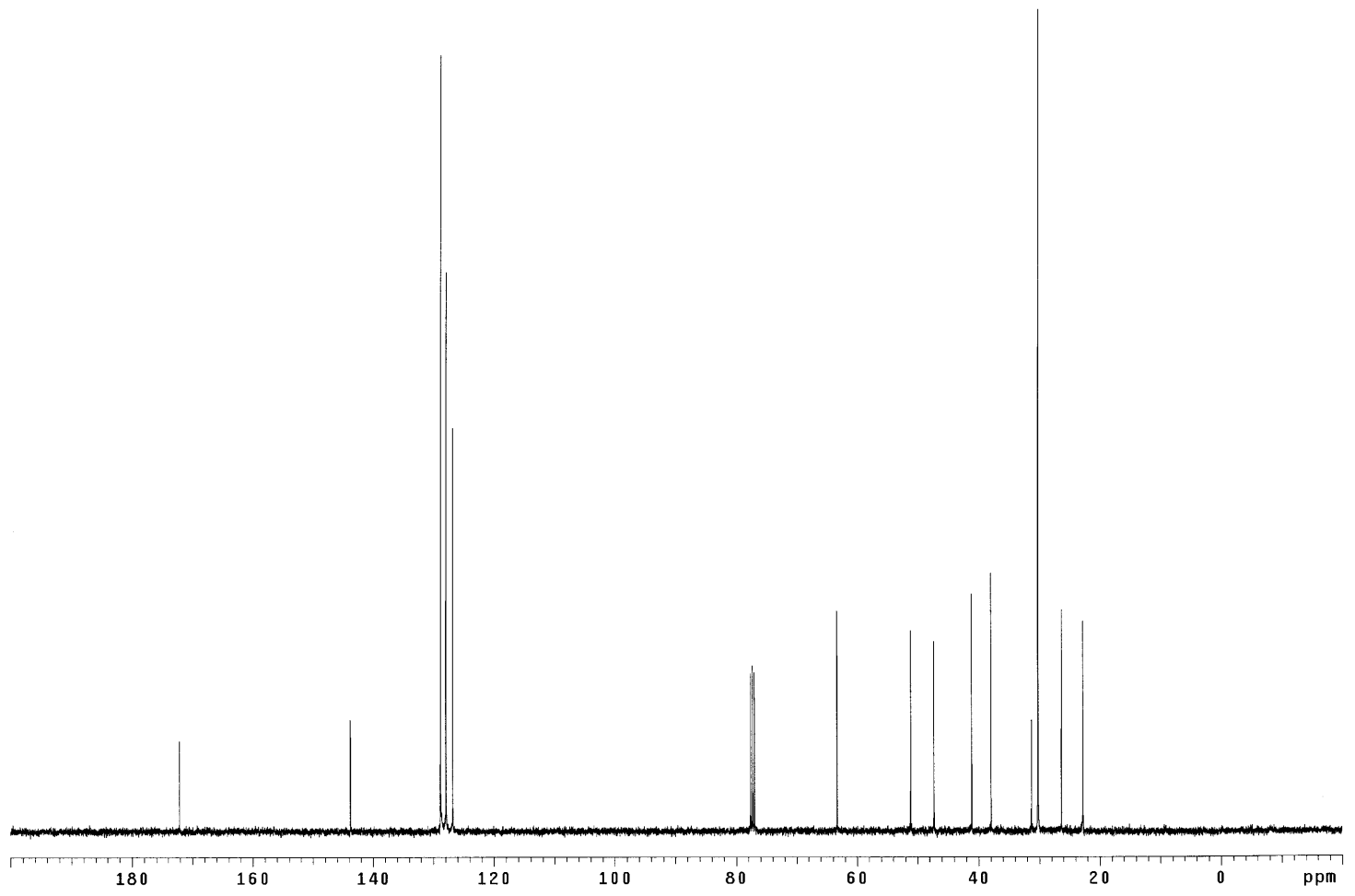



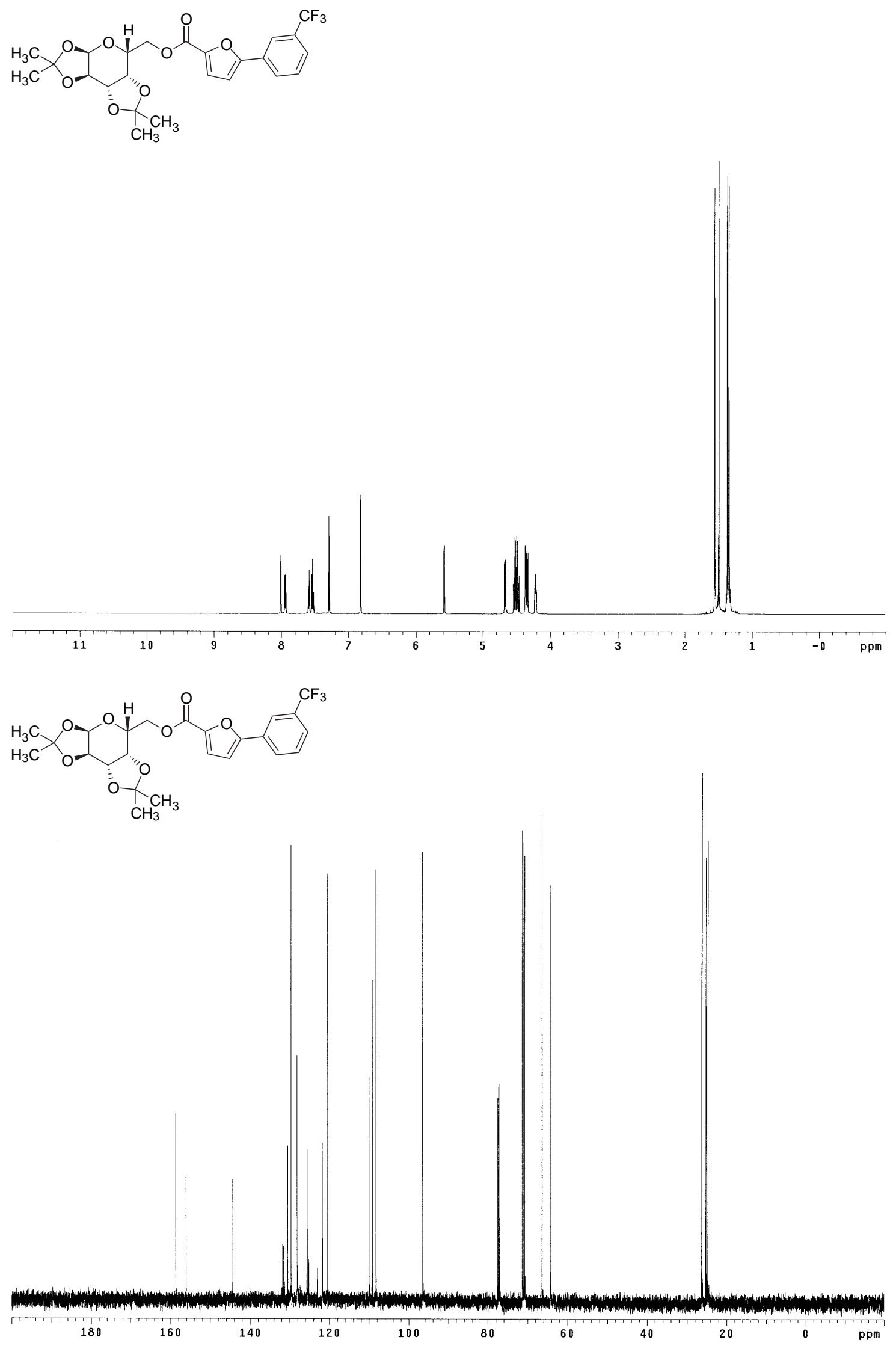

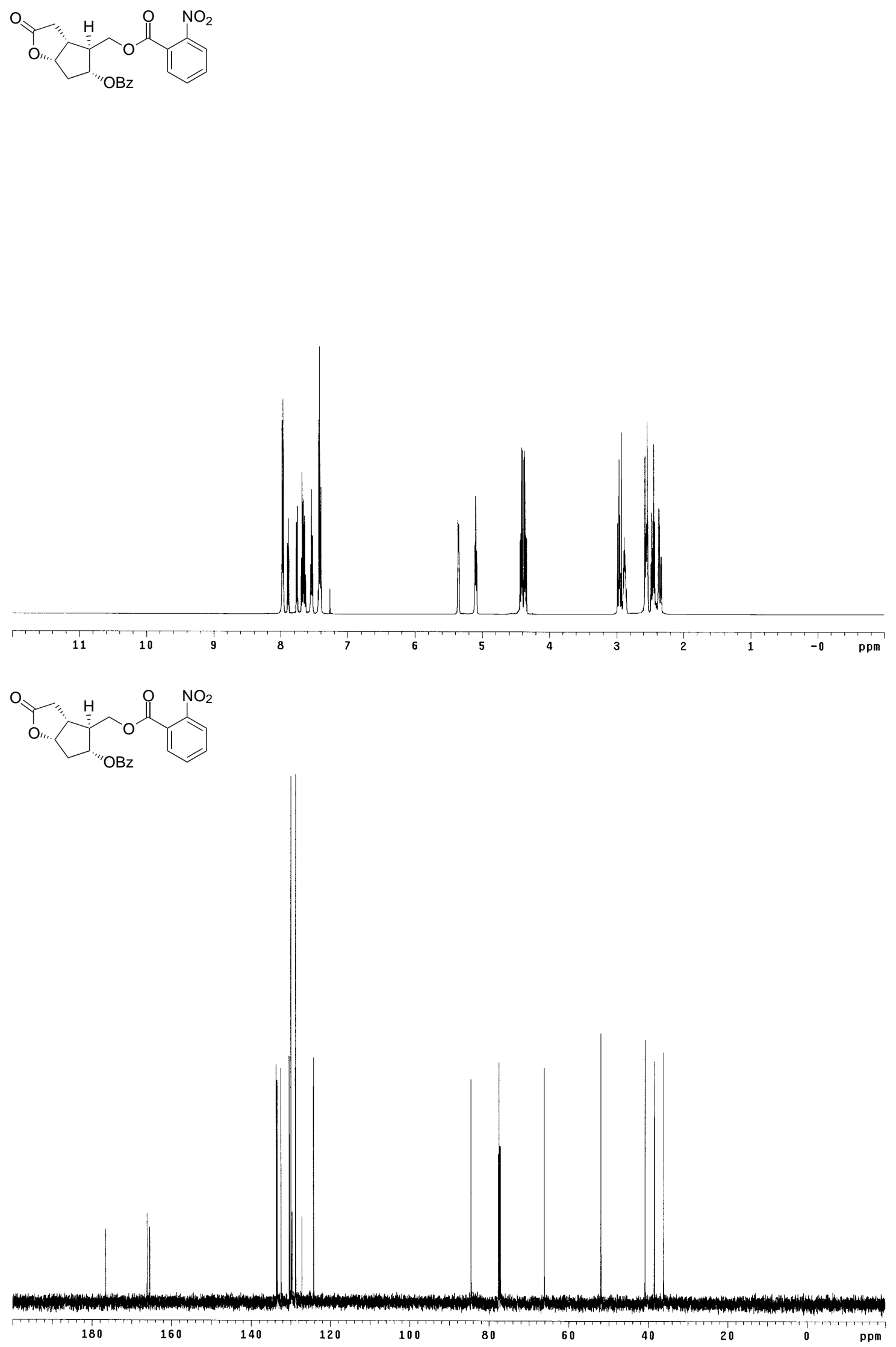
<smiles>Cc1ccc(COC(=O)Cc2ccc(Cl)cc2)cc1</smiles>
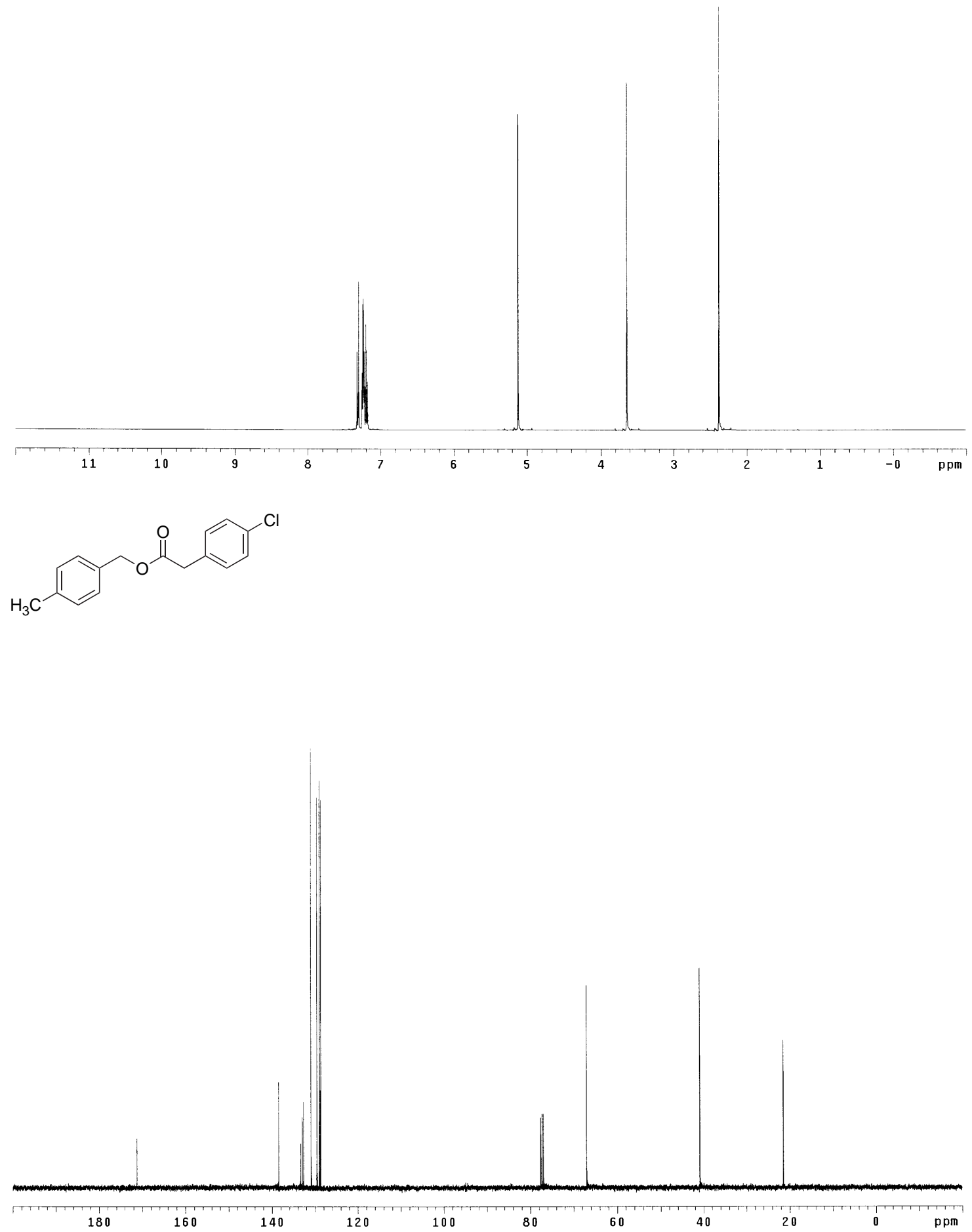
<smiles>CC1(C)OCC2OC3(C(=O)OCc4cccc(Oc5ccccc5)c4)OC(C)(C)OC3C2O1</smiles>
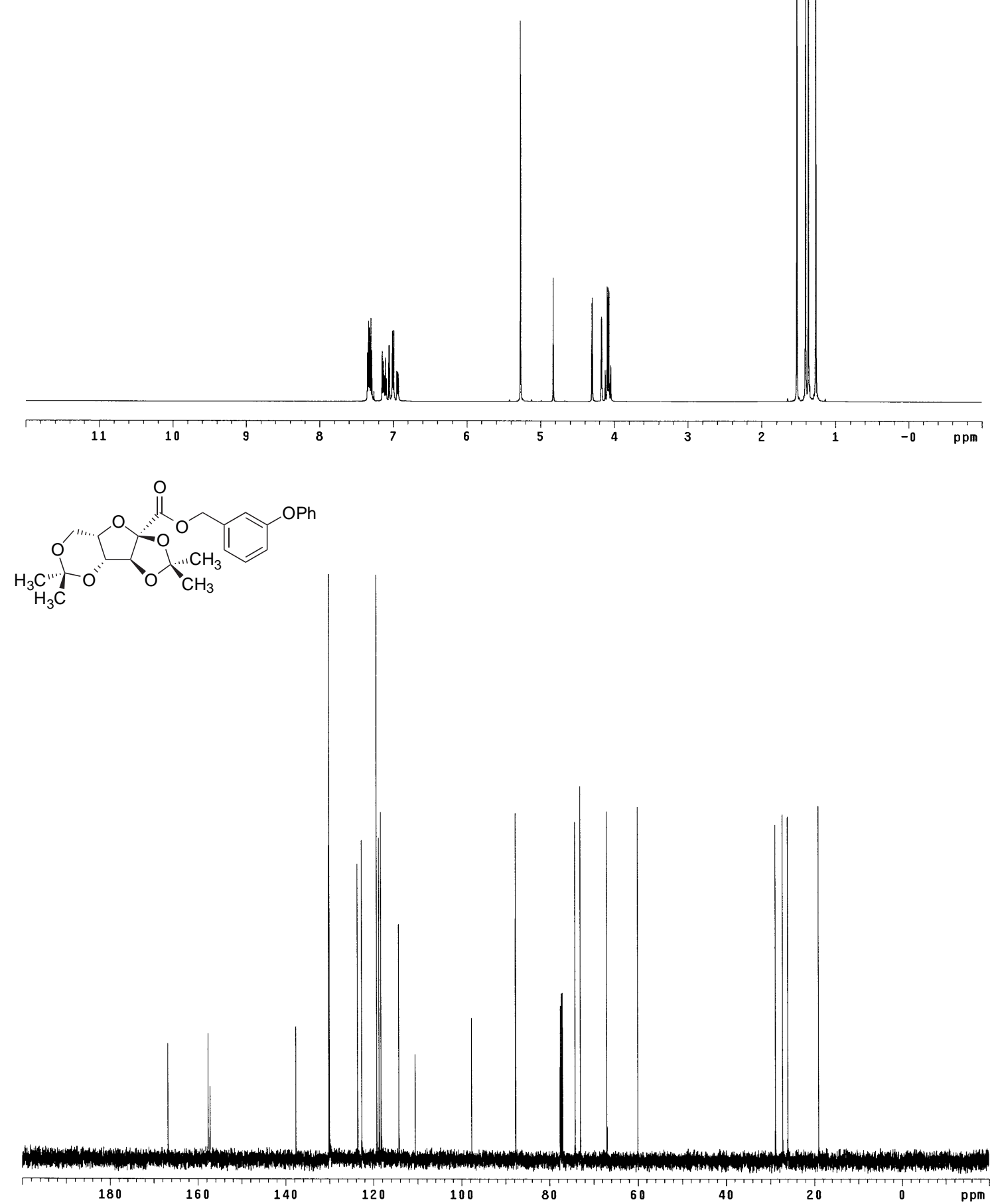

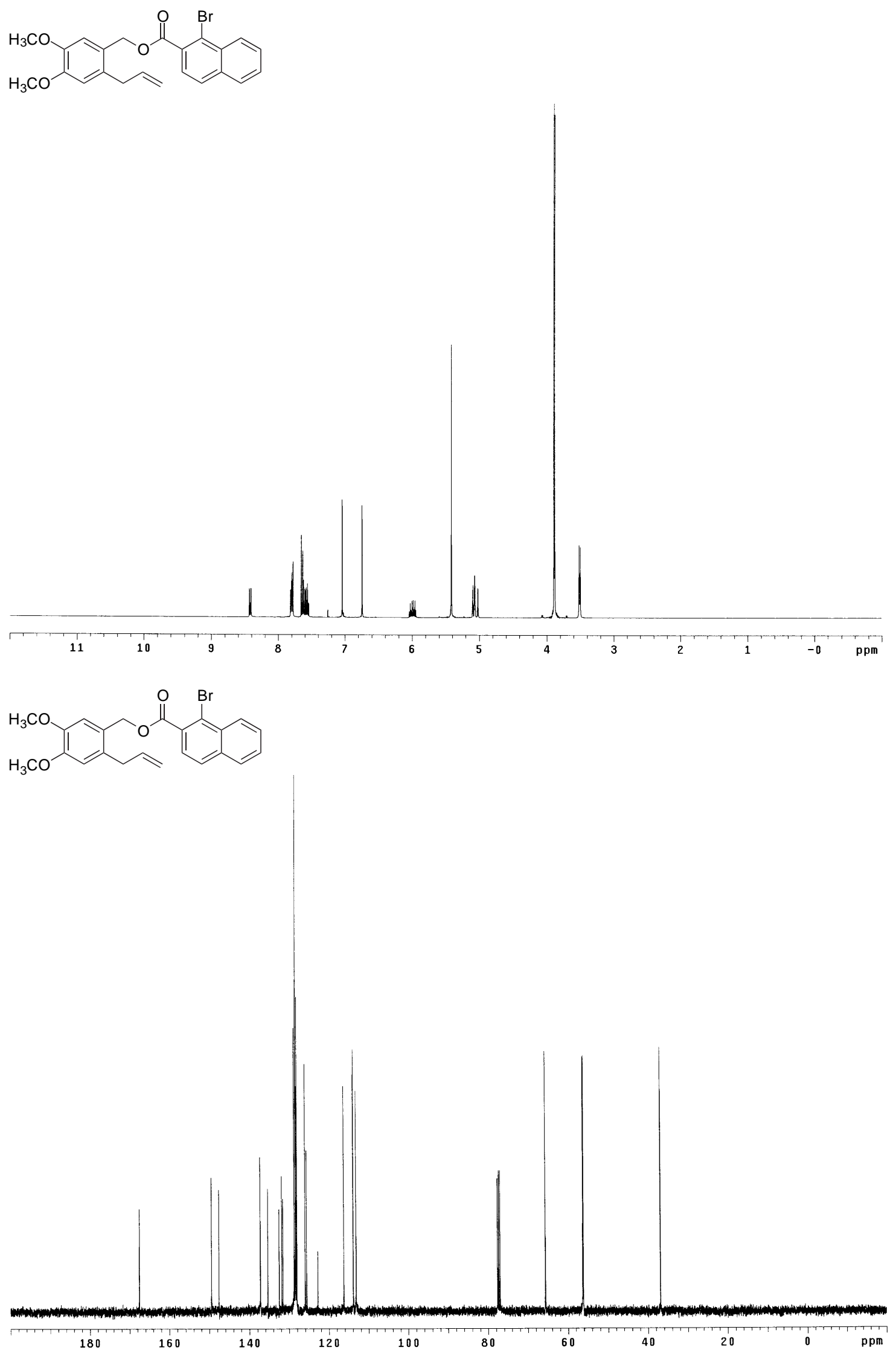

S26 

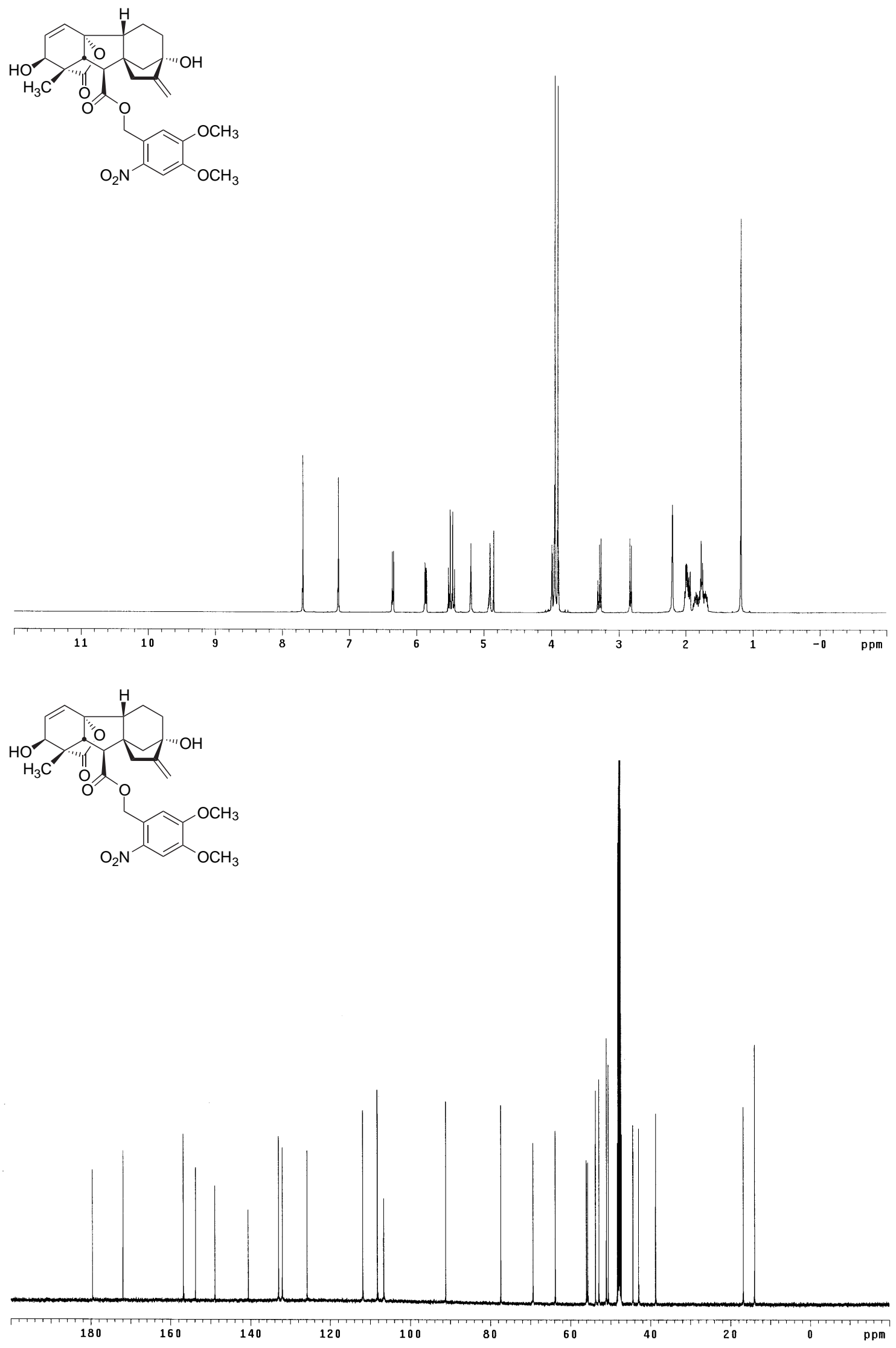

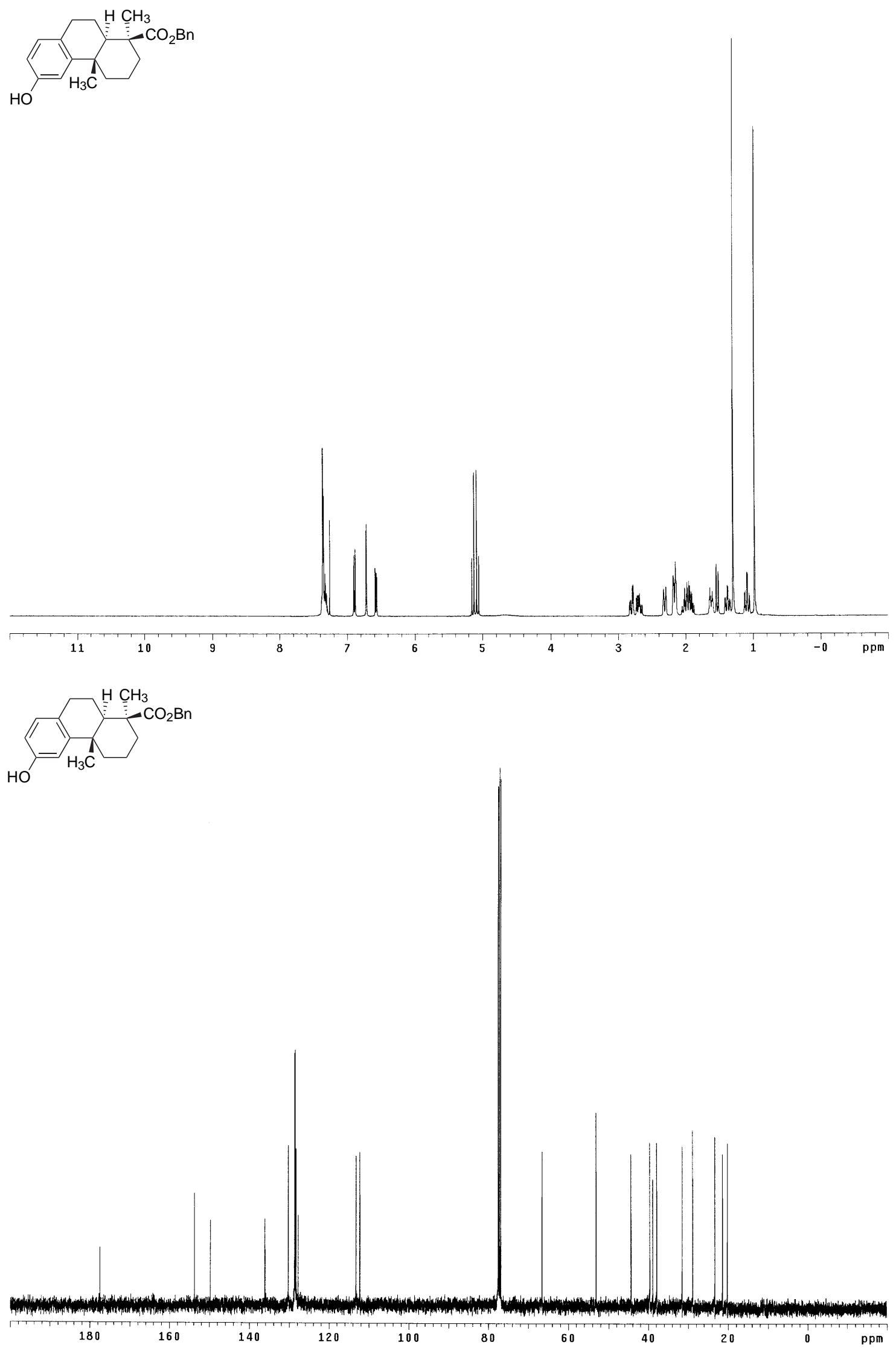

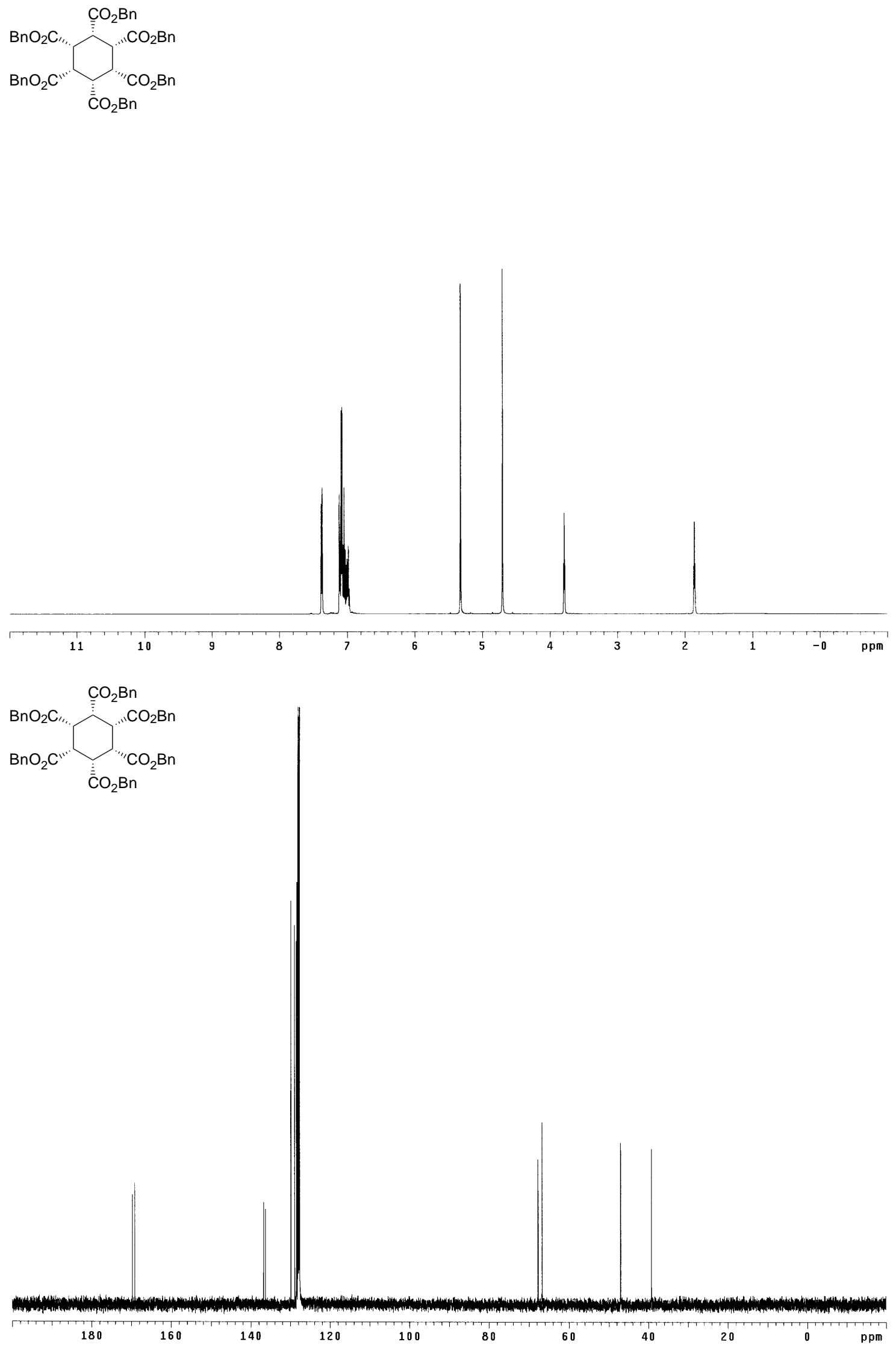

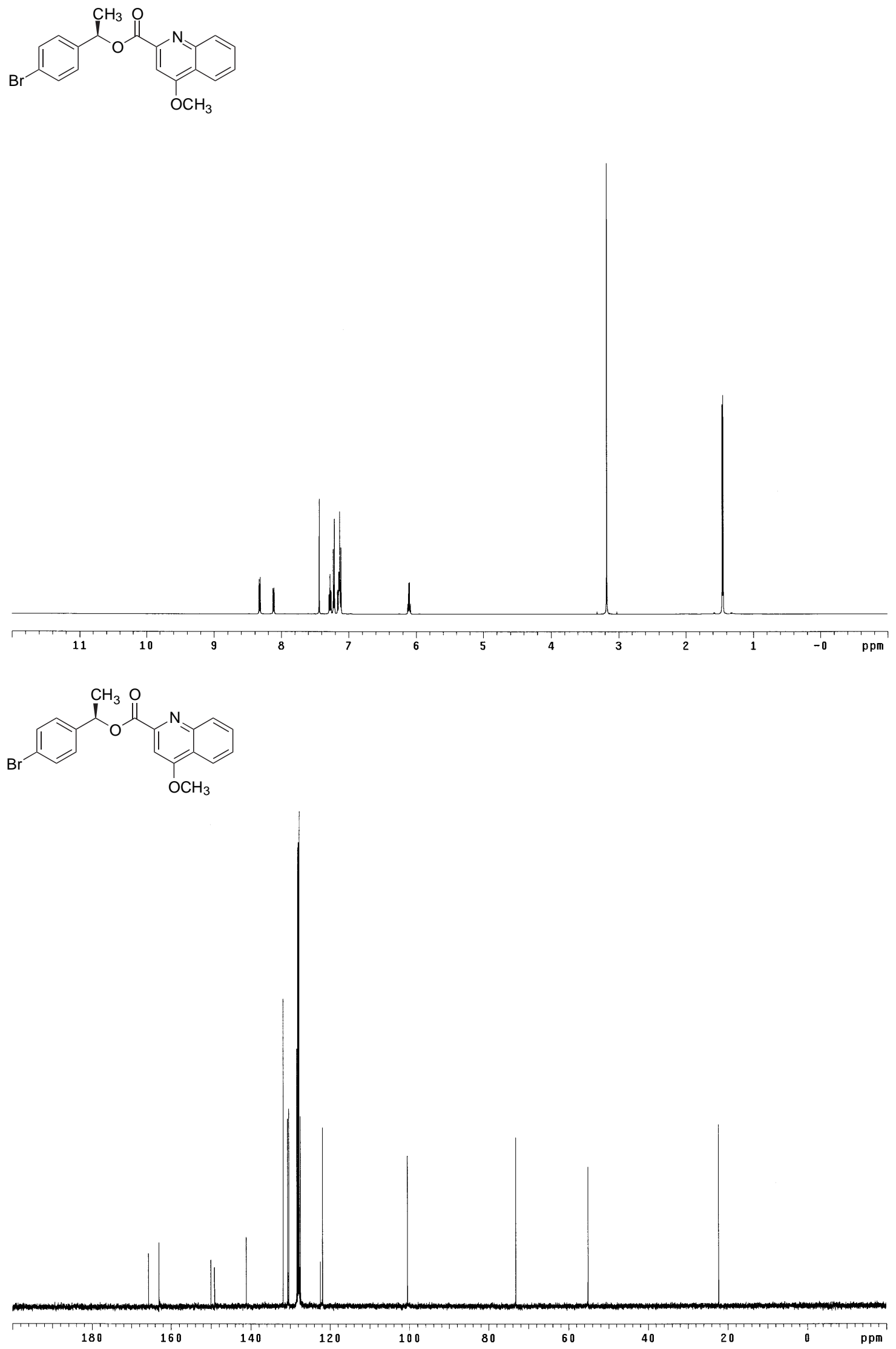
<smiles>COc1ccc(CCC(C)OC(=O)CCCC(=O)c2ccccc2)cc1</smiles>
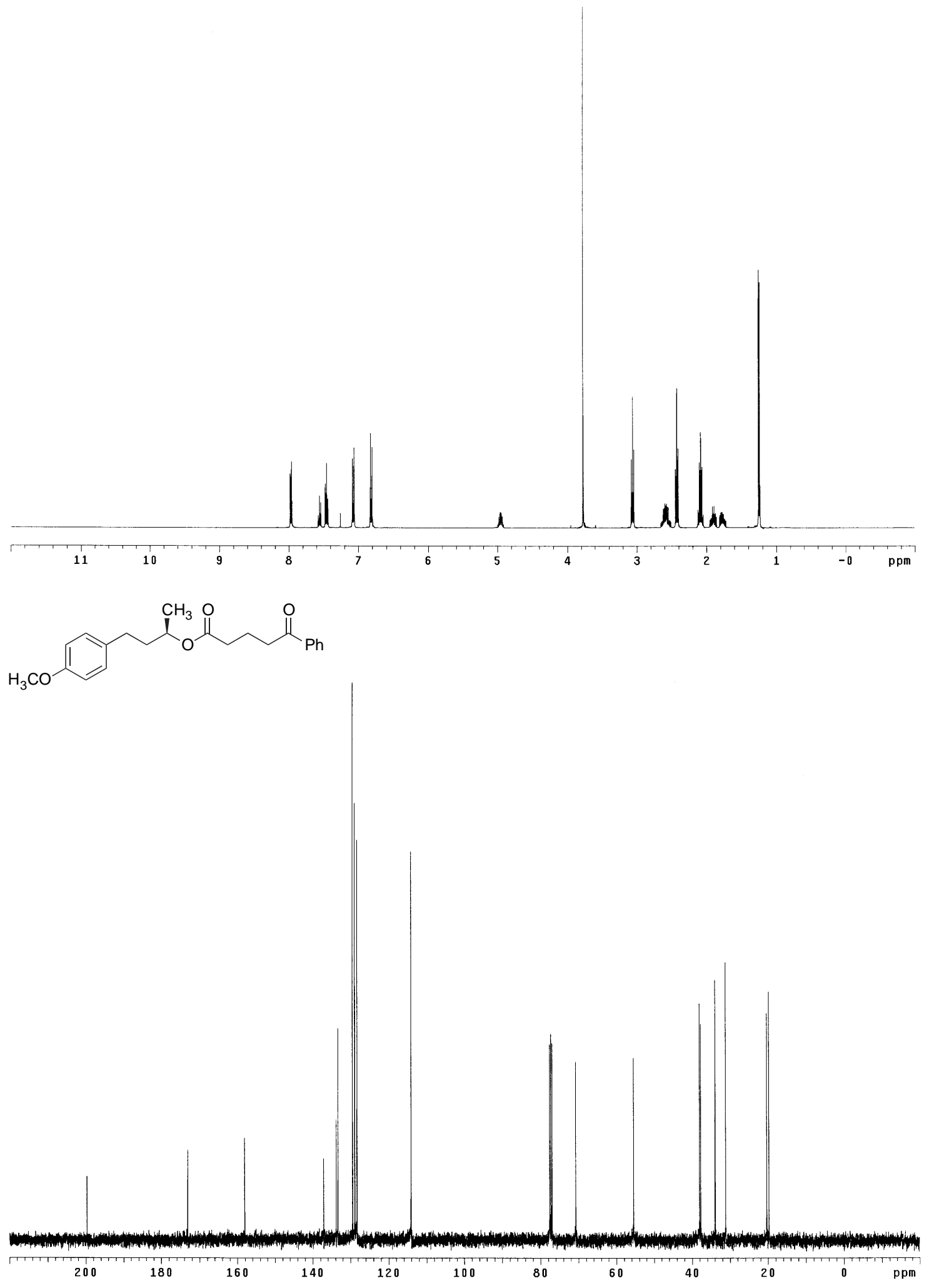

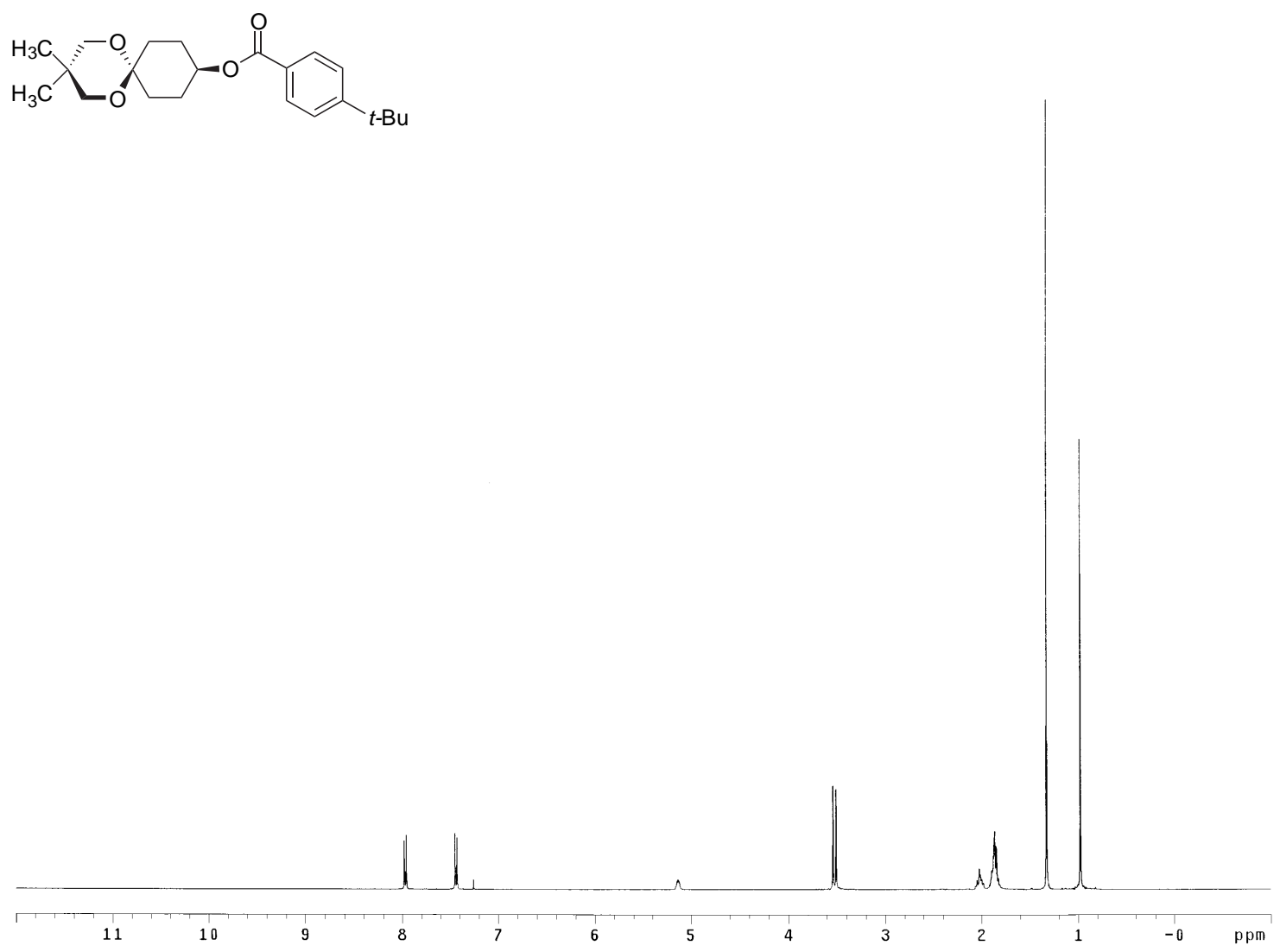<smiles>CC1(C)COC2(CCC(OC(=O)c3ccc(C(C)(C)C)cc3)CC2)OC1</smiles>

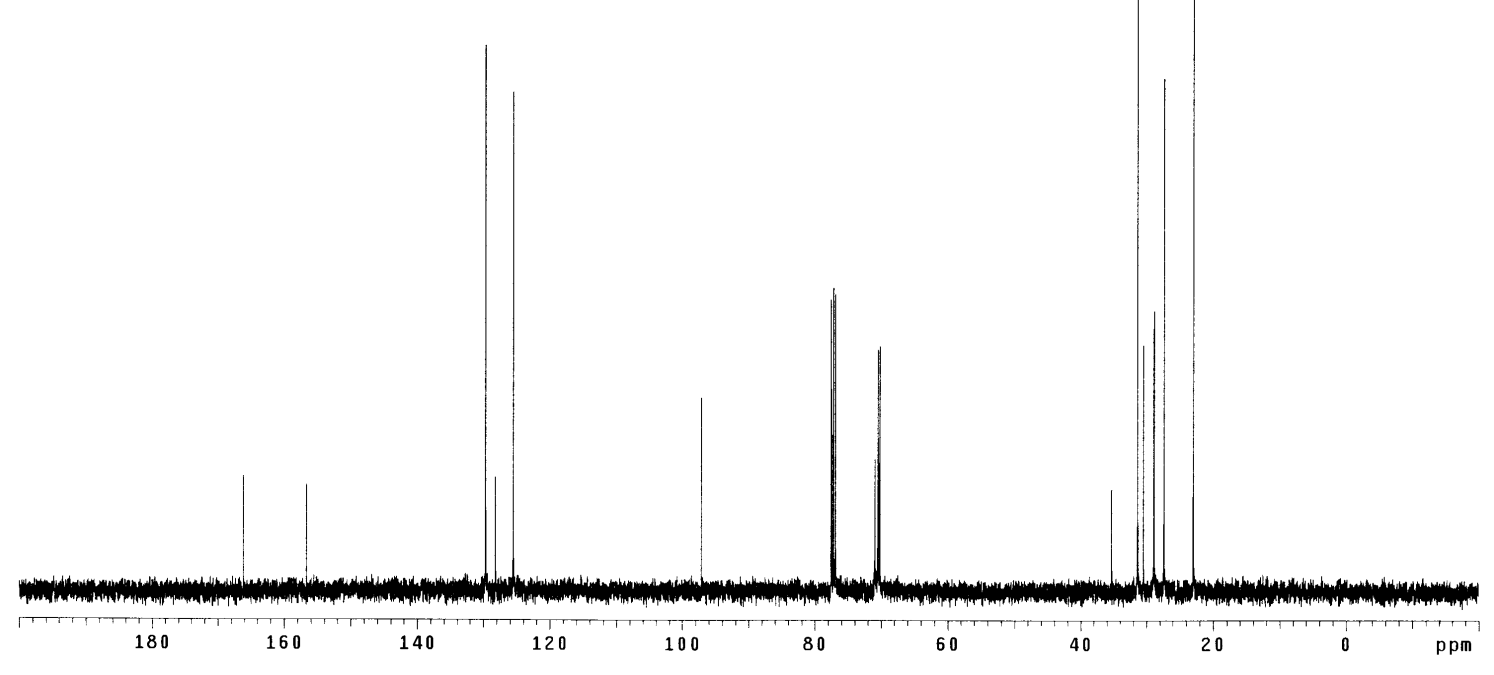



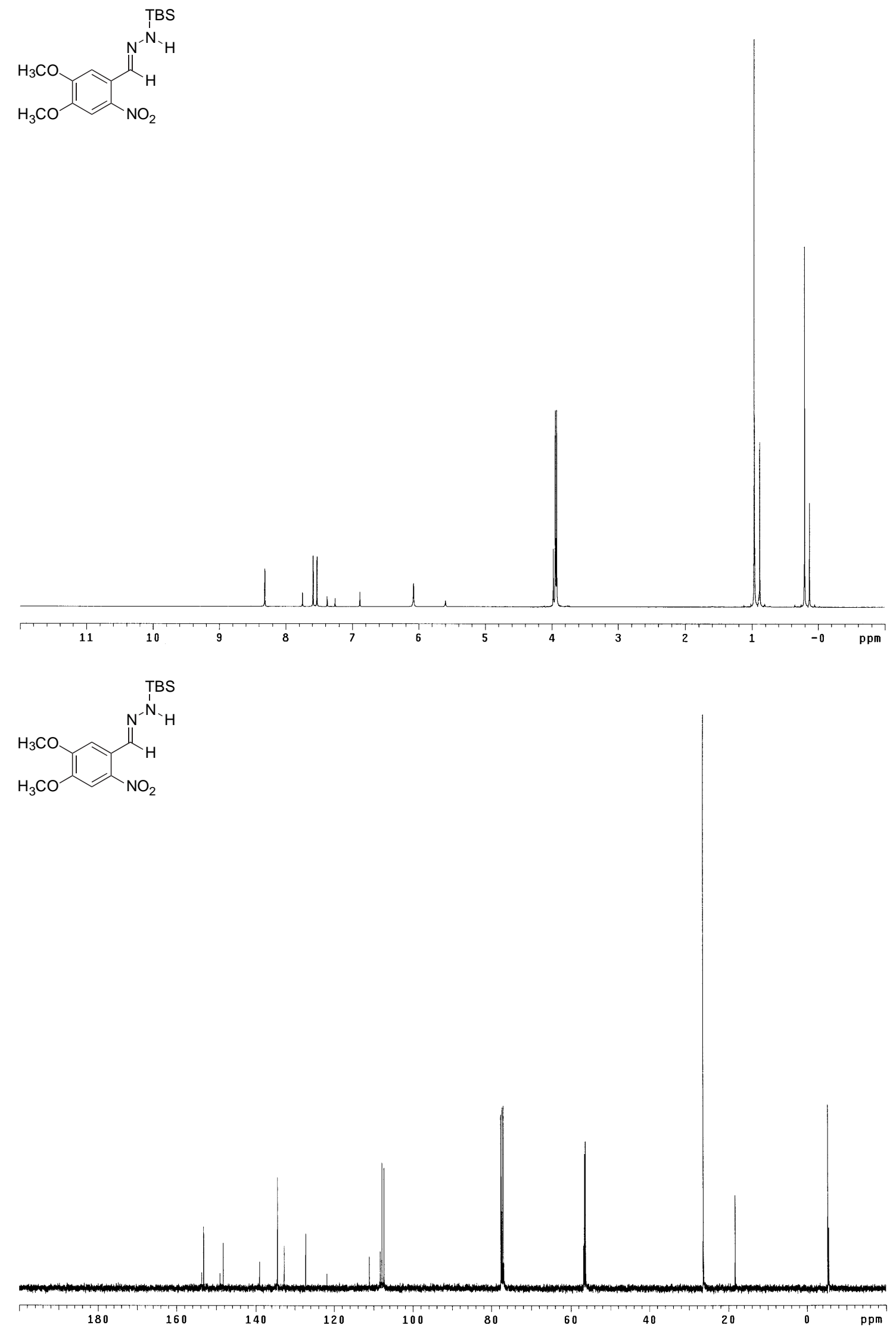

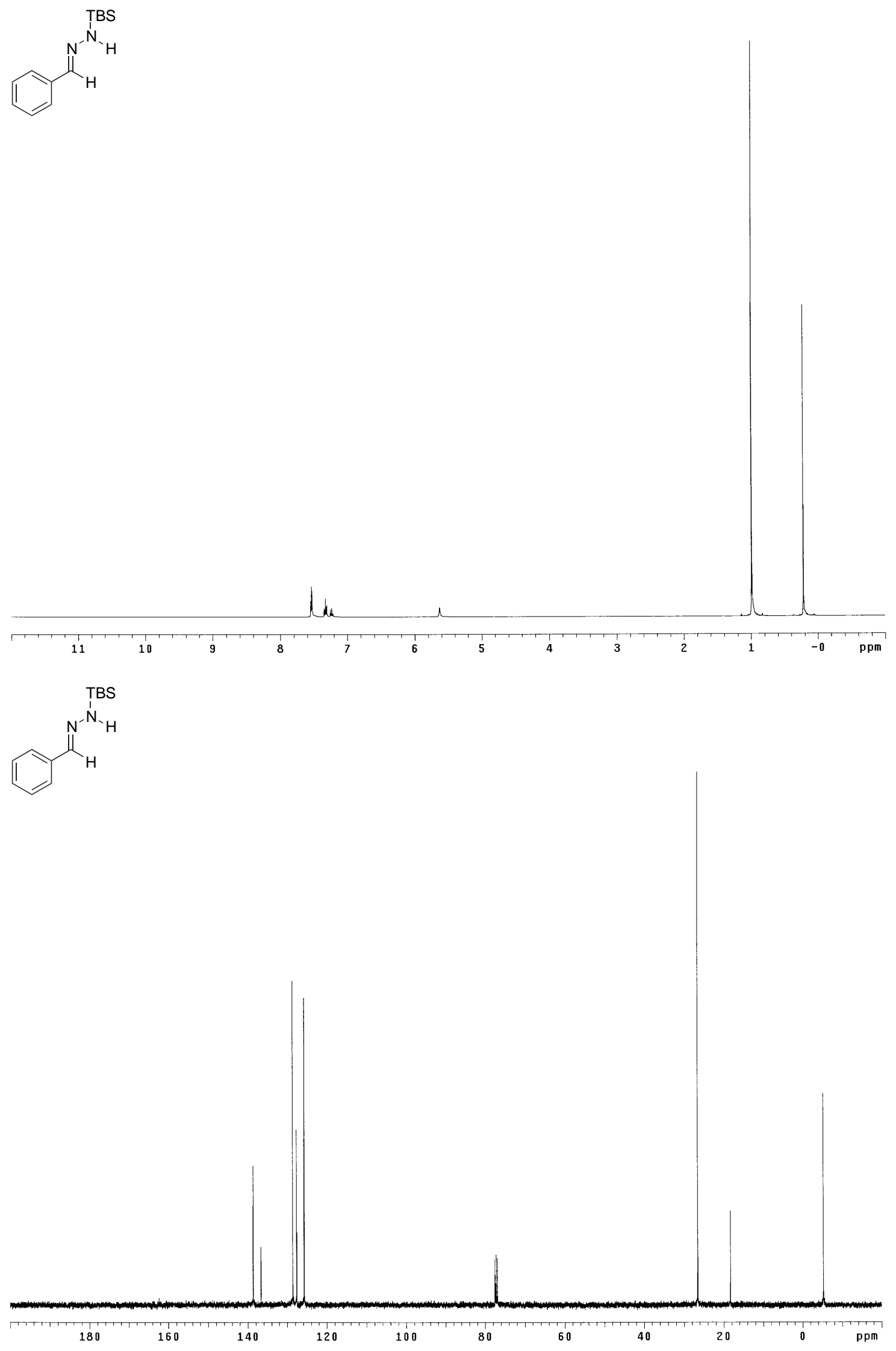